Cochrane Database of Systematic Reviews

\title{
Fluphenazine (oral) versus placebo for schizophrenia (Review)
}

Matar HE, Almerie MQ, Sampson SJ

Matar HE, Almerie MQ, Sampson SJ.

Fluphenazine (oral) versus placebo for schizophrenia.

Cochrane Database of Systematic Reviews 2018, Issue 6. Art. No.: CD006352.

DOI: 10.1002/14651858.CD006352.pub3.

www.cochranelibrary.com

Fluphenazine (oral) versus placebo for schizophrenia (Review) 
TABLE OF CONTENTS

ABSTRACT 1

PLAIN LANGUAGE SUMMARY

SUMMARY OF FINDINGS

BACKGROUND

OBJECTIVES

METHODS

Figure 1.

Figure 2.

RESULTS

Figure 3.

Figure 4.

Figure 5.

DISCUSSION

AUTHORS' CONCLUSIONS

ACKNOWLEDGEMENTS

REFERENCES

CHARACTERISTICS OF STUDIES

DATA AND ANALYSES

Analysis 1.1. Comparison 1: ORAL FLUPHENAZINE versus PLACEBO, Outcome 1: Global state: 1. Not improved or worsened ...

Analysis 1.2. Comparison 1: ORAL FLUPHENAZINE versus PLACEBO, Outcome 2: Global state: 2. Relapse

Analysis 1.3. Comparison 1: ORAL FLUPHENAZINE versus PLACEBO, Outcome 3: Global state: 3. Percentage of time in prodrome state (skewed data)

Analysis 1.4. Comparison 1: ORAL FLUPHENAZINE versus PLACEBO, Outcome 4: Global state: 4. Percentage of time in exacerbated state (skewed data)

Analysis 1.5. Comparison 1: ORAL FLUPHENAZINE versus PLACEBO, Outcome 5: Global state: 5. average score: CGI - severity of illness score (high = poor)

Analysis 1.6. Comparison 1: ORAL FLUPHENAZINE versus PLACEBO, Outcome 6: Leaving the study early: 1 . Non-specific reasons

Analysis 1.7. Comparison 1: ORAL FLUPHENAZINE versus PLACEBO, Outcome 7: Leaving the study early: 2 . Specific reason short term

Analysis 1.8. Comparison 1: ORAL FLUPHENAZINE versus PLACEBO, Outcome 8: Leaving the study early: 3. Marked improvement/ hospital discharge

Analysis 1.9. Comparison 1: ORAL FLUPHENAZINE versus PLACEBO, Outcome 9: Adverse effects: 1. Anticholinergic effects - short term

Analysis 1.10. Comparison 1: ORAL FLUPHENAZINE versus PLACEBO, Outcome 10: Adverse effects: 2. Cardivascular effects short term

Analysis 1.11. Comparison 1: ORAL FLUPHENAZINE versus PLACEBO, Outcome 11: Adverse effects: 3. CNS - short term ........... Analysis 1.12. Comparison 1: ORAL FLUPHENAZINE versus PLACEBO, Outcome 12: Adverse effects: 4. Death - long term .......... Analysis 1.13. Comparison 1: ORAL FLUPHENAZINE versus PLACEBO, Outcome 13: Adverse effects: 5. Endocrine - short term .. Analysis 1.14. Comparison 1: ORAL FLUPHENAZINE versus PLACEBO, Outcome 14: Adverse effects: 6a. Extrapyramidal effects - short term

Analysis 1.15. Comparison 1: ORAL FLUPHENAZINE versus PLACEBO, Outcome 15: Adverse effects: 6b. Extrapyramidal effects - medium term

Analysis 1.16. Comparison 1: ORAL FLUPHENAZINE versus PLACEBO, Outcome 16: Adverse effects: 7. Others - short term ....... Analysis 1.17. Comparison 1: ORAL FLUPHENAZINE versus PLACEBO, Outcome 17: Sensitivity analysis: 1 . CHRONIC versus ACUTE

Analysis 1.18. Comparison 1: ORAL FLUPHENAZINE versus PLACEBO, Outcome 18: Sensitivity analysis: 2. LOW DOSES (1-5 mg/ day) versus HIGH DOSES (5mg/day>)

Analysis 1.19. Comparison 1: ORAL FLUPHENAZINE versus PLACEBO, Outcome 19: Sensitivity analysis: 3. OPERATIONAL CRITERIA versus LOOSE DEFINITIONS

Analysis 1.20. Comparison 1: ORAL FLUPHENAZINE versus PLACEBO, Outcome 20: Sensitivity analysis: 4. BEFORE 1990 versus AFTER 1990 
[Intervention Review]

\section{Fluphenazine (oral) versus placebo for schizophrenia}

Hosam E Matar ${ }^{1}$, Muhammad Qutayba Almerie², Stephanie J Sampson ${ }^{3}$

${ }^{1}$ Trauma and Orthopaedics, North West Health Education, Liverpool, UK. 2Department of General Surgery, Leeds Teaching Hospitals NHS Trust, Leeds, UK. ${ }^{3}$ Centre for Reviews and Dissemination, University of York, York, UK

Contact: Hosam E Matar, hematar@doctors.org.uk, hematar@hotmail.co.uk.

Editorial group: Cochrane Schizophrenia Group.

Publication status and date: Edited (no change to conclusions), published in Issue 7, 2020.

Citation: Matar HE, Almerie MQ, Sampson SJ. Fluphenazine (oral) versus placebo for schizophrenia. Cochrane Database of Systematic Reviews 2018, Issue 6. Art. No.: CD006352. DOI: 10.1002/14651858.CD006352.pub3.

Copyright $\Subset 2018$ The Cochrane Collaboration. Published by John Wiley \& Sons, Ltd.

\section{A B S T R A C T}

\section{Background}

Fluphenazine is one of the first drugs to be classed as an 'antipsychotic' and has been widely available for five decades.

\section{Objectives}

To compare the effects of oral fluphenazine with placebo for the treatment of schizophrenia. To evaluate any available economic studies and value outcome data.

\section{Search methods}

We searched the Cochrane Schizophrenia Group's Trials Register (23 July 2013, 23 December 2014, 9 November 2016 and 28 December 2017 ) which is based on regular searches of CINAHL, BIOSIS, AMED, EMBASE, PubMed, MEDLINE, PsycINFO, and registries of clinical trials. There is no language, date, document type, or publication status limitations for inclusion of records in the register.

\section{Selection criteria}

We sought all randomised controlled trials comparing oral fluphenazine with placebo relevant to people with schizophrenia. Primary outcomes of interest were global state and adverse effects.

\section{Data collection and analysis}

For the effects of interventions, a review team inspected citations and abstracts independently, ordered papers and re-inspected and quality assessed trials. We extracted data independently. Dichotomous data were analysed using fixed-effect risk ratio (RR) and the $95 \%$ confidence interval $(\mathrm{Cl})$. Continuous data were excluded if more than $50 \%$ of people were lost to follow-up, but, where possible, mean differences (MD) were calculated. Economic studies were searched and reliably selected by an economic review team to provide an economic summary of available data. Where no relevant economic studies were eligible for inclusion, the economic review team valued the already-included effectiveness outcome data to provide a rudimentary economic summary.

\section{Main results}

From over 1200 electronic records of 415 studies identified by our initial search and this updated search, we excluded 48 potentially relevant studies and included seven trials published between 1964 and 1999 that randomised 439 (mostly adult participants). No new included trials were identified for this review update. Compared with placebo, global state outcomes of 'not improved or worsened' were not significantly different in the medium term in one small study ( $n=50,1 \mathrm{RCT}, \mathrm{RR} 1.12 \mathrm{Cl} 0.79$ to 1.58 , very low quality of evidence). The risk of relapse in the long term was greater in two small studies in people receiving placebo ( $n=86,2$ RCTs, RR $0.39 \mathrm{Cl} 0.05$ to 3.31 , very low quality of evidence), however with high degree of heterogeneity in the results. Only one person allocated fluphenazine was reported in the same small study to have died on long-term follow-up ( $n=50,1$ RCT, RR $2.38 \mathrm{Cl} 0.10$ to 55.72, low quality of evidence). Short-term extrapyramidal adverse effects were significantly more frequent with fluphenazine compared to placebo in two other studies for the outcomes of akathisia $(n=$ 
227, 2 RCTs, RR $3.43 \mathrm{Cl} 1.23$ to 9.56, moderate quality of evidence) and rigidity ( $\mathrm{n}=227,2 \mathrm{RCTs}, \mathrm{RR} 3.54 \mathrm{Cl} 1.76$ to 7.14 , moderate quality of evidence). For economic outcomes, we valued outcomes for relapse and presented them in additional tables.

\section{Authors' conclusions}

The findings in this review confirm much that clinicians and recipients of care already know, but they provide quantification to support clinical impression. Fluphenazine's global position as an effective treatment for psychoses is not threatened by the outcome of this review. However, fluphenazine is an imperfect treatment and if accessible, other inexpensive drugs less associated with adverse effects may be an equally effective choice for people with schizophrenia.

\section{PLAIN LANGUAGE SUMMARY}

\section{Fluphenazine versus Placebo for Schizophrenia}

Review question: Is fluphenazine effective for the treatment of schizophrenia compared with placebo?

\section{Background}

Fluphenazine is one of the first drugs to be classed as an 'antipsychotic' and has been widely available for decades.

\section{Searching for evidence}

We updated the electronic search in December 2017 for trials that randomised people with schizophrenia to receive oral fluphenazine or placebo. No new studies were found to be added in this update.

\section{Evidence found}

Seven trials met the review requirements and provided useable data.The evidence currently available is of poor quality and suggests that whilst fluphenazine is a potent and effective antipsychotic, it has considerable side effects.

\section{Conclusions}

Antipsychotic drugs are the first line and mainstay of treatment for schizophrenia. They help to effectively treat psychotic symptoms such as hearing voices and seeing things (hallucinations) and having strange beliefs (delusions). Fluphenazine was one of the first antipsychotics and has been available for around 50 years. Fluphenazine is inexpensive and in developing countries, may be one of the only drug treatments available. In most of Europe and North America, despite still being available, the arrival of newer antipsychotic drugs has reduced the use of fluphenazine and its market share. Fluphenazine has debilitating side effects, including: dizziness; movement disorders such as involuntary movements or spasms; shaking and tremors; inner restlessness and the inability to sit still; and problems with blood pressure, fever and muscle stiffness.

This review included seven studies and compared the effects of fluphenazine taken by mouth with placebo ('dummy' treatment). In the main, the findings of the review support the widespread view that fluphenazine is a potent and effective antipsychotic but has considerable side effects, other antipsychotic drugs may well be preferable. Fluphenazine is an imperfect treatment with serious side effects, so other inexpensive antipsychotic drugs with fewer side effects may be better for people with schizophrenia. Despite this, fluphenazine has a low cost and is widely available, so is likely to remain one of the most widely used treatments for schizophrenia worldwide. However, some of fluphenazine's side effects could be expensive in terms of human suffering and personal cost of treatment. Even though fluphenazine has been used as an antipsychotic drug for decades, there are still a surprisingly small number of well-conducted studies measuring its effectiveness and potential to cause side effects. Future large-scale research should report on important outcomes such as improvement in mental health, relapse, hospital discharge and admission, levels of satisfaction with treatment and quality of life.

This plain language summary has been written by a consumer Ben Gray from RETHINK. 
SUMMARY OF FINDINGS

Summary of findings 1. ORAL FLUPHENAZINE versus PLACEBO for Schizophrenia

\section{ORAL FLUPHENAZINE versus PLACEBO for Schizophrenia}

Patient or population: patients with Schizophrenia

Settings: inpatient and outpatient (Australia and US)

Intervention: ORAL FLUPHENAZINE versus PLACEBO

\begin{tabular}{|c|c|c|c|c|c|c|}
\hline \multirow[t]{3}{*}{ Outcomes } & \multicolumn{2}{|c|}{ Illustrative comparative risks* $(95 \% \mathrm{CI})$} & \multirow{3}{*}{$\begin{array}{l}\text { Relative effect } \\
(95 \% \mathrm{Cl})\end{array}$} & \multirow{3}{*}{$\begin{array}{l}\text { No of Partici- } \\
\text { pants } \\
\text { (studies) }\end{array}$} & \multirow{3}{*}{$\begin{array}{l}\text { Quality of the } \\
\text { evidence } \\
\text { (GRADE) }\end{array}$} & \multirow[t]{3}{*}{ Comments } \\
\hline & Assumed risk & Corresponding risk & & & & \\
\hline & Control & $\begin{array}{l}\text { ORAL FLUPHENAZINE versus } \\
\text { PLACEBO }\end{array}$ & & & & \\
\hline $\begin{array}{l}\text { Global state: Not improved or wors- } \\
\text { ened - medium term } \\
\text { Dichotomised Montgomery-Asberg De- } \\
\text { pression Rating Scale (MDRS) } \\
\text { Follow-up: } 12 \text { weeks }\end{array}$ & 680 per $1000^{1}$ & $\begin{array}{l}762 \text { per } 1000 \\
(537 \text { to } 1000)\end{array}$ & $\begin{array}{l}\text { RR } 1.12 \\
(0.79 \text { to } 1.58)\end{array}$ & $\begin{array}{l}50 \\
\text { (1 study) }\end{array}$ & $\begin{array}{l}\oplus \Theta \Theta \Theta \\
\text { very low 2,3 }\end{array}$ & \\
\hline \multirow{6}{*}{$\begin{array}{l}\text { Global state: Relapse - long term } \\
\text { Clinical judgement } \\
\text { Follow-up: } 52 \text { weeks }\end{array}$} & Low & & \multirow{6}{*}{$\begin{array}{l}\text { RR } 0.39 \\
(0.05 \text { to } 3.31)\end{array}$} & \multirow{6}{*}{$\begin{array}{l}86 \\
\text { (2 studies) }\end{array}$} & \multirow{6}{*}{$\begin{array}{l}\oplus \ominus \ominus \ominus \\
\text { very low } 5,6\end{array}$} & \multirow{6}{*}{$\begin{array}{l}\text { Note: high de- } \\
\text { gree of het- } \\
\text { erogeneity be- } \\
\text { tween included } \\
\text { studies. }\end{array}$} \\
\hline & 200 per 10001,4 & $\begin{array}{l}78 \text { per } 1000 \\
\text { (10 to } 662)\end{array}$ & & & & \\
\hline & \multicolumn{2}{|l|}{ Moderate } & & & & \\
\hline & 600 per 10001,4 & $\begin{array}{l}234 \text { per } 1000 \\
\text { (30 to } 1000)\end{array}$ & & & & \\
\hline & \multicolumn{2}{|l|}{ High } & & & & \\
\hline & 800 per 10001,4 & $\begin{array}{l}312 \text { per } 1000 \\
(40 \text { to } 1000)\end{array}$ & & & & \\
\hline \multirow{2}{*}{$\begin{array}{l}\text { Adverse effects: Death - long term } \\
\text { Occurrences of death } \\
\text { Follow-up: } 52 \text { weeks }\end{array}$} & Low 7 & & \multirow[t]{2}{*}{$\begin{array}{l}\text { RR } 2.38 \\
\text { (0.1 to } 55.72 \text { ) }\end{array}$} & \multirow[t]{2}{*}{$\begin{array}{l}50 \\
\text { (1 study) }\end{array}$} & \multirow[t]{2}{*}{$\begin{array}{l}\oplus \oplus \ominus \ominus \\
\text { low } 3,5\end{array}$} & \\
\hline & 0 per 1000 & $\begin{array}{l}\mathbf{0} \text { per } \mathbf{1 0 0 0} \\
(0 \text { to } 0)\end{array}$ & & & & \\
\hline
\end{tabular}




\begin{tabular}{|c|c|c|c|c|c|c|}
\hline \multirow{4}{*}{\multicolumn{2}{|c|}{$\frac{\delta}{0} \frac{\pi}{E}$}} & \multicolumn{2}{|l|}{ Moderate 7} & & & \\
\hline & & 30 per 1000 & $\begin{array}{l}71 \text { per } 1000 \\
\text { (3 to } 1000)\end{array}$ & & & \\
\hline & & \multicolumn{2}{|l|}{ High7 } & & & \\
\hline & & 90 per 1000 & $\begin{array}{l}\mathbf{2 1 4} \text { per } 1000 \\
(9 \text { to } 1000)\end{array}$ & & & \\
\hline \begin{tabular}{ll}
$\overline{\tilde{v}}$ & 0 \\
0 & $\overline{0}$ \\
\hdashline
\end{tabular} & \multirow{6}{*}{$\begin{array}{l}\text { Adverse effects: Extrapyramidal ef- } \\
\text { fects (akathisia) - short term } \\
\text { Instances of akathisia } \\
\text { Follow-up: mean } 6 \text { weeks }\end{array}$} & \multicolumn{2}{|l|}{ Low8 } & \multirow{6}{*}{$\begin{array}{l}\text { RR } 3.43 \\
(1.23 \text { to } 9.56)\end{array}$} & \multirow{6}{*}{$\begin{array}{l}227 \\
\text { ( } 2 \text { studies) }\end{array}$} & \multirow{6}{*}{$\begin{array}{l}\oplus \oplus \oplus \ominus \\
\text { moderate } 9\end{array}$} \\
\hline 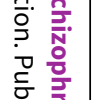 & & 0 per 1000 & $\begin{array}{l}0 \text { per } 1000 \\
(0 \text { to } 0)\end{array}$ & & & \\
\hline 常 & & \multicolumn{2}{|l|}{ Moderate 8} & & & \\
\hline 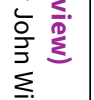 & & 100 per 1000 & $\begin{array}{l}\mathbf{3 4 3} \text { per } \mathbf{1 0 0 0} \\
(123 \text { to } 956)\end{array}$ & & & \\
\hline $\begin{array}{ll}< \\
6 \\
n\end{array}$ & & \multicolumn{2}{|l|}{ High8 } & & & \\
\hline$\vec{z}$ & & 200 per 1000 & $\begin{array}{l}\mathbf{6 8 6} \text { per } 1000 \\
(246 \text { to } 1000)\end{array}$ & & & \\
\hline & \multirow{6}{*}{$\begin{array}{l}\text { Adverse effects: Extrapyramidal ef- } \\
\text { fects (rigidity) - short term } \\
\text { Instances of rigidity } \\
\text { Follow-up: mean } 6 \text { weeks }\end{array}$} & \multicolumn{2}{|l|}{ Low 10} & \multirow{6}{*}{$\begin{array}{l}\text { RR } 3.54 \\
\text { (1.76 to } 7.14)\end{array}$} & \multirow{6}{*}{$\begin{array}{l}227 \\
\text { (2 studies) }\end{array}$} & \multirow{6}{*}{$\begin{array}{l}\oplus \oplus \oplus \odot \\
\text { moderate } 9\end{array}$} \\
\hline & & 50 per 1000 & $\begin{array}{l}\mathbf{1 7 7} \text { per } \mathbf{1 0 0 0} \\
\text { (88 to } 357 \text { ) }\end{array}$ & & & \\
\hline & & \multicolumn{2}{|l|}{ Moderate 10} & & & \\
\hline & & 250 per 1000 & $\begin{array}{l}\mathbf{8 8 5} \text { per } 1000 \\
(440 \text { to } 1000)\end{array}$ & & & \\
\hline & & \multicolumn{2}{|l|}{ High10 } & & & \\
\hline & & 500 per 1000 & $\begin{array}{l}\mathbf{1 0 0 0} \text { per } \mathbf{1 0 0 0} \\
\text { (880 to } 1000)\end{array}$ & & & \\
\hline & $\begin{array}{l}{ }^{\star} \text { The basis for the assumed risk (e.g. th } \\
\text { based on the assumed risk in the comp } \\
\text { Cl: Confidence interval; RR: Risk ratio; }\end{array}$ & $\begin{array}{l}\text { nedian control } \\
\text { son group and }\end{array}$ & $\begin{array}{l}\text { risk across studie } \\
\text { ative effect of th }\end{array}$ & $\begin{array}{l}\text { otnotes. The } \\
\text { d its } 95 \% \mathrm{CI}) \text {. }\end{array}$ & responding $r$ & d its $95 \%$ conf \\
\hline
\end{tabular}


GRADE Working Group grades of evidence

High quality: Further research is very unlikely to change our confidence in the estimate of effect.

Moderate quality: Further research is likely to have an important impact on our confidence in the estimate of effect and may change the estimate.

Low quality: Further research is very likely to have an important impact on our confidence in the estimate of effect and is likely to change the estimate.

Very low quality: We are very uncertain about the estimate.

1 Mean baseline risk presented for single study.

2 Risk of bias: rated 'very serious' (downgraded by 2 points) - randomisation unclear, with no mention or description of methods. Raters of scales not stated to be independent of treatment.

3 Imprecision: rated 'serious' (downgraded by 1 point) - 95\% confidence intervals for best estimate of effect include both 'no effect' and appreciable benefit/harm.

4 Low risk: equates to intervention group ( $11 \%)$ in one study with a higher risk in the other included study ( $71 \%)$; high risk in the control group (74\%).

5 Risk of bias: rated 'serious' (downgraded by 1 point) - lack of information for participants leaving the study early. Not all adverse effects data reported, and data not reported for various rating scales by intervention group.

6 Imprecision: rated 'very serious' (downgraded by 2 points) - only two small studies presented data on this outcome, with considerable heterogeneity present $(\mathrm{P}=0.0003 ; \mathrm{I} 2$ $=92 \%)$.

7 Low risk: equates to control group (0\%), with a moderate risk in the intervention group (3.6\%).

8 Low risk: equates to control group (3.4\%), with a moderate risk in the intervention group (12.7\%).

9 Risk of bias: rated 'serious' (downgraded by 1 point) - one of the two included studies did not: provide details of randomisation; report SDs for continuous outcomes; account for participants lost to follow-up.

10 Low risk: equates to control group (7.7\%), with a moderate risk in the intervention group $(27.3 \%)$.

Key:

High quality - no downgrading of the evidence.

Moderate quality - evidence downgraded by 1 point ('serious').

Low quality - evidence downgraded by 1 point twice ('serious') or 2 points ('very serious').

Very low quality - evidence downgraded any further than listed above. 


\section{B A C K G R O U N D}

\section{Description of the condition}

One in every 10,000 people per year is diagnosed with schizophrenia, with a lifetime prevalence of about $1 \%$ (Jablensky 1992). It often runs a chronic course with acute exacerbations and often partial remissions. Over the past few decades, a large body of evidence has accumulated linking excessive dopamine transmission to psychosis and more direct evidence emerges from neuro-imaging studies which showed an increased dopamine synthesis (Hietala 1995; Lindstrom 1999; Meyer 2002), an exaggerated release of dopamine and a higher than normal levels of dopamine at baseline (Abi-Dargham 2000; Gjedde 2001). The antipsychotic group of drugs with its anti-dopaminergic effects is the mainstay treatment for this illness (Dencker 1980). These are generally regarded as highly effective, especially in controlling such symptoms as hallucinations and fixed false beliefs (delusions) (Kane 1986). Moreover, they seem to reduce the risk of acute relapse. A systematic review undertaken two decades ago also suggested that, for those with serious mental illness, stopping antipsychotics resulted in 58\% of people relapsing, whereas only $16 \%$ of those who were still on the drugs became acutely ill within a one-year period (Davis 1986).

Schizophrenia usually begins in young adulthood and has a lifetime prevalence of about $1 \%$ irrespective of culture, social class and race. Schizophrenia is a chronic relapsing mental illness, characterised by symptoms such as hallucinations, delusions, disordered thinking, and emotional withdrawal. Antipsychotic drugs are effective for controlling florid symptoms such as hallucinations and delusions but are less effective for treating emotional withdrawal. Antipsychotics are associated with adverse effects such as movement disorders, and the overall cost of the illness to the individual, their carers and the community is considerable.

\section{Description of the intervention}

Fluphenazine, a phenothiazine derivative, was one of the first drugs to be classed as an 'antipsychotic' and was approved by the FDA in 1959. In Britain it was first used for the relief of anxiety. The American reports, however, were the first to indicate its value in psychotic illness (Darling 1959; Holt 1960). Fluphenazine has trifluoromethyl and piperazine groups which bring about increase in potency that in many pharmacodynamic properties may be about 40 times as potent as chlorpromazine. This is associated with a rapid and prolonged action, relatively little sedative activity and little or no increase in autonomic and haemodynamic effects.

Fluphenazine is an inexpensive and widely accessible antipsychotic drug that has been available to treat people with schizophrenia for five decades. In this review, for perhaps the first time, we objectively quantify the effects of oral administration of fluphenazine in comparison with placebo. It is indeed a potent antipsychotic but with considerable adverse effects. Other drugs may well be preferable.

\section{How the intervention might work}

Fluphenazine is thought to elicit its antipsychotic effects via interference with central dopaminergic pathways and blocking receptors, particularly $D 2$, in the mesolimbic zone of the brain. Extrapyramidal side effects are a result of interaction with dopaminergic pathways in the basal ganglia. As fluphenazine is not specific to one action within the body, it is known to cause adverse effects ranging from orthostatic hypotension as a result of its alpha adrenergic blocking activity to anticholinergic and extrapyramidal symptoms (tardive dyskinesia, pseudo-parkinsonism, dystonia, dyskinesia, akathisia). In addition, the use of fluphenazine has been associated with a potentially fatal disturbance of blood pressure, temperature and muscle control (neuroleptic malignant syndrome). As with all antipsychotic medications, fluphenazine is characterised by inter-individual variability in pharmacokinetics, most marked with the oral preparation. It is extensively metabolised, undergoing 'first pass' metabolism by the liver and is excreted in both the urine and faeces. Fluphenazine is highly protein-bound (greater than $90 \%$ ) in plasma. With oral fluphenazine, peak plasma/serum levels are attained within a few hours. The serum half-life of it is approximately 15 hours. Fluphenazine crosses the blood-brain barrier, crosses the placenta easily and cannot be removed by dialysis (Wikipedia 2006).

\section{Why it is important to do this review}

Fluphenazine is still one of the drugs commonly used for people with schizophrenia and is given by mouth or short-acting injection. Although we have not found precise data on how much fluphenazine is used worldwide, it is one of the World Health Organization's Essential Drugs (WHO 2005) and in the developing world, where non-proprietary preparations of fluphenazine are inexpensive, it may be one of the only drug treatments available. However, although it is still available in most of Europe and North America, the arrival of a newer generation of antipsychotic drugs has reduced its market share in the respective countries. This version of the review updates our past work (Matar 2007a; Matar 2007b). This is an update of a Cochrane Review first published in 2007 (Issue 1) of The Cochrane Database of Systematic Reviews.

In terms of the costs of schizophrenia, this was estimated at about $£ 6.7$ billion in England in 2004/05, of which the direct costs were $£ 2$ million while the indirect costs accounted for the rest (Mangalore 2007). Based on the only available BNF costs from 1999 (BNF 1999), oral fluphenazine (hydrochloride) costs approximately 1.77 pence per $1 \mathrm{mg}$ tablet, which based on a maximum therapeutic dose of $20 \mathrm{mg}$ per day, ranges to $35 \mathrm{p}$ per person per day. The newer, atypical antipsychotics in comparison are more expensive than typical antipsychotics, with olanzapine available at $£ 13.11$ for 28 five milligram tablets, and clozapine (Clozaril) at $£ 21.56$ for 28 one hundred milligram tablets.

It is essential to complement the clinical effectiveness of oral fluphenazine with its cost-effectiveness; Davies et al. (Davies 2007) conducted a study on cost-effectiveness of the first generation antipsychotics (i.e. flupentixol, trifluoperazine, chlorpromazine) and the second generation antipsychotics (i.e. risperidone, olanzapine, amisulpiride). The study findings argue that there is no evidence to suggest that atypical (second generation) antipsychotics are more cost-effective than typical (first generation) antipsychotics.

\section{O B J E C T IVES}

To compare the effects of oral fluphenazine with placebo for the treatment of schizophrenia. 
For an economic review team to critically appraise and summarise current evidence on the resource use, cost and cost-effectiveness of trifluoperazine for schizophrenia.

\section{METHODS}

\section{Criteria for considering studies for this review}

\section{Types of studies}

We included all relevant randomised controlled trials. We included trials that are described as 'double blind' - in which randomisation is implied - in a sensitivity analysis (see Sensitivity analysis). We excluded quasi-randomised studies, such as those that allocate intervention by alternate days of the week. Where people are given additional treatments as well as oral fluphenazine, we only included data if the adjunct treatment was evenly distributed between groups and it was only the fluphenazine or placebo that is randomised.

With regards to selecting studies for economic evaluations, two review authors graded studies as per the following:

Grade A - Full economic evaluation: studies that focus on cost-effectiveness analysis, cost-utility analysis and cost benefit analysis.

Grade B - Partial economic evaluation: studies that focus on costanalysis, cost-minimisation studies and cost-description of oral fluphenazine.

Grade C - Randomised trials that reported limited information, such as estimates of resources use or costs associated with oral fluphenazine.

\section{Types of participants}

Adults, however defined, with schizophrenia or related disorders, including schizophreniform disorder, schizoaffective disorder and delusional disorder, by any means of diagnosis.

We are interested in making sure that information is as relevant as possible to the current care of people with schizophrenia, so highlighted the current clinical state clearly (acute, early post-acute, partial remission, remission), as well as the stage (prodromal, first episode, early illness, persistent), and whether the studies primarily focused on people with particular problems (for example, negative symptoms, treatment-resistant illnesses).

\section{Types of interventions}

\section{Fluphenazine: any dose of only oral administration}

\section{Placebo: (active or inactive) or no treatment}

\section{Types of outcome measures}

Where possible, outcomes were made binary by dividing them into two categories - 'clinically significant change' and 'no clinically significant change'.

We categorised outcomes as short term (0-8 weeks), medium term (9 to 26 weeks) and long term ( 27 weeks to 104 weeks).

\section{Primary outcomes}

1. Global state

1.1 Not improved or worsened

2. Adverse effects

2.1 General

2.2 Specific

2.2.1 Extrapyramidal symptoms (parkinsonian symptoms, dystonia, akathisia, and tardive dyskinesia)

2.2.2 Anticholinergic symptoms

2.2.3 Others

\section{Secondary outcomes}

1. Global state

\subsection{Relapse}

1.2 Time in exacerbated state

1.3 Leaving the study early

1.4 Length of stay in hospital

1.5 Satisfaction with treatment - participant/carer

1.6 Death

2. Mental state

2.1 General symptoms

2.2 Specific symptoms

2.2.1 Positive symptoms (delusions, hallucinations, disordered thinking)

2.2.2 Negative symptoms (avolition, poor self-care, blunted affect)

2.2.3 Mood - depression

3. Behaviour

3.1 General behaviour

3.2 Specific behaviours (e.g. aggressive or violent behaviour)

3.2.1 Social functioning

3.2.2 Employment status during trial (employed/unemployed)

3.2.3 Occurrence of violent incidents (to self, others or property)

4. Economic

\subsection{Cost of care}

\section{5. 'Summary of findings' table}

We used the GRADE approach to interpret findings (Schünemann 2008); and used GRADE profiler to import data from RevMan 5 to create 'Summary of findings' tables (GRADEpro; Review Manager). These tables provided outcome-specific information concerning the overall quality of evidence from each included study in the comparison, the magnitude of effect of the interventions examined, and the sum of available data on all outcomes we rated as important to patient care and decision making. We selected the following main outcomes for inclusion in the 'Summary of findings' table: 
1. Global state - not improved or worsened - medium term.

2. Relapse - long term.

3. Adverse effects: death - long term.

4. Adverse effects: extrapyramidal effects (akathisia) - short term.

5. Adverse effects: extrapyramidal effects (rigidity) - short term.

\section{Search methods for identification of studies}

\section{Electronic searches}

\section{Cochrane Schizophrenia Group's Study-Based Register of Trials}

On 23 December 2014 and 9 November 2016, the information specialist searched the register using the following search strategy:

\section{( ${ }^{\star}$ Fluphenazine ${ }^{\star}$ AND *Placebo*) in Intervention Field of STUDY}

In such study-based register, searching the major concept retrieves all the synonyms and relevant studies because all the studies have already been organised based on their interventions and linked to the relevant topics.

This register is compiled by systematic searches of major resources (including AMED, BIOSIS, CINAHL, EMBASE, MEDLINE, PsycINFO, PubMed, and registries of clinical trials) and their monthly updates, hand-searches, grey literature, and conference proceedings (see Group's Module). There is no language, date, document type, or publication status limitations for inclusion of records into the register.

For previous searches, please see Appendix 1.

\section{Searching other resources}

\section{Reference searching}

We inspected references of all identified studies for further relevant studies.

\section{Personal contact}

We contacted the first author of each included study for information regarding unpublished trials.

\section{Data collection and analysis}

Methods used in data collection and analysis for this update are below; for previous methods please see Appendix 2 and Appendix 3 .

\section{Selection of studies}

Review authors HEM and MQA will independently inspect citations from the searches and identify relevant abstracts; SJS independently re-inspected a random $20 \%$ sample of these abstracts to ensure reliability of selection. Where disputes arose, we acquired the full report for more detailed scrutiny. HEM then obtained and inspected full reports of the abstracts or reports meeting the review criteria. SJSre-inspected a random $20 \%$ of these full reports in order to ensure reliability of selection. Where it was not possible to resolve disagreement by discussion, we attempted to contact the authors of the study concerned for clarification.

\section{Data extraction and management}

\section{Extraction}

Review authors (HEM, MQA) extracted data from all included studies. In addition, to ensure reliability, SJS independently extracted data from a random sample of these studies, comprising $10 \%$ of the total. We attempted to extract data presented only in graphs and figures whenever possible, but included only if two reviewers independently obtain the same result. If studies were multi-centre, then where possible we extracted data relevant to each. We discussed any disagreement and documented our decisions. If necessary, we attempted to contact authors through an open-ended request in order to obtain missing information or for clarification. HEM helped clarify issues regarding any remaining problems and we documented these final decisions.

\section{Management}

\subsection{Forms}

We extracted data onto standard, simple forms.

We included continuous data from rating scales only if:

a) the psychometric properties of the measuring instrument have been described in a peer-reviewed journal (Marshall 2000); and b) the measuring instrument has not been written or modified by one of the trialists for that particular trial.

c) the instrument was a global assessment of an area of functioning and not sub-scores which are not, in themselves, validated or shown to be reliable. However there are exceptions, we included sub-scores from mental state scales measuring positive and negative symptoms of schizophrenia.

Ideally the measuring instrument should either be i. a self-report or ii. completed by an independent rater or relative (not the therapist). We realise that this is not often reported clearly; in 'Description of studies' noted if this was the case or not.

\subsection{Endpoint versus change data}

There are advantages of both endpoint and change data: change data can remove a component of between-person variability from the analysis; however, calculation of change needs two assessments (baseline and endpoint) that can be difficult to obtain in unstable and difficult-to-measure conditions such as schizophrenia. We decided primarily to use endpoint data, and only use change data if the former were not available. If necessary, combined endpoint and change data in the analysis, as we prefered to use mean differences (MDs) rather than standardised mean differences (SMDs) throughout (Higgins 2011).

\subsection{Skewed data}

Continuous data on clinical and social outcomes are often not normally distributed. To avoid the pitfall of applying parametric tests to non-parametric data, we applied the following standards to relevant continuous data before inclusion.

For endpoint data from studies including fewer than 200 participants:

a) when a scale starts from the finite number zero, we subtracted the lowest possible value from the mean, and divide this by the standard deviation. If this value is lower than one, it strongly suggests that the data are skewed and we excluded these data. If this ratio is higher than one but less than two, there is suggestion that the data are skewed: we entered these data and test whether their inclusion or exclusion would change the results substantially. Finally, if the ratio is larger than two we included these data, 
because it is less likely that they are skewed (Altman 1996; Higgins 2011).

b) if a scale starts from a positive value (such as the Positive and Negative Syndrome Scale (PANSS), which can have values from 30 to 210 (Kay 1986)), we modified the calculation described above to take the scale starting point into account. In these cases skewed data are present if $2 \mathrm{SD}>(\mathrm{S}-\mathrm{S} \mathrm{min})$, where $\mathrm{S}$ is the mean score and ' $\mathrm{S}$ min' is the minimum score.

Please note: we entered all relevant data from studies of more than 200 participants in the analysis irrespective of the above rules, because skewed data pose less of a problem in large studies. We also entered all relevant change data, as when continuous data are presented on a scale that includes a possibility of negative values (such as change data), it is difficult to tell whether or not data are skewed.

\subsection{Common measurement}

To facilitate comparison between trials we, where relevant, converted variables that can be reported in different metrics, such as days in hospital (mean days per year, per week or per month) to a common metric (e.g. mean days per month).

\subsection{Conversion of continuous to binary}

Where possible, we made efforts to convert outcome measures to dichotomous data. This can be done by identifying cut-off points on rating scales and dividing participants accordingly into 'clinically improved' or 'not clinically improved'. It is generally assumed that if there is a $50 \%$ reduction in a scale-derived score such as the Brief Psychiatric Rating Scale (BPRS) (Overall 1962), or the PANSS (Kay 1986), this could be considered as a clinically significant response (Leucht 2005, Leucht 2005). If data based on these thresholds were not available, we used the primary cut-off presented by the original authors.

\subsection{Direction of graphs}

Where possible, we entered data in such a way that the area to the left of the line of no effect indicates a favourable outcome for insert your intervention here. Where keeping to this made it impossible to avoid outcome titles with clumsy double-negatives (e.g. 'not unimproved') we reported data where the left of the line indicates an unfavourable outcome and noted this in the relevant graphs.

\section{Assessment of risk of bias in included studies}

Review authors insert relevant initials here worked independently to assess risk of bias by using criteria described in the Cochrane Handbook for Systematic Reviews of Interventions to assess trial quality (Higgins 2011a). This set of criteria is based on evidence of associations between potential overestimation of effect and the level of risk of bias of the article that may be due to aspects of sequence generation, allocation concealment, blinding, incomplete outcome data and selective reporting, or the way in which these 'domains' are reported.

If the raters disagreed, we made the final rating by consensus, with the involvement of another member of the review group. Where inadequate details of randomisation and other characteristics of trials are provided, we attempted to contact authors of the studies in order to obtain further information. We reported nonconcurrence in quality assessment, but if disputes arise regarding the category to which a trial is to be allocated, we resolved this by discussion.

We noted the level of risk of bias in both the text of the review, Figure 1 , Figure 2, and the 'Summary of findings 1. 
Figure 1. Study flow diagram: 2006 search.

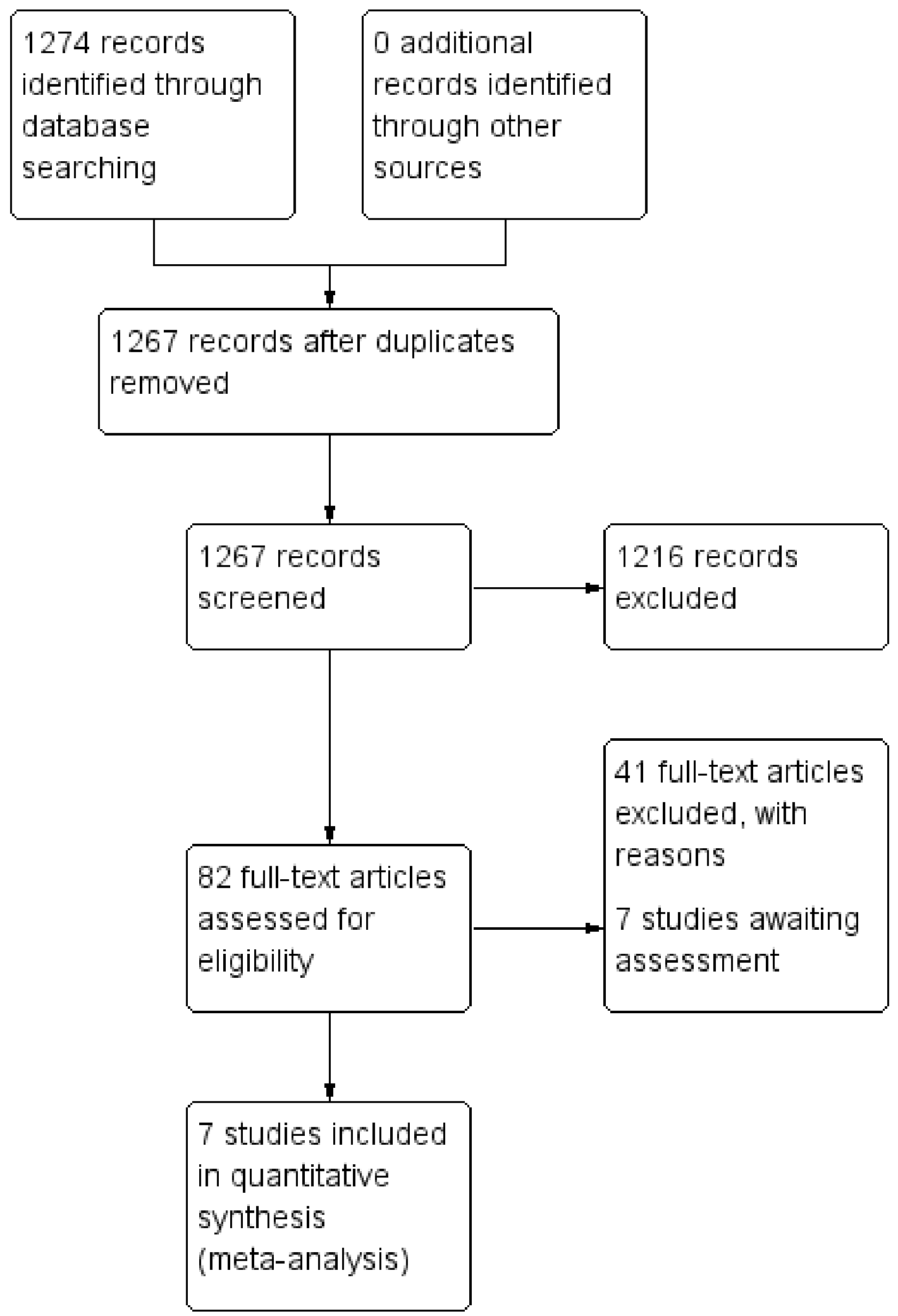


Figure 2. Study flow diagram: 2012 update search (no additional studies).

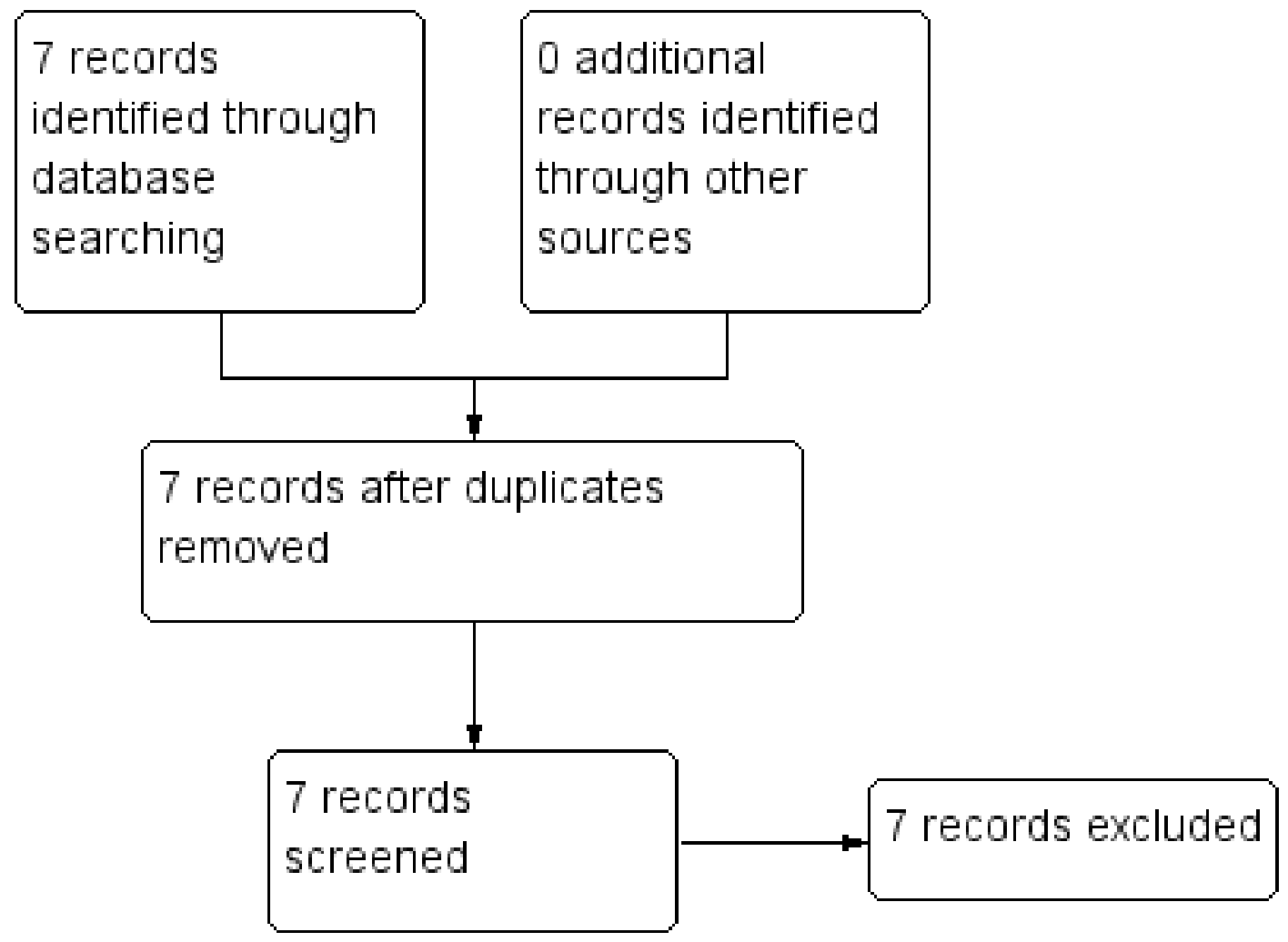

\section{Measures of treatment effect}

\section{Binary data}

For binary outcomes we calculated a standard estimation of the risk ratio (RR) and its $95 \%$ confidence interval $(\mathrm{Cl})$, as it has been shown that RR is more intuitive than odds ratios (Boissel 1999); and that odds ratios tend to be interpreted as RR by clinicians (Deeks 2000). Although the number needed to treat for an additional beneficial outcome (NNTB) and the number needed to treat for an additional harmful outcome (NNTH), with their Cls, are intuitively attractive to clinicians, they are problematic to calculate and interpret in meta-analyses (Hutton 2009). For binary data presented in the 'Summary of findings' table/s we, where possible, calculated illustrative comparative risks.

\section{Continuous data}

For continuous outcomes we estimated MD between groups. We preferred not to calculate effect size measures (SMD). However if scales of very considerable similarity are used, we presumed there is a small difference in measurement, and we calculated effect size and transform the effect back to the units of one or more of the specific instruments.

\section{Unit of analysis issues}

\section{Cluster trials}

Studies increasingly employ 'cluster randomisation' (such as randomisation by clinician or practice), but analysis and pooling of clustered data poses problems. Firstly, authors often fail to account for intra-class correlation in clustered studies, leading to a unitof-analysis error whereby $\mathrm{P}$ values are spuriously low, Cls unduly narrow and statistical significance overestimated (Divine 1992). This causes type I errors (Bland 1997; Gulliford 1999).

Where clustering has been incorporated into the analysis of primary studies, we presented these data as if from a non-cluster randomised study, but adjusted for the clustering effect.

Where clustering is not accounted for in primary studies, we presented data in a table, with a ( $\left.{ }^{*}\right)$ symbol to indicate the presence of a probable unit of analysis error. We contacted first authors of studies to obtain intra-class correlation coefficients for their clustered data and adjusted for this by using accepted methods (Gulliford 1999).

We sought statistical advice and have been advised that the binary data from cluster trials presented in a report should be divided by a 'design effect'. This is calculated using the mean number of participants per cluster $(\mathrm{m})$ and the intra-class correlation coefficient (ICC): thus design effect $=1+(m-1){ }^{*}$ ICC (Donner 2002). If the ICC is not reported we assumed it to be 0.1 (Ukoumunne 1999).

If cluster studies have been appropriately analysed and taken intraclass correlation coefficients and relevant data documented in the report into account, synthesis with other studies was possible using the generic inverse variance technique.

\section{Cross-over trials}

A major concern of cross-over trials is the carry-over effect. This occurs if an effect (e.g. pharmacological, physiological or psychological) of the treatment in the first phase is carried over to the second phase. As a consequence, participants can differ significantly from their initial state at entry to the second phase, 
despite a wash-out phase. For the same reason cross-over trials are not appropriate if the condition of interest is unstable (Elbourne 2002). As both carry-over and unstable conditions are very likely in severe mental illness, we only used data from the first phase of cross-over studies.

\section{Studies with multiple treatment groups}

Where a study involves more than two treatment arms, if relevant, we presented the additional treatment arms in comparisons. If data are binary we simply added these and combined within the two-by-two table. If data are continuous we combined data following the formula for combining data in the Cochrane Handbook for Systematic Reviews of Interventions (Higgins 2011). Where additional treatment arms are not relevant, we did not reproduce these data.

\section{Dealing with missing data}

\section{Overall loss of credibility}

At some degree of loss of follow-up, data must lose credibility (Xia 2009). We chose that, for any particular outcome, should more than $50 \%$ of data be unaccounted for we would not reproduce these data or use them within analyses. If, however, more than $50 \%$ of those in one arm of a study are lost, but the total loss is less than $50 \%$, we addressed this within the 'Summary of findings' table/s by down-rating quality. Finally, we also downgraded quality within the 'Summary of findings' table/s should the loss be $25 \%$ to $50 \%$ in total.

\section{Binary}

In the case where attrition for a binary outcome is between $0 \%$ and $50 \%$ and where these data are not clearly described, we presented data on a 'once-randomised-always-analyse' basis (an intentionto-treat analysis (ITT)). Those leaving the study early were all assumed to have the same rates of negative outcome as those who completed, with the exception of the outcome of death and adverse effects. For these outcomes the rate of those who stay in the study - in that particular arm of the trial - was used for those who did not. We undertook a sensitivity analysis testing how prone the primary outcomes are to change when data only from people who complete the study to that point are compared to the intention-totreat analysis using the above assumptions.

\section{Continuous}

\subsection{Attrition}

We used data where attrition for a continuous outcome is between $0 \%$ and $50 \%$, and data only from people who complete the study to that point were reported.

\subsection{Standard deviations}

If standard deviations (SDs) are not reported, we tried to obtain the missing values from the authors. If these are not available, where there are missing measures of variance for continuous data, but an exact standard error (SE) and Cls available for group means, and either $\mathrm{P}$ value or $\mathrm{t}$ value available for differences in mean, we can calculate SDs according to the rules described in the Cochrane Handbook for Systematic Reviews of Interventions (Deeks 2011). When only the SE is reported, SDs are calculated by the formula SD $=S E * \sqrt{ }(\mathrm{n})$. The Cochrane Handbook for Systematic Reviews of Interventions present detailed formulae for estimating
SDs from $\mathrm{P}, \mathrm{t}$ or $\mathrm{F}$ values, Cls, ranges or other statistics (Deeks 2011). If these formulae do not apply, we calculated the SDs according to a validated imputation method which is based on the SDs of the other included studies (Furukawa 2006). Although some of these imputation strategies can introduce error, the alternative would be to exclude a given study's outcome and thus to lose information. Nevertheless, examined the validity of the imputations in a sensitivity analysis that excludes imputed values.

\subsection{Assumptions about participants who left the trials early or were lost to follow-up}

Various methods are available to account for participants who left the trials early or were lost to follow-up. Some trials just present the results of study completers; others use the method of last observation carried forward (LOCF); while more recently, methods such as multiple imputation or mixed-effects models for repeated measurements (MMRM) have become more of a standard. While the latter methods seem to be somewhat better than LOCF (Leon 2006), we feel that the high percentage of participants leaving the studies early and differences between groups in their reasons for doing so is often the core problem in randomised schizophrenia trials. We therefore did not exclude studies based on the statistical approach used. However, by preference we used the more sophisticated approaches, i.e. we prefered to use MMRM or multiple-imputation to LOCF, and we only presented completer analyses if some kind of ITT data were not available at all. Moreover, we addressed this issue in the item 'Incomplete outcome data' of the 'Risk of bias' tool.

\section{Assessment of heterogeneity}

\section{Clinical heterogeneity}

We considered all included studies initially, without seeing comparison data, to judge clinical heterogeneity. We simply inspected all studies for participants who are clearly outliers or situations that we had not predicted would arise and, where found, discussed such situations or participant groups.

\section{Methodological heterogeneity}

We considered all included studies initially, without seeing comparison data, to judge methodological heterogeneity. We simply inspected all studies for clearly outlying methods which we had not predicted would arise and discussed any such methodological outliers.

\section{Statistical heterogeneity}

\subsection{Visual inspection}

We inspected graphs visually to investigate the possibility of statistical heterogeneity.

\subsection{Employing the $I^{2}$ statistic}

We investigated heterogeneity between studies by considering the $\mathrm{I}^{2}$ statistic alongside the $\mathrm{Chi}^{2} \mathrm{P}$ value. The $\mathrm{I}^{2}$ statistic provides an estimate of the percentage of inconsistency thought to be due to chance (Higgins 2003). The importance of the observed value of $\mathrm{I}^{2}$ depends on the magnitude and direction of effects as well as the strength of evidence for heterogeneity (e.g. $\mathrm{P}$ value from $\mathrm{Chi}^{2}$ test, or a confidence interval for $\mathrm{I}^{2}$ ). We interpreted an $\mathrm{I}^{2}$ estimate greater than or equal to $50 \%$ and accompanied by a statistically significant $\mathrm{Chi}^{2}$ statistic as evidence of substantial heterogeneity (Deeks 2011). When substantial levels of heterogeneity are found 
in the primary outcome, we explored reasons for heterogeneity (Subgroup analysis and investigation of heterogeneity).

\section{Assessment of reporting biases}

Reporting biases arise when the dissemination of research findings is influenced by the nature and direction of results (Egger 1997). These are described in Chapter 10 of the Cochrane Handbook for Systematic Reviews of Interventions (Sterne 2011). We are aware that funnel plots may be useful in investigating reporting biases, but are of limited power to detect small-study effects. We did not use funnel plots for outcomes where there are 10 or fewer studies, or where all studies are of similar size. In other cases, where funnel plots are possible, we will seek statistical advice in their interpretation.

\section{Data synthesis}

We understand that there is no closed argument for preference for use of fixed-effect or random-effects models. The random-effects method incorporates an assumption that the different studies are estimating different, yet related, intervention effects. This often seems to be true to us and the random-effects model takes into account differences between studies, even if there is no statistically significant heterogeneity. There is, however, a disadvantage to the random-effects model: it puts added weight onto small studies, which often are the most biased ones. Depending on the direction of effect, these studies can either inflate or deflate the effect size. We chose to use a random-effect model for all analyses.

\section{Economic Summary}

Data was summarised according to the Cochrane Campbell Economic Methods Group (Higgins 2011) and a narrative abstract provided for each included study. A table summarising the data was also provided for any studies had they been identified.

We anticipated that most studies would be Grade C level of economic evidence and that we would use data from such studies to calculate a GBP value associated with the outcomes. These approximate values were calculated by (a) using the PSSRU calculation of $£ 338$ (weighted average of all adult mental health inpatient bed days) per hospital bed day based in a UK NHS setting (PSSRU 2012), and (b) assuming that one relapse equals one hospital admission, a median length of stay as 16 days, as per Hospital Episode Statistics 2012 (HES 2012; main speciality 'adult mental illness') we utilised results of the effects of the intervention that presented service use data for an adult ward as well as for relapse rates (HES is a data warehouse containing details of all admissions, outpatient appointments and A\&E attendances at NHS hospitals in England).

We have not factored any associated costs (including cost and resource use of treatment) prior to the relevant measured outcomes of relapse and hospital discharge. We are using UK NHS PSSRU reference costs of 2012, and therefore present the outcomes in terms of a GBP value found in the comparison data as a proxy measure for relative risk, which is achieved through the assumption of average (median) length of hospital stay (16 days) and average cost per day (£338). The average cost of relapse - based on our assumption that one relapse equals one hospital admission lasting 16 days $(338 \times 16)$ - has been calculated at $£ 5,408$ per person. From this number, the average cost of relapse has been calculated for both (a) the number of participants alone who experienced relapse in both the intervention or control group ( $n=$ relapsed $\times 5,408)$ and (b) the entire population at risk of relapse between groups ( $£$ of $n=$ relapsed per group $\div$ total $N$ receiving intervention across studies).

The authors wish to emphasise the numerous assumptions that have been made for the purposes of presenting this economic data, specifically at Grade $C$ quality level:

1. The current included studies contributing to the Grade C-level of quality were undertaken between the years of 1963 to 1999; and, taking this into account -

2. The average length of stay and costs have been calculated from current available data, that is, according to 2012 HES costs, from most primarily a UK NHS perspective; and

3. The GBP value data that are presented reflect a proxy measure only; that is, the GBP value of the intervention effect on the measured outcome, and not taking into account any costs or resource use that may likely have been incurred prior to the actual outcome (which includes, but is not limited to, costs and resource use prior to intervention, the intervention itself and post-intervention up to outcome).

\section{Subgroup analysis and investigation of heterogeneity}

\section{Subgroup analyses}

\subsection{Primary outcome}

No subgroup analysis was expected.

\section{Investigation of heterogeneity}

We reported if inconsistency was high. Firstly, we investigated whether data have been entered correctly. Secondly, if data are correct, we inspected the graph visually and remove outlying studies successively to see if homogeneity is restored. For this review we have decided that should this occur with data contributing to the summary finding of no more than $10 \%$ of the total weighting, we presented data. If not, we did not pool these data and discussed any issues. We know of no supporting research for this 10\% cut-off but are investigating use of prediction intervals as an alternative to this unsatisfactory state.

When unanticipated clinical or methodological heterogeneity is obvious we simply stated hypotheses regarding these for future reviews or versions of this review. We do not anticipate undertaking analyses relating to these.

\section{Sensitivity analysis}

\section{Implication of randomisation}

We included trials in a sensitivity analysis if they were described in some way that implies randomisation. For primary outcomes, if the inclusion of these trials did not result in a substantive difference, they remained in the analyses. If their inclusion did result in statistically significant differences, we did not add the data from these lower-quality studies to the results of the higher-quality trials, but presented these data within a subcategory.

\section{Assumptions for lost binary data}

Where assumptions have to be made regarding people lost to follow-up (see Dealing with missing data), we compared the findings of the primary outcomes when we use our assumption compared with completer data only. If there is a substantial 
difference, we reported results and discussed them, but continued to employ our assumption.

Where assumptions have to be made regarding missing SD data (see Dealing with missing data), we compared the findings of primary outcomes when we used our assumption compared with complete data only. We undertook a sensitivity analysis to test how prone results are to change when completer data only were compared to the imputed data using the above assumption. If there was a substantial difference, we reported results and discussed them, but continued to employ our assumption.

\section{Risk of bias}

We analysed the effects of excluding trials that are judged to be at high risk of bias across one or more of the 'Risk of bias' domains (implied as randomised with no further details available, allocation concealment, blinding and outcome reporting) for the meta-analysis of the primary outcome. If the exclusion of trials at high risk of bias did not alter the direction of effect or the precision of the effect estimates substantially, then we included relevant data from these trials.

\section{Imputed values}

We undertook a sensitivity analysis to assess the effects of including data from trials where we use imputed values for ICC in calculating the design effect in cluster-randomised trials.

If substantial differences were noted in the direction or precision of effect estimates in any of the sensitivity analyses listed above, we did not pool data from the excluded trials with the other trials contributing to the outcome, but presented them separately.

\section{Fixed-and random-effects}

We synthesised data using radnom-effects model; however, we also synthesised data for the primary outcome using a fixed effect model to evaluate whether this alters the significance of the results.

It was expected that several sensitivity analyses could be undertaken within this review. The following hypotheses were be tested:

When compared with placebo, for the primary outcomes of interest (see: Criteria for considering studies for this review), fluphenazine is differentially effective for:

\section{Men and women.}

2. People who are under 18 years of age, between 18 and 64 , or over 65 years of age.

3. People who became ill recently (i.e. acute episode approximately less than one month's duration) as opposed to people who have been ill for a longer duration.

4. People who are given low doses (1- $5 \mathrm{mg} /$ day), and those given high doses (over $5 \mathrm{mg} /$ day).

5. People who have schizophrenia diagnosed according to any operational criterion i.e. a pre-stated checklist of symptoms/ problems/time periods/exclusions) as opposed to those who have entered the trial with loosely defined illness.

6. People treated earlier (pre-1990) and people treated in recent years (1990 to 2006).

We additionally applied all sensitivity analyses to the primary outcomes of this review.

\section{Economic summary}

We undertook a sensitivity analysis taking into account both the mean length of hospital stay; the median length of hospital stay (HES 2012); and the associated upper (£376) and lower quartile (£299) ranges of the weighted average cost of all adult mental health inpatient bed days (PSSRU 2012), to investigate how far this affects the direction of the estimated value.

\section{RES U L T S}

\section{Description of studies}

For substantive descriptions of studies please see the Included studies and Excluded studies tables.

\section{Effects of intervention}

The initial 2006 search yielded 1274 electronic records for 422 studies, of which we rejected 834 during the first inspection. We inspected the remaining 433 papers. Three hundred and forty-three were rejected, as they were clearly not relevant. The remaining 82 papers ( 55 studies) were considered to match the inclusion criteria closely enough to be mentioned in either the 'Included studies'; 'excluded studies' and 'awaiting classification' tables.

The 2012 update search yielded seven studies, each of which was excluded. The seven studies previously awaiting 'classification' were moved to 'excluded studies' for this review. Therefore, the current review cites 48 studies as 'excluded studies' and 16 reports of the seven 'included studies'. There was over $90 \%$ agreement for trial selection and once we had investigated any disagreement and acquired and reassessed the papers, concordance was $100 \%$. Initially, there was also over $90 \%$ agreement in the extracted data. We easily resolved any disagreement by discussion (see Figure 1 and Figure 2). Further update undertaken in December 2017 and yielded no new studies.

\section{Economic}

We identified 15 potential studies in our economic evaluation search (Figure 3), none of which met our inclusion criteria for Grade A and B. Had we found any studies of Grade A or B quality, they would have been presented in Table 1. Eleven of these references were excluded on the basis of the title or abstract alone, leaving with four references left for assessment. These four references referred to two studies and these two studies were subsequently excluded (Table 2). We therefore present data for Grade C economic evaluation only. 
Figure 3. Study flow diagram: economic Cochrane Schizophrenia Group's Health Economic Database (CSzGHED) search 23 July 2013.

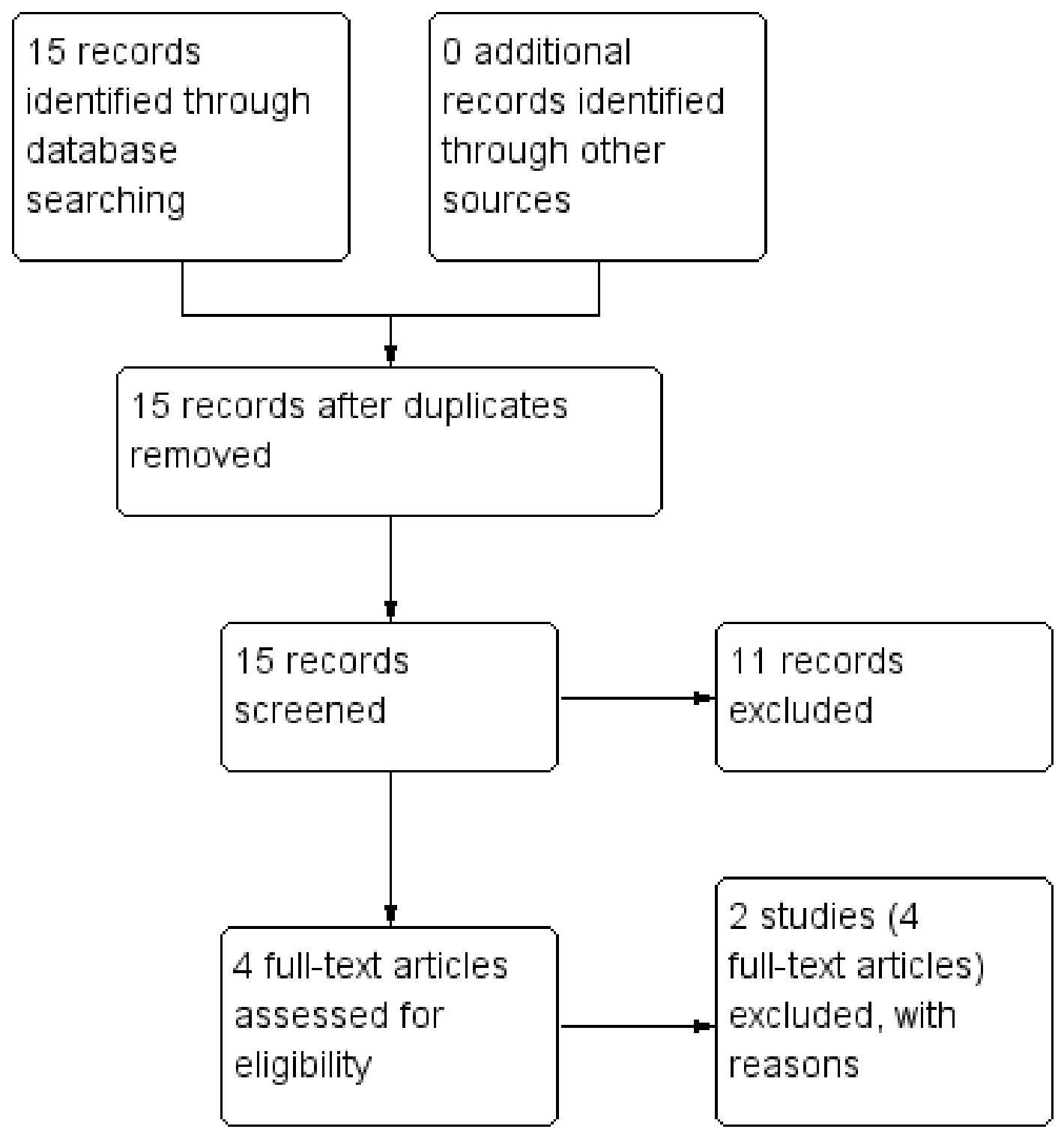

\section{Included studies}

We included seven studies (total $n=439$ participants).

We found no studies meeting our inclusion criteria for economic evaluation Grades A and B. However, for Grade C-level evidence, we utilised the data from relevant economic outcomes of interest (relapse and hospital discharge) from three trials included in the effectiveness section of the systematic review (Marder 1994; Millar 1963; Rifkin 1976).

\subsection{Methods}

In all included studies, randomisation was either reported or implied. The mean duration of treatment was about 170 days ( six months), but this was highly skewed (standard deviation (SD) 253). The most common study length was six weeks (Carpenter 1999; Clark 1971; Millar 1963) but the range was considerable with the longest lasting two years (Marder 1994).

\subsection{Setting}

Four studies were hospital-based (Clark 1971; Goldberg 1964; Hordern 1964; Millar 1963), while three were undertaken in the community (Carpenter 1999; Marder 1994; Rifkin 1976). Five studies were conducted in the United States of America (Carpenter 1999; Clark 1971; Goldberg 1964; Marder 1994; Rifkin 1976), one in Australia (Hordern 1964) and one in the United Kingdom (Millar 1963).

\subsection{Participants}

All trials included participants diagnosed with schizophrenia and two of the seven trials described the diagnostic criteria used (Diagnostic and Statistical Manual version III (DSM-III) or Research Diagnostic Criteria (RDC)). The other studies used a clinical diagnosis of schizophrenia. The mean age of the participants was about 38 years, range 16 to 75, and they were mostly chronic patients with a mean hospitalisation period of about 20 years. In 
Marder 1994, all participants were men, whilst in Hordern 1964 and Millar 1963 the participants were all women. In the remaining studies participants were of mixed sex.

\subsection{Study size}

The mean number of participants was about $\mathrm{n}=60$, ranging from 36 to 190 .

\subsection{Interventions}

All trials compared oral fluphenazine with inactive placebo. The doses of oral fluphenazine in these studies ranged from $2.5 \mathrm{mg} /$ day (Millar 1963) up to a potential of $20 \mathrm{mg} /$ day (Rifkin 1976). The mean dose was $8.2 \mathrm{mg}$ per day (SD 3.9). The standard oral dosage in minor disturbances $2 \mathrm{mg}$ to $5 \mathrm{mg} /$ day, or in the treatment of psychotic disorders up to $20 \mathrm{mg}$ to $40 \mathrm{mg}$ daily (www.psychotropics.dk).

\subsection{Outcomes}

\subsubsection{General remarks}

Most outcomes were dichotomous, and presented as such, or were continuous data. In many studies, outcomes were few and where data were reported they were rendered unusable. None of the included studies attempted to quantify levels of satisfaction or quality of life and there is no evidence of any direct economic evaluation of fluphenazine. However, we were able to measure some aspects of the global and mental state and adverse effects.

\subsection{Outcome scales}

The following scales were used and provided data for the analysis.

\subsubsection{Global state:}

\subsubsection{Clinical Global Impression (CGI) Guy 1976}

A rating instrument commonly used in studies in schizophrenia that enables clinicians to quantify severity of illness and overall clinical improvement. A seven-point scoring system is usually used with low scores indicating decreased severity and/or greater recovery. Carpenter 1999 and Clark 1971 reported dichotomised data from this scale, measuring improvement scores. Continuous data from Clark 1971 were also used in our results, however SDs were imputed using the method described in Dealing with missing data.

\subsubsection{The Multidimensional Scale for Rating Psychiatric Patients (MDRSP) Lorr 1953}

The Multidimensional Rating Scale or Hamilton's schizophrenia scale is a modification of the Inpatient Multidimensional Psychiatric Scale. The MDRSP is completed after a psychiatric interview. It consists of 18 items, in the form of simple questions, to be rated along a four-point scale. The severity scores are defined by short behavioural descriptions on the form, thus avoiding interpretation problems. The scale is mainly designed for the evaluation of chronically hospitalised schizophrenic patients. Hordern 1964 reported dichotomised data from this scale for levels of improvement.

\subsubsection{Brief Psychiatric Rating Scale (BPRS) Overall 1962}

The scale measures positive symptoms and quantifies factors such as thought disorder, activation, hostility. somatic, hallucinatory, and depressive states. The original scale had 16 items, but a revised 18 -item scale is more commonly used, with scores ranging from 0 to 126. Each item is defined on a seven-point scale from $0=$ not present to seven = extremely severe. Higher scores equate to severity of illness.

\section{Excluded studies}

We excluded 48 studies. Seven were not randomised, did not imply randomisation or did not describe the allocation procedure at all. In one study, participants were not suffering from schizophrenia. Another sizeable proportion of the trials did not compare oral fluphenazine with placebo, but with other treatments. A few were fluphenazine-withdrawal studies which are not relevant to this review. These withdrawal studies will be included in a future review. Three studies had no usable outcomes. Either data did not have clear clinical implications or genuinely relevant clinical data were not adequately reported. Frequently the numbers of participants in each group were not specified, means or SDs were not given or data were not reported from individual arms of cross-over studies. The seven studies identified in the 2012 search were all excluded, owing either to no randomisation (Kinross-Wright 1963; Matheu 1961), no diagnosis of schizophrenia (Hanlon 1970; Howell 1961), not the appropriate intervention (Marder 1993; Shafti 2009) or no usable data were presented (Zahn 1993).

For the economic search, we excluded two studies (four references); three papers were in fact systematic reviews relating to the previous version of this review (Matar 2007), and one paper compared costs and benefits of two doses of fluphenazine decanoate (Mardar 1984), as opposed to oral (Table 2).

\section{Awaiting assessment}

No studies are awaiting assessment.

\section{Ongoing studies}

We are not aware of any ongoing studies.

\section{Risk of bias in included studies}

Please see the relevant 'Risk of bias' tables in the Characteristics of included studies section and Figure 4; Figure 5. 
Figure 4. 'Risk of bias' graph: review authors' judgements about each risk of bias item presented as percentages across all included studies.

Random sequence generation (selection bias)

Allocation concealment (selection bias)

Blinding (performance bias and detection bias): All outcomes Incomplete outcome data (attrition bias): All outcomes

Selective reporting (reporting bias)

Other bias

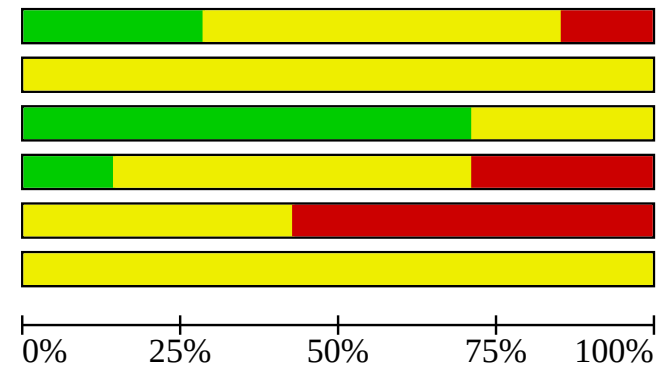


Figure 5. 'Risk of bias' summary: review authors' judgements about each risk of bias item for each included study.

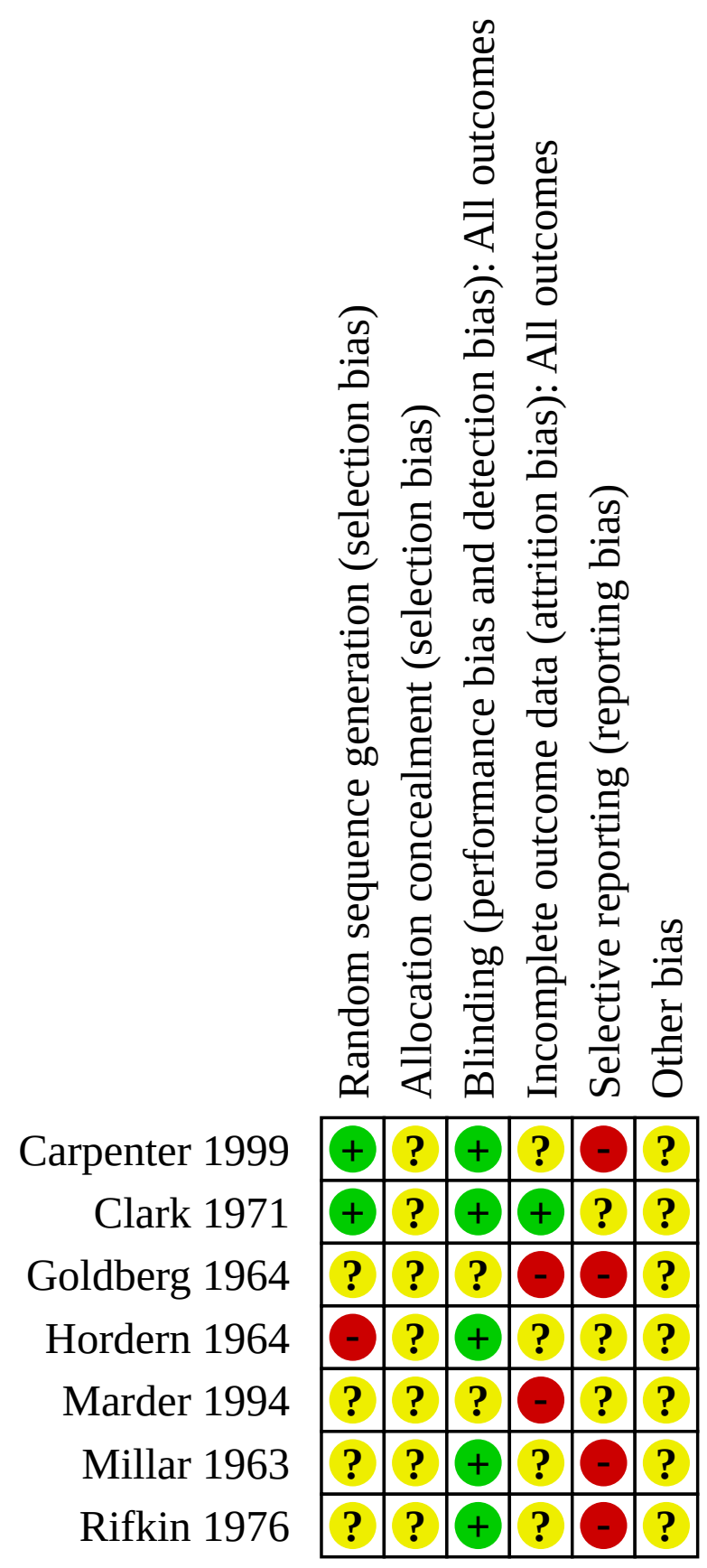

\section{Allocation}

None of the seven included studies described the methods used to generate random allocation, yet six of them were reported to be "randomly assigned" and readers are given little assurance that bias was minimised during the allocation procedure. Hordern 1964, did not mention "random assignment", and reported that

assignment of participants to fluphenazine or placebo groups was matched on age, length of illness, and severity of illness and the number of participants in each group was identical. Millar 1963 also obtained the same numbers in each group in a randomly assigned procedure with no further description. 


\section{Blinding}

Only two studies (25\%) gave a description of their attempts to make the investigation double-blind. Clark 1971 reported that identically appearing medication was administrated from a bottle labelled only with the participant's name and Millar 1963 reported that only the hospital pharmacist knew the composition of the groups. However neither of them actually tested how successful these attempts were. In the other six trials, it was indicated that attempts at blinding had been made, but without any further description.

\section{Incomplete outcome data}

Five studies reported that participants left the study early. Only two, Goldberg 1964 and Clark 1971, reported specifically the reasons for withdrawal.

\section{Selective reporting}

Studies frequently presented both dichotomous and continuous data in graphs, or just reported statistical measures of probability ( $P$ values). This often made it impossible to acquire raw data for synthesis. Continuous data were frequently poorly described; often no standard deviations/standard errors were presented or no data were presented at all. In this way a lot of potentially informative data were lost. In some studies it seemed that attempts had been made to use the original trials as vehicles for answering a host of other questions about schizophrenia. As a consequence, data from the randomised parts of the studies became buried beneath copious subgroup analyses.

\section{Other potential sources of bias}

The quality of trials has been assessed in individual 'Risk of bias' tables under the Characteristics of included studies section, using the guidance from the Cochrane Handbook for Systematic Reviews of Interventions categories (Higgins 2011). Due to poor reporting standards from particularly old studies, the majority of the risk of bias domains have been rated 'unclear' for the risk of bias.

\section{Effects of interventions}

See: Summary of findings 1 ORAL FLUPHENAZINE versus PLACEBO for Schizophrenia

\section{COMPARISON: ORAL FLUPHENAZINE verSUS PLACEBO}

\subsection{Global state}

\subsubsection{Not improved or worsened}

We found no significant difference between oral fluphenazine and placebo for 'not improved or worse' (CGI) over short-term assessment ( $n=125,3$ RCTs). Dichotomised multidimensional rating scale scores at 12 weeks 'not improved or worse' were also non-significant ( $\mathrm{n}=50,1 \mathrm{RCT}$, Analysis 1.1).

\subsubsection{Relapse}

Only Millar 1963 reported on relapse up to six weeks (short term) with results indicating a trend favouring fluphenazine $(n=38,1$ RCT, risk ratio (RR) $0.2595 \%$ confidence interval $(\mathrm{Cl}) 0.06$ to $1.03, \mathrm{P}=$ 0.05). Two studies, Marder 1994 and Rifkin 1976, reported data for long-term relapse, which significantly favoured fluphenazine but data are heterogeneous (12 92\%). Using a random-effects model rendered data equivocal $(n=86,2$ RCTs, Analysis 1.2).

\subsubsection{Percentage of time in prodrome state}

Marder 1994 reported data at one- and two-year time points, but data are skewed (high SDs) and are best inspected outside of a forest plot, using an additional table (Analysis 1.3). The data suggest that a greater amount of time was spent in a prodromal state amongst placebo participants, at both one and two years.

\subsubsection{Percentage of time in exacerbated state}

Again, Marder 1994 reported data at one- and two-year time points, but data are skewed and are best inspected outside of a forest plot, using an additional table (Analysis 1.4). Data suggest that, by one year, participants receiving oral fluphenazine spent more time in an exacerbated state that those on placebo. However, by two years, people receiving placebo spent longer in an exacerbated state.

\subsubsection{CGI severity of illness - average score}

Data for global state using the CGI were reported in one study (Clark 1971), which demonstrated greater improvement in global state ( $\mathrm{n}=36,1 \mathrm{RCT}$, mean difference (MD) $-0.7795 \% \mathrm{Cl}-1.39$ to $-0.15)$, this was a statistically significant result $(P=0.02)$; however, these data were imputed using the adjusted final mean and the $P$ value between studies, and the significance of the results should be treated with caution (Analysis 1.5).

\subsection{Leaving study early}

\subsubsection{Non-specific reasons}

Although people allocated to oral fluphenazine left the study less often than participants who were given placebo in the short term, the data did not reach statistical significance ( $n=227,2$ RCTs). For -medium-term assessment, we found only one study reporting on attrition $(n=50)$ and data were not significantly different. Longterm follow-up from two studies $(n=86)$ were also equivocal, and as a proxy measure for treatment acceptability the oral fluphenazine group did not find treatment any more acceptable than the placebo group when assessed over short-, medium- and long-term evaluation. Overall, across all time periods, only about $15 \%$ of people left these studies early ( $n=363,5$ RCTs, Analysis 1.6).

\subsubsection{Specific reasons}

Leaving the study early due to court case transfers was significantly higher $(P=0.02)$ in the fluphenazine group ( $n=190,1$ RCT, RR $10.6595 \% \mathrm{Cl} 1.39$ to 81.58 ). Other reasons for leaving the study early: 'incorrect diagnosis' ( $n=190,1$ RCT), 'marked early remission' ( $n=190,1$ RCT) and 'serious complication of treatment' ( $n=190,1$ RCT) were not significantly different. We found the number of participants leaving the study early due to treatment failure favoured oral fluphenazine with significantly more people dropping out from the placebo group ( $\mathrm{n}=190,1 \mathrm{RCT}$, RR 0.11 95\% Cl 0.03 to 0.35, Analysis 1.7).

\subsubsection{Marked improvement/ hospital discharge}

Data were equivocal for this positive outcome (forest plots are presented to display results right to the line of no effect, indicating a favourable outcome for oral fluphenazine). Only one participant receiving oral fluphenazine in one small study was discharged due to marked improvement ( $\mathrm{n}=36,1 \mathrm{RCT}$, Analysis 1.8$)$. 


\subsection{Adverse effects}

\subsubsection{Anticholinergic effects}

There is some suggestion that fluphenazine increases a person's chance of experiencing anticholinergic effects such as constipation ( $\mathrm{n}=190,1 \mathrm{RCT}, \mathrm{RR} 2.2295 \% \mathrm{Cl} 1.19$ to 4.15$)$, dry mouth ( $\mathrm{n}=227$, 2 RCTs, RR $3.6295 \% \mathrm{Cl} 1.39$ to 9.42) and increased salivation (n $=190,1 \mathrm{RCT}$, RR $18.1095 \% \mathrm{Cl} 1.06$ to 309.15). Data for blurred vision, drooling, gastrointestinal distress, nasal congestion, urinary disturbance, and vomiting were not significantly different (Analysis 1.9).

\subsubsection{Cardiovascular effects}

No significant differences were found between fluphenazine and placebo for dizziness/faintness/weakness ( $n=190,1$ RCT), hypotension ( $n=37,1 R C T)$, syncope $(n=37,1 R C T)$, or tachycardia $(\mathrm{n}=37,1 \mathrm{RCT}$, Analysis 1.10).

\subsubsection{Central nervous system}

There is also some suggestion that fluphenazine increases a person's chance of experiencing some neurological symptoms such as drowsiness ( $n=190,1$ RCT, RR $3.9195 \% \mathrm{Cl} 1.98$ to 7.71 ). Reports of headache did not reveal any significant differences between fluphenazine and placebo groups ( $n=190,1$ RCT). Other outcomes, anxiety, convulsion/seizures, depression, sedation/lethargy were equivocal (Analysis 1.11).

\subsubsection{Death}

Only one study (Rifkin 1976) reported on the outcome of death, with one death occurring in the fluphenazine group during long-term follow-up ( $n=50,1$ RCT, Analysis 1.12).

\subsubsection{Endocrine}

We found no statistically significant difference between fluphenazine and placebo for the outcomes of amenorrhoea $(n=$ 190,1 RCT), lactation ( $n=190,1$ RCT) or swelling of the breasts $(n=$ 190, 1 RCT) at short term (Analysis 1.13).

\subsubsection{Extrapyramidal effects}

In the short term, there is evidence that fluphenazine increases a person's chances of experiencing akathisia $(n=227,2$ RCTs, RR 3.43 $95 \% \mathrm{Cl} 1.23$ to 9.56 ), facial rigidity ( $\mathrm{n}=190,1 \mathrm{RCT}, \mathrm{RR} 2.7795 \% \mathrm{Cl}$ 1.03 to 7.46 ), 'loss of associated movements' ( $n=190,1$ RCT, RR 6.39 $95 \% \mathrm{Cl} 1.95$ to 20.98 ), rigidity ( $\mathrm{n}=227,2 \mathrm{RCTs}$, RR $3.5495 \% \mathrm{Cl} 1.76$ to 7.14 ) and tremor ( $n=227,2$ RCTs, RR $3.1995 \% \mathrm{Cl} 1.25$ to 8.11 ). We found measures of akinesia, associated movements, dystonia and restlessness/insomnia were not significantly different from those allocated to placebo. Evidence in the medium term indicates that fluphenazine increases the likelihood of having parkinsonism ( $\mathrm{n}=$ 50, 1 RCT, RR $5.5095 \% \mathrm{Cl} 1.36$ to 22.32), but akathisia, akinesia and dystonia were equivocal (Analysis 1.14).

\subsubsection{Other}

We did not find any statistically significant data for the outcomes of convulsion/seizures ( $n=190,1$ RCT), diarrhoea $(n=190,1$ RCT), infection ( $n=190,1$ RCT), or rash ( $n=227,2$ RCTs, Analysis 1.16).

\subsection{Economic outcomes \\ Cost of relapse}

See Analysis 1.2, and additional Table 3 and Table 4 to aid interpretation of results.

\section{Hospital discharge}

There were no data for this outcome in the included studies.

\section{SENSITIVITY ANALYSES}

\subsection{Men and women}

Three studies included either all male (Marder 1994) or all female (Hordern 1964; Millar 1963) participants. However, only Marder 1994 reported data for any of our primary outcomes; therefore, a sensitivity analysis was not possible for this comparison. Note HM: this section is repeated below.

\subsection{People who are under 18 years of age, between 18 and 64, or over 65 years of age}

The age ranges of all participants across the included studies were all similar (between 16 and 58 years old). Where participants younger than 18 were included in the relevant studies (the youngest being 16 years old in Goldberg 1964, and 17 years old in Rifkin 1976), it was not possible to extract their data from the individual reports. Therefore, a sensitivity analysis has not been undertaken.

\subsection{Chronic versus acutely ill people (< one month in duration)}

Limited data were available from only one study. Participants who were chronically ill did not leave the study early in greater numbers than acutely ill patients. We found relapse did occur more often in the placebo arm of those chronically ill compared with those acutely ill, but the sample sizes were small and uneven and more data are required to draw any inferences (Analysis 1.17).

\subsection{Low doses (1-5 mg/day) and high doses (over $5 \mathrm{mg} /$ day)}

Again, limited data were available, but it is suggested that there is little difference between levels of improvement between participants in studies that used either a high dose $(15 \mathrm{mg} /$ day used in Carpenter 1999; $n=38,1 \mathrm{RCT}$ ) or a flexible dose regimen in the short term (2-10 mg/day in Clark 1971; or up to $14 \mathrm{mg} /$ day in Hordern 1964; $\mathrm{n}=87,2$ RCTs, Analysis 1.18).

\subsection{Diagnosed according to any operational criterion versus those with loosely defined illness}

It is indicated that there is again little difference in results for no improvement when participants have been diagnosed according to operational criteria (DSM-III-R, $n=38,1 \mathrm{RCT}$ ) or with loose diagnostic criteria or definitions ( $n=87,2$ RCTs, Analysis 1.19).

\subsection{Studies published before 1990 versus studies published between 1990 and the present}

Data were available for the outcomes of 'no global improvement' in the short term. There were no clear differences between the results of earlier studies and those published in the last 16 years (Analysis 1.20).

\subsection{Implication of randomisation}

Only one study was rated as a low risk of bias for adequate randomisation (Clark 1971); results for the primary outcome of 
global state (not improved or worse) remain the same when all other studies that implied randomisation were removed from the meta-analysis ( $n=37,1 \mathrm{RCT}$, RR $0.59,95 \% \mathrm{Cl} 0.24$ to 1.42 ). For the other secondary outcomes of adverse effects; the effect of removing the other studies that were meta-analysed with Clark 1971 and implied as being randomised is that data are no longer statistically significant for short-term extrapyramidal akathisia (from $P=0.02$ to $P=0.18)$, or tremor $(P=0.01$ to $P=0.09)$.

\subsection{Assumptions for lost binary data}

There were no clear differences between the results when completer-only data were used compared to data assumed for those lost to follow-up.

\subsection{Risk of bias}

Each included study was rated as a 'high' risk of bias across one or more of the domains of randomisation (implied as randomised with no further details available): allocation concealment, blinding and outcome reporting for the meta-analysis of the primary outcome. The result of excluding each study on this basis leaves us with no data to compare, therefore a sensitivity analysis was not possible.

\subsection{Imputed values}

We also sought to undertake a sensitivity analysis to assess the effects of including data from trials where we used imputed values for ICC in calculating the design effect in cluster-randomised trials. However, we encountered no such studies.

\subsection{Fixed-effect and random-effects}

We found that there was no difference in the results when synthesising data for the primary outcome of global state (not improved or worse) using a random-effects model. However, for short-term extrapyramidal effects (tremor), when using a randomeffects model, results were no longer statistically significant (from $P=0.01$ to $P=0.07$ ).

\subsection{Economic outcomes}

See Analysis 1.2 and additional Table 3 and Table 4 to aid interpretation of results.

\section{DISCUSSION}

\section{Summary of main results}

\section{COMPARISON ONE: ORAL FLUPHENAZINE verSUS PLACEBO}

\subsection{Global State}

\subsubsection{No improvement}

There were few data available for global improvement. Data were only obtained from three studies, and both short-term and medium-term assessment did not reveal any significant differences between fluphenazine and placebo, although a trend may be evident from the graphical representations of the data, suggesting that oral fluphenazine is superior to placebo, and perhaps this would have clearly emerged if larger and longer studies were used.

\subsubsection{Relapse}

There are surprisingly little data regarding relapse but the strongest results come from a small study with a duration of one year (Rifkin 1976), however, there was substantial heterogeneity present, perhaps due to the difference between the participant population and stages (remitted, non-psychotic participants in Rifkin 1976, and participants with at least two episodes of acute schizophrenia or continuing psychotic symptoms in previous two years in Marder 1994). A larger sample size would have probably ensured more unequivocal data in favour of fluphenazine.

\subsection{Leaving study early}

The finding that using fluphenazine resulted in more people staying in the study could be seen as heartening. Perhaps a genuine decrease in the distressing symptoms of schizophrenia leads to an increased concordance with medication, despite the unpleasant adverse effects of this drug.

\subsection{Mental state}

In spite of more than five decades of research on this benchmark antipsychotic treatment, very little can be said from trials regarding its direct effect on mental state regarding general or specific symptoms of schizophrenia.

\subsection{Adverse effects}

Although we were able to include a few studies in this review, clinicians will not be surprised that fluphenazine produces acute extrapyramidal disorders; dystonia, parkinsonism, akathisia, tremor, rigidity, weakness and anticholinergic effects. This Cochrane review, however, is a rare report of the best available and quantitative data on a compound over half a century old. Estimates of the incidence of extrapyramidal disorders, however, are not available from this review, as these necessitate a long follow-up period that was only attempted in a few trials. It may be surprising that there was only one death incident reported among over 439 people with schizophrenia who were randomised to oral fluphenazine or placebo. The lifetime incidence of suicide for people suffering from schizophrenia is $10 \%$ to $13 \%$ (Caldwell 1992). The occurrence of only one death indicates that either trial-care is more vigilant than routine care or that death is an under-reported outcome.

\subsection{Economic summary}

As we have stated, the current economic evidence we present uses up-to-date values calculated using PSSRU unit costs of health and social care in GBP terms and average length of stay in UK NHS hospitals using HES data. Bearing this in mind, the Grade $\mathrm{C}$ level of economic evidence used was taken from the effect of intervention data of relapse/worsening from studies that were conducted between 1963 to 1994 in either the UK or USA. Therefore, the international applicability of the data presented is questionable, as is the accuracy of the potential value (GBP) that was calculated from the measured outcome only. What the results do show us, however, is what is already known - that there is a price attached to relapse and other outcome measures commonly addressed in systematic reviews - this economic summary is intended to highlight this issue and promote discussion in order for the research community to clarify the best way to approach economic analyses in systematic reviews.

\section{SENSITIVITY ANALYSES}

As we knew would be likely from the start, the power to detect a real difference between studies in any one of the sensitivity analyses was very low. Only subsets of already limited lists of trials 
were available. The wide confidence intervals could be hiding true differences in effect between the acutely and chronically ill people, and early trials versus current studies.

\section{Overall completeness and applicability of evidence}

\section{Generalisability}

This work includes studies that span nearly four decades of evaluative studies within psychiatry. It is possible that the rigour of these experiments has changed over time, as have the participants. There is some empirical evidence that the quality of schizophrenia trial reporting has not changed much over time (Thornley 1998) or, if it has changed, it may even have deteriorated (Ahmed 1998). We have found no time-related differences in reporting of studies within this review and no suggestion of a change of the effect size over time. We identified trials by meticulous searching; nevertheless, for a compound formulated so long ago, publication biases may be difficult to avoid. The strength of this review is that it presents up-to-date quantitative data for a benchmark treatment for schizophrenia which is used throughout the world.

\section{Applicability}

The seven included studies involve many people who would be recognisable in everyday practice. There are those with strictly diagnosed illnesses, very likely to suffer from schizophrenia, and people whose illness was diagnosed using less rigorous criteria. The dose of fluphenazine in the studies included in this review could be considered standard (mean $8.2 \mathrm{mg} /$ day SD 3.9). Although the outcomes that have been used in this review are accessible to both clinicians and recipients of care, generalising to treatment in community settings, could be problematic. Four studies were undertaken in hospital and three in the community, which is where most people with schizophrenia now reside.

There are no Grade A or B economic evaluations conducted on fluphenazine. With Grade $C$ data which reports outcome measures, we have attempted to value the outcomes in GBP terms. This may not be an accurate measure of costs incurred or saved and as such we would not recommend that these results be used. This is intended to encourage debate on how best to use such reported data.

\section{Heterogeneity}

Two outcomes were heterogeneous, but all other outcomes were homogeneous. However, no more than five studies were pooled so the chances of data being heterogeneous were always small. In addition, several methods were used to observe different adverse effects e.g. tremor and blurred vision. This made analyses and interpretation for the results even more difficult.

\section{Limited data}

Data were often inadequately reported and rendered many outcomes unusable. Most trials report only six- to 12-week outcomes for a mostly lifelong illness. No studies reported on service utilisation, economic outcomes, or on satisfaction with care.

\section{Quality of the evidence}

\section{General}

Generally, the quality of the available evidence was rated as either very low, low to moderate (See Summary of findings 1 ). This was largely due to the age of the included studies and poor reporting standards, some of which were published up to 50 years ago, pre-dating the CONSORT statement (Moher 2001; Schulz 2010). Missing or unreported outcomes were common, which restricted the amount of evidence available for use in this systematic review and data that may have been relevant in meta-analysis. Any future studies in this area must adhere to CONSORT principles, ensuring that all trials are transparently reported, that all tables and figures express what data they are presenting, so that no trials can reach publication without revelation of methodological inadequacies. A flow diagram should also be used in order to document the process in which participants are recruited to those that are ultimately followed-up, promoting completeness, clarity and transparency of reporting.

\section{Specific: economic evaluation}

We did not come across any studies that was of Grade A or B economic evaluation (which includes but not limited to cost-effectiveness analysis, cost-utility analysis and cost-benefit analysis).

\section{Potential biases in the review process}

The review authors sought to adhere to the protocol, through the independent inspection of citations and full articles of potentially relevant studies. Furthermore, the review authors independently extracted data onto standard simple forms; however, we met for discussion where inconsistencies or disagreements arose regarding the available data.

\section{Agreements and disagreements with other studies or reviews}

We are not aware of other systematic reviews evaluating the effects of oral fluphenazine versus placebo in the treatment of schizophrenia.

\section{Limitations of the economic evaluation}

The economic authors appreciate the limitations of the methods used in the economic summary. It is fair to say that the data provided display a rudimentary estimate of the value in GBP terms associated with the outcomes of relapse and hospital discharge. As we did not include cost of treatment or costs associated with treatment, it is acknowledged that the direction of the estimated result may well change. The aim of this economic summary is to generate debate and discussion; to not take effectiveness data at face value without considering potential economic consequences; and to utilise the data in a way that will be of greater use to decision/policy-makers. We will welcome discussion on the methods used for Grade $C$ level economic evidence and the planned methods described for Grade A and B level evidence should future reviews find those studies. We are aware that policy-makers and commissioners often consider these reviews while deciding on service provision and valuing outcomes in GBP terms may make it easier to review evidence such as relapse. 


\section{AUTHORS' CONCLUSIONS}

\section{Implications for practice}

\section{For people with schizophrenia}

Many people with schizophrenia and their non-professional carers recognise psychotic symptoms as phenomena generated by a damaging and pernicious illness and may see the effect of fluphenazine, as demonstrated within this review, as positive. Others may consider these data as supporting well-publicised objections to the use of drugs; drugs potent in their ability to cause unpleasant adverse effects, and to potentially erode a person's ability to make informed decisions.

\section{For clinicians}

This review will confirm much that clinicians already know, but it does provide some quantification to support clinical impression. Fluphenazine is an antipsychotic, prone to cause a variety of extrapyramidal and anticholinergic effects. Evidence about its short-term antipsychotic effect is weak. However, fluphenazine is a low-cost and widely available choice for the clinician. Despite its many adverse effects, fluphenazine is likely to remain one of the most widely used treatments for schizophrenia worldwide.

\section{For managers or policy makers}

Fluphenazine is widely available and inexpensive. It is understandable that it remains one of the many drugs used for treating people with serious mental illnesses. However, some of fluphenazine's adverse effects could be expensive in terms of human suffering and cost of treatment. It could, therefore, be more beneficial to use another drug if the latter was equally potent, but had a more favourable adverse-effect profile.

\section{Implications for research}

\section{General}

So much more could have been learnt about the effects of oral fluphenazine if the studies in this review had clearly described the method of allocation and the integrity of blinding; especially for the more subjective outcomes. Most included studies, however, predated the CONSORT statement (Moher 2001). Concrete and simple outcomes are of interest. For example, clearly reporting improvement, 'number of violent incidents', 'relapse' (giving some description of criteria), 'hospital discharge or admission', and 'presence of delusions or hallucinations' would have been helpful, and simple reporting of levels of satisfaction and quality of life would have been very informative.

\section{Specific}

Even though fluphenazine has been used as an antipsychotic drug for decades, there are still a surprisingly small number of well-conducted randomised, placebo-controlled trials measuring its efficacy and potential to cause adverse effects. The use of oral fluphenazine for millions of people is based on clinical experience rather than the poorly reported trials that involve, in total, only a few hundred participants. Clinicians and researchers are mainly satisfied with the current levels of understanding, and, therefore new studies evaluating oral fluphenazine versus placebo will be very rare. The fluphenazine story is, however, incomplete. Questions remain regarding the effect of this drug on mental state and long-term extrapyramidal effects. One or more large, methodologically sound, randomised, placebo-controlled trials could help answer these questions. With the advent of universally available effective, even moderately effective, antipsychotic drugs, the day for studies comparing oral fluphenazine with placebo has passed.

\section{ACKNOWLEDGEMENTS}

We would like to thank members of the Cochrane Schizophrenia Group, Prof. Clive E Adams, Tessa Grant and Judy Wright for their continuing support. Thanks also go to Dr. Adib Essali who first introduced us to The Cochrane Collaboration.

The Cochrane Schizophrenia Group produce and maintain a template for the methods section of their reviews. We have used this template and adapted it for our requirements. 


\section{R E F E R E N C E S}

\section{References to studies included in this review}

\section{Carpenter 1999 \{published data only\}}

Carpenter WT Jr, Buchanan RW, Kirkpatrick B, Breier AF. Diazepam treatment of early signs of exacerbation in schizophrenia. American Journal of Psychiatry 1999;156(2):299-303. [MEDLINE: 99178642]

\section{Clark 1971 \{published data only\}}

Clark ML, Huber WK, Charalampous KD, Serafetinides EA, Trousdale W, Colmore JP. Drug treatment in newly admitted schizophrenic patients. Archives of General Psychiatry 1971;25(5):404-9. [MEDLINE: 72081786]

Clark. Phenothiazines in schizophrenics. Psychopharmacology Bulletin 1969;6(3):37-40.

\section{Goldberg 1964 \{published data only\}}

* Cole JO, Goldberg SC, Klerman GL. Phenothiazine treatment in acute schizophrenia. Archives of General Psychiatry 1964;10:246-61. [MEDLINE: 71204770]

Gibbons RD, Lewine RRJ, Davis JM, Schooler NR, Cole JO. An empirical test of a kraepelinian vs. a bleulerian view of negative symptoms. Schizophrenia Bulletin 1985;11(3):390-5. [MEDLINE: 71204770]

Goldberg SC, Klerman GL, Cole JO. Changes in schizophrenic psychopathology and ward behaviour as a function of phenothiazine treatment. British Journal of Psychiatry 1965;111:120-33. [MEDLINE: 5677325]

Goldberg SC, Mattsson N, Cole JO, Klerman GL. Prediction of improvement in schizophrenia under four phenothiazines. Archives of General Psychiatry 1967;16:107-17. [MEDLINE: 6066689]

Goldberg SC, Mattsson NB. Schizophrenic subtypes defined by response to drugs and placebo. Diseases of the Nervous System 1968;29(5):S153-8. [MEDLINE: 68399894]

Klerman GL, Goldberg SG, Davis D. Relationship between the hospital milieu and the response to phenothiazines in the treatment of schizophrenics. Acta Psychiatrica Belgica 1970;70(6):716-29. [MEDLINE: 71204770]

\section{Hordern 1964 \{published data only\}}

Hordern A, King A, Holt NF, Collins J, Toussaint J. Thioproperazine in chronic schizophrenia. British Journal of Psychiatry 1964;110:531-9. [MEDLINE: 79181666]

Marder 1994 \{published data only\}

Marder SR, Wirshing WC, van Putten T, Mintz J, McKenzie J, Johnston-Cronk K, et al. Fluphenazine vs placebo supplementation for prodromal signs of relapse in schizophrenia. Archives of General Psychiatry 1994;51(4):280-7. [MEDLINE: 94213575]

\section{Millar 1963 \{published data only\}}

Millar J. A trial of fluphenazine in schizophrenia. British Journal of Psychiatry 1963;109:428-32. [MEDLINE: 769023]
Rifkin 1976 \{published data only\}

Rifkin A, Quitkin F, Kane J, Klein DF, Ross D. The effect of fluphenazine upon social and vocational functioning in remitted schizophrenics. Biological Psychiatry 1979;14(3):499-508. [MEDLINE: 224958] [PsycINFO 64-08562]

Rifkin A, Quitkin F, Kane J, Klein DF. Fluphenazine decanoate, oral fluphenazine, and placebo in the treatment of remitted schizophrenics. II. Rating scale data. Psychopharmacology Bulletin 1977;13(2):40-50. [MEDLINE: 323910]

Rifkin A, Quitkin F, Klein DF. Fluphenazine decanoate, oral fluphenazine, and placebo in treatment of remitted schizophrenics. II. Rating scale data. Archives of General Psychiatry 1977;34(10):15-9. [MEDLINE: 78019044]

* Rifkin A, Quitkin F, Rabiner CJ, Klein DF. Comparison of fluphenazine decanoate, oral fluphenazine, and placebo in remitted outpatient schizophrenics. Psychopharmacology Bulletin 1976;12(2):24-6. [MEDLINE: 769022]

Rifkin A, Quitkin F, Rabiner CJ, Klein DF. Fluphenazine decanoate, fluphenazine hydrochloride given orally, and placebo in remitted schizophrenics. I. Relapse rates after one year. Archives of General Psychiatry 1977;34(1):43-7. [MEDLINE: 77111134]

\section{References to studies excluded from this review}

Adler 1994 \{published data only\}

Adler LA, Rotrosen J, Edson R, Lavori P, Lohr J, Hitzemann R, . Vitamin E treatment for tardive dyskinesia. Archives of General Psychiatry 1999;56(9):836-41. [EMBASE 1999313441]

* Adler LA, Rotrosen J, Lavori P, Edson R. Vitamin E treatment of TD: development of a VA cooperative study. Biological Psychiatry 1994;35:730-1. [MEDLINE: 11760]

Caligiuri MP, Lohr JB, Rotrosen J, Adler L, Lavori P, Edson R, et al. Reliability of an instrumental assessment of tardive dyskinesia: results from VA Cooperative Study 394. Psychopharmacology 1997;132(1):61-6. [EMBASE 1997216311]

Baladini 1970 \{published data only\}

Baldini JT, Neary ER. Controlled trials of an amitriptylinefluphenazine combination in depressive neuroses and psychoses: a collaborative study. Current Therapeutic Research, Clinical and Experimental 1970;12(2):84-93. [MEDLINE: 70113586]

Boyer 1995 \{published data only\}

* Boyer P, Lecrubier Y, Puech AJ, Dewailly J, Aubin F. Treatment of negative symptoms in schizophrenia with amisulpride. British Journal of Psychiatry 1995;166(1):68-72. [MEDLINE: 7894879]

Boyer P, Lecrubier Y, Puech AJ. Treatment of positive and negative symptoms: pharmacologic approaches. Modern Problems of Pharmacopsychiatry 1990;24:152-74. [MEDLINE: 11782241] 
Boyer P, Puech AJ, Lecrubier Y. Double blind trial versus placebo of low dose amisulpride (Solian 50) in schizophrenia with exclusively negative symptoms. Preliminary analysis of results [Etude en double insu contre placebo de l'amisulpride (Solian (r) 50) a faible dose chez des schizophrenes purement deficitaires. Premiere analyse des resultats]. Annales de Psychiatrie 1988;3(3):321-5. [EMBASE 1988242981]

Boyer P, Puech AJ. Determinants for clinical activity of neuroleptic drugs: chemical substances, doses, assessment tools [Modalities d'action clinique des neuroleptiques: substances, doses, instruments de mesure utilises]. Psychiatrie and Psychobiologie 1987;2(4):296-305. [PsycINFO 76-12830]

Lecrubier Y. Amisulpride in deficit schizophrenia. In: 6th World Congress of Biological Psychiatry; 1997 Jun 22-27; Nice, France. 1997. [MEDLINE: 7894879]

Rein W, Turjanski S. Clinical update on amisulpride in deficit schizophrenia. International Clinical Psychopharmacology 1997;12(Suppl 2):S19-27. [MEDLINE: 97361270]

\section{Breier 1987 \{published data only\}}

Breier A, Wolkowitz OM, Doran AR, Roy A, Boronow J, Hommer DW, et al. Neuroleptic responsivity of negative and positive symptoms in schizophrenia. American Journal of Psychiatry 1987;144:1549-55. [MEDLINE: 3688278]

\section{Carpenter 1992 \{published data only\}}

Carpenter WT, Buchanan RW, Breier A, Kirkpatrick B, Hanlon T, Levine J, et al. Novel neuroleptic dosage reduction strategies. Schizophrenia Research 1992;6(2):107. [MEDLINE: 3688278]

\section{Chacon 1972 \{published data only\}}

Chacon C, Harper P, Harvey GF. Work study in the assessment of the effects of phenothiazines in schizophrenia. Comprehensive Psychiatry 1972;13(6):549-54. [MEDLINE: 73051431] [PsycINFO 1973-31686-001]

\section{Chacon 1973 \{published data only\}}

Chacon C, Harper P. Clinical and work performance variables in phenothiazine therapy of schizophrenia. Acta Psychiatrica Scandinavica 1973;49(1):65-76. [MEDLINE: 4572169]

\section{Coffman 1987 \{published data only\}}

Coffman JA, Nasrallah HA, Lyskowski J, McCalley-Whitters M, Dunner FJ. Clinical effectiveness of oral and parenteral rapid neuroleptization. Journal of Clinical Psychiatry 1987;48(1):20-4. [EMBASE 1987061089]

\section{Del Giudice 1975 \{published data only\}}

Del Giudice J, Clark WG, Gocka EF. Prevention of recidivism of schizophrenics treated with fluphenazine enanthate. Psychosomatics 1975;16(1):32-6. [MEDLINE: 76032528] [PsycINFO 54-12277]

\section{Doran 1990 \{published data only\}}

Doran AR, Labarca R, Wolkowitz OM, Roy A, Douillet P, Pickar D. Circadian variation of plasma homovanillic acid levels is attenuated by fluphenazine in patients with Schizophrenia. Archives of General Psychiatry 1990;47:558-63. [MEDLINE: 2350208]

\section{Dowing 1963 \{published data only\}}

Downing RW, Ebert JN, Shubrooks SJ. Effect of phenothiazines on the thinking of acute schizophrenics. Perceptual and Motor Skills 1963;17(2):511-20. [PsycINFO 1964-06498-001]

\section{Elman 1999 \{published data only\}}

Elman I, Goldstein DS, Eisenhofer G, Folio J, Malhotra AK, Adler $\mathrm{CM}$, et al. Mechanism of peripheral noradrenergic stimulation by clozapine. Neuropyschopharmacology 1999;20(1):29-34. [MEDLINE: 99103168]

\section{Haider 1968 \{published data only\}}

Haider I. A controlled trial of fluphenazine enanthate in hospitalized chronic schizophrenics. British Journal of Psychiatry 1968;114(512):837-41. [MEDLINE: 4874164]

\section{Hanlon 1970 \{published data only\}}

Hanlon TE, Ota KY, Kurland AA. Comparative effects of fluphenazine, fluphenazine-chlordiazepoxide and fluphenazine-imipramine. Diseases of the Nervous System 1970;31(3):171-7. [MEDLINE: 4909632]

\section{Held 1970 \{published data only\}}

Held JM, Cromwell RL, Frank ET Jr, Fann WE. Effect of phenothiazines on reaction time in schizophrenics. Journal of Psychiatric Research 1970;7(3):209-13. [MEDLINE: 70166858]

\section{Hogarty 1979 \{published data only\}}

Hogarty GE, Schooler NR, Ulrich R, Mussare F, Ferro P, Herron E. Fluphenazine and social therapy in the aftercare of schizophrenic patients. Relapse analyses of a twoyear controlled study of fluphenazine decanoate and fluphenazine hydrochloride. Archives of General Psychiatry 1979;36(12):1283-94. [MEDLINE: 80041623]

Holden 1970 \{published data only\}

Holden JM, Itil TM, Keskiner A. Assessment and significance of changes in laboratory values with haloperidol and fluphenazine hydrochloride therapy. Biological Psychiatry 1970;2(2):173-82. [MEDLINE: 4918019]

\section{Howell 1961 \{published data only\}}

Howell RJ, Brown HM, Beaghler HE. A comparison of fluphenazine, trifluoperazine and a placebo in the context of an active treatment unit. Journal of Nervous and Mental Disease 1961;132:522-30. [MEDLINE: 13716275]

\section{Itil 1971 \{published data only\}}

Itil TM, Saletu B, Hsu W, Kiremitci N, Keskiner A. Clinical and quantitative EEG changes at different dosage levels of fluphenazine treatment. Acta Psychiatrica Scandinavica 1971;47(4):440-51. [MEDLINE: 4947806]

Itil 1975 \{published data only\}

Itil TM, Marasa J, Saletu B, Davis S, Mucciardi AN. Computerized EEG: predictor of outcome in schizophrenia. Journal of Nervous and Mental Disease 1975;160(3):188-203. [MEDLINE: 75116033]

Kane 1982 \{published data only\}

Kane JM, Rifkin A, Quitkin F, Nayak D, Ramos Lorenzi J. Fluphenazine vs placebo in patients with remitted, acute 
first-episode schizophrenia. Archives of General Psychiatry 1982;39(1):70-3. [MEDLINE: 82112452]

\section{Kinross-Wright 1963 \{published data only\}}

Kinross-Wright J, Vogt AH, Charalampous KD. A new method of drug therapy. American Journal of Psychiatry 1963;119:779-80. [MEDLINE: 14032917]

\section{Kinross-Wright 1964 \{published data only\}}

Kinross-Wright J, Charalampous KD. A controlled study of a very long-acting phenothiazine preparation. International Journal of Neuropsychiatry 1964;1:66-70. [PsycINFO 60-03426]

\section{Leff 1971 \{published data only\}}

Hirsch SR, Gaind R, Rohde PD, Stevens BC, Wing JK. Outpatient maintenance of chronic schizophrenic patients with long-acting fluphenazine: double-blind placebo trial. Report to the Medical Research Council Committee on Clinical Trials in Psychiatry. British Medical Journal 1973;1(854):633-7. [MEDLINE: 4571196]

* Leff JP, Wing JK. Trial of maintenance therapy in schizophrenia. British Medical Journal 1971;3(775):599-604. [MEDLINE: 71287275]

\section{Litman 1994 \{published data only\}}

Litman RE, Hommer DW, Radant A, Clem T, Pickar D. Quantitative effects of typical and atypical neuroleptics on smooth pursuit eye tracking in schizophrenia. Schizophrenia Research 1994;12(2):107-20. [MEDLINE: 94318574]

\section{Marder 1989 \{published data only\}}

Marder SR, van Putten T, Aravagiri M, Hubbard JW, Hawes EM, McKay G, et al. Plasma levels of parent drug and metabolites in patients receiving oral and depot fluphenazine. Psychopharmacology Bulletin 1989;25(3):479-82. [MEDLINE: 2626520]

\section{Marder 1993 \{published data only\}}

Marder SR, Wirshing WC, Eckman T. Psychosocial and pharmacological strategies for maintenance therapy: effects on two - year outcome. Schizophrenia Research 1993;9:260.

\section{Martin 1975 \{published data only\}}

Martin IC. Implications of phenothiazine side effects: a study of antiparkinsonian agents in an older population. Acta Psychiatrica Scandinavica 1975;51(2):110-8. [MEDLINE: 235189]

\section{Matheu 1961 \{published data only\}}

Matheu H, Fogel EJ. Clinical effects of fluphenazine dihydrychloride in chronic schizophrenia. Journal of Neuropsychiatry 1961;3:105-11. [MEDLINE: 14471099]

\section{Mattes 1984 \{published data only\}}

Mattes JA, Nayak D. Lithium versus fluphenazine for prophylaxis in mainly schizophrenic schizo-affectives. Biological Psychiatry 1984;19(3):445-9. [MEDLINE: 6722235] [PsycINFO 72-10290]

\section{Pichot 1988 \{published data only\}}

Boyer P, Lecrubier Y, Puech AJ. Treatment of positive and negative symptoms: pharmacologic approaches. Modern
Problems of Pharmacopsychiatry 1990;24:152-74. [MEDLINE: 11782241]

Boyer P, Puech AJ. Determinants for clinical activity of neuroleptic drugs: chemical substances, doses, assessment tools [Modalities d'action clinique des neuroleptiques: substances, doses, instruments de mesure utilises]. Psychiatrie and Psychobiologie 1987;2(4):296-305. [PsycINFO 76-12830]

* Pichot P, Boyer P. A double blind, controlled, multicenter trial of low dose amisulpride (Solian(R) 50) versus low dose fluphenazine in the treatment of negative symptoms in chronic schizophrenia [Essai multicentrique controle, en double insu, amisulpride (solian(r) 50) contre fluphenazine a faibles doses dans le traitement du syndrome deficitaire des schizophrenies chroniques]. Annales de Psychiatrie 1988;3(3):312-20. [EMBASE 1988242980]

\section{Pickar 1986 \{published data only\}}

Pickar D, Labarca R, Doran AR, Wolkowitz OM, Roy A, Breier A, Linnoila M, Paul SM. Longitudinal measurement of plasma homovanillic acid levels in schizophrenic patients. Correlation with psychosis and response to neuroleptic treatment. Archives of General Psychiatry 1986;43(7):669-76. [MEDLINE: 3718170]

Pickar 1992 \{published data only\}

Pickar D, Owen RR, Litman RE, Hsiao JK, Su TP. Predictors of clozapine response in schizophrenia. Journal of Clinical Psychiatry 1994;55(Suppl B):129-32. [MEDLINE: 95050371]

* Pickar D, Owen RR, Litman RE, Konicki E, Gutierrez R, Rapaport MH. Clinical and biologic response to clozapine in patients with schizophrenia. Crossover comparison with fluphenazine. Archives of General Psychiatry 1992;49(5):345-53. [MEDLINE: 92264872]

\section{Quitkin 1978 \{published data only\}}

Quitkin F, Rifkin A, Kane J, Ramos Lorenzi JR, Klein DF. Long-acting oral vs injectable antipsychotic drugs in schizophrenics: a one-year double-blind comparison in multiple episode schizophrenics. Archives of General Psychiatry 1978;35(7):889-92. [MEDLINE: 78234523]

\section{Sampath 1992 \{published data only\}}

Sampath G, Shah A, Krska J, Soni SD. Neuroleptic discontinuation in the very stable schizophrenic patient - relapse rates and serum neuroleptic levels. Human Psychopharmacology 1992;7(4):255-64. [EMBASE 1992364197]

Schlosberg 1978 \{published data only\}

Schlosberg A, Shadmi M. A comparative controlled study of two long-acting phenothiazines: pipotiazine palmitate and fluphenazine decanoate. Current Therapeutic Research 1978;23(5):642-54. [PsycINFO 62-01680]

\section{Schooler 1976 \{published data only\}}

Gelenberg AJ, Doller JC, Schooler NR, Mieske M, Severe J, Mandel MR. Acute extrapyramidal reactions with fluphenazine hydrochloride and fluphenazine decanoate. American Journal of Psychiatry 1979;136:217-9. [MEDLINE: 79101484] 
Levine J, Schooler NR, Severe J, Escobar J, Gelenberg A, Mandel $\mathrm{M}$, et al. Discontinuation of oral and depot fluphenazine in schizophrenic patients after one year of continuous medication: a controlled study. Advances in Biochemical Psychopharmacology 1980;24:483-93. [MEDLINE: 80262441]

Mandel MR, Severe JB, Schooler NR, Gelenberg AJ, Mieske M. Development and prediction of postpsychotic depression in neuroleptic-treated schizophrenics. Archives of General Psychiatry 1982;39(2):197-203. [MEDLINE: 82159410]

* Schooler NR, Levine J, +NIMH-PRB Collaborative Fluphenazine Study Group. The initiation of long-term pharmacotherapy in schizophrenia: dosage and side effect comparisons between oral and depot fluphenazine. Pharmacopsychiatry 1976;9(4):159-69. [MEDLINE: 77036977]

Schooler NR, Levine J, Severe JB, Brauzer B, DiMascio A, Klerman GL, et al. Prevention of relapse in schizophrenia. An evaluation of fluphenazine decanoate. Archives of General Psychiatry 1980;37(1):16-24. [MEDLINE: 80108511]

Schooler NR, Levine J, Severe JB. Depot fluphenazine in the prevention of relapse in schizophrenia: evaluation of a treatment regimen. Psychopharmacology Bulletin 1979;15(2):44-7. [MEDLINE: 373006]

Schooler NR, Levine J. Dosage and side effect comparisons between oral and depot fluphenazine. Psychopharmacology Bulletin 1977;13(3):29-31. [MEDLINE: 329328]

\section{Shafti 2009 \{published data only\}}

Shafti SS. Augmentation of olanzapine by fluphenazine decanoate in poorly responsive schizophrenia. Clinical Schizophrenia and Related Psychoses 2009;3(2):97-102.

\section{Shenoy 1981 \{published data only\}}

Shenoy RS, Sadler AG, Goldberg SC, Hamer RM, Ross B. Effects of a six-week drug holiday on symptom status, relapse, and tardive dyskinesia in chronic schizophrenics. Journal of Clinical Psychopharmacology 1981;1(3):141-5. [MEDLINE: 82053610]

\section{Steingard 1994 \{published data only\}}

Steingard S, Allen M, Schooler NR. A study of the pharmacologic treatment of medication-compliant schizophrenics who relapse. Journal of Clinical Psychiatry 1994;55(11):470-2.

\section{Stevens 1976 \{published data only\}}

Stevens B. The social value of fluphenazine decanoate. Acta Psychiatrica Belgica 1976;76(5):792-804. [MEDLINE: 77178598]

\section{Turner 1966 \{published data only\}}

Turner P. A comparison of fluphenazine and chlorpromazine on critical flicker fusion frequency. Journal of Pharmacy and Pharmacology 1966;18:836. [MEDLINE: 67163670]

\section{Van Praag 1970 \{published data only\}}

van Praag HM, Breetveld J, van Mesdag Etty $\mathrm{H}$, Westerhuis R, Pen A, Schut T. A controlled comparative study of fluphenazine and fluphenazine enanthate in acute and chronic psychotic patients. Psychiatria Neurologia Neurochirurgia 1970;73(3):165-75. [MEDLINE: 4912332]

\section{Vestre 1962 \{published data only\}}

Vestre ND, Hall WB, Schiele BC. A comparison of fluphenazine, triflupromazine, and phenobarbital in the treatment of chronic schizophrenic patients: a double-blind controlled study. Journal of Clinical and Experimental Psychopathology 1962;23:149-59. [MEDLINE: 67163670]

\section{Watt 1978 \{published data only\}}

Watt DC. Maintenance drugs for schizophrenia. Lancet 1978;2(8098):1045-6. [MEDLINE: 79052029]

\section{Wistedt 1981 \{published data only\}}

Wistedt B, Jorgensen A, Wiles D. A depot neuroleptic withdrawal study. Plasma concentration of fluphenazine and flupenthixol and relapse frequency. Psychopharmacology 1982;78(4):301-4. [MEDLINE: 83118214]

* Wistedt B. A depot neuroleptic withdrawal study. A controlled study of the clinical effects of the withdrawal of depot fluphenazine decanoate and depot flupenthixol decanoate in chronic schizophrenic patients. Acta Psychiatrica Scandinavica 1981;64(1):65-84. [MEDLINE: 7032224]

Wistedt B. Neuroleptics and depression. Archives of General Psychiatry 1982;39(6):745. [MEDLINE: 6124226]

\section{Wistedt 1983 \{published data only\}}

Wistedt B, Wiles D, Jorgensen A. A depot neuroleptic withdrawal study neurological effects. Psychopharmacology 1983;80(2):101-5. [MEDLINE: 4874164]

\section{Zahn 1993 \{published data only\}}

Zahn TP, Pickar D. Autonomic effects of clozapine in schizophrenia - comparison with placebo and fluphenazine. Biological Psychiatry 1993;34(1-2):3-12.

\section{Additional references}

\section{Abi-Dargham 2000}

Abi-Dargham A, Rodenhiser J, Printz D, Zea-Ponce Y, Gil R, Kegeles LS, et al. Increased baseline occupancy of D2 receptors by dopamine in schizophrenia. Proceedings of the National Academy of Sciences 2000;97(14):8104-9. [MEDLINE: 10884434]

\section{Ahmed 1998}

Ahmed I, Soares K, Seifas R, Adams CE. Randomised controlled trials in Archives of General Psychiatry (1959-1995): a prevalence study. Archives of General Psychiatry 1998;55(8):754-5.

\section{Altman 1996}

Altman DG, Bland JM. Detecing skewness from summary information. BMJ 1996;313:1200. [OLZ020600]

\section{Bland 1997}

Bland JM, Kerry SM. Statistics notes. Trials randomised in clusters. BMJ 1997;315:600.

\section{BNF 1999}

British Medical Association. British National Formulary No. 38. Antipsychotic drugs. BNF September 1999. 


\section{Boissel 1999}

Boissel JP, Cucherat M, Li W, Chatellier G, Gueyffier F, Buyse $M$, et al. The problem of therapeutic efficacy indices. 3. Comparison of the indices and their use [Apercu sur la problematique des indices d'efficacite therapeutique, 3: comparaison des indices et utilisation. Groupe d'Etude des Indices D'efficacite]. Therapie 1999;54(4):405-11. [PMID: 10667106]

\section{Caldwell 1992}

Caldwell CB, Gottesman II. Schizophrenia - a high-risk factor for suicide: clues to risk reduction. Suicide and Life-Threatening Behavior 1992;22:479-93.

\section{CEA}

Cost-Effectiveness Analysis Registry (CEA). https:// research.tufts-nemc.org/cear4/ accessed 11/09/13.

\section{Darling 1959}

Darling HF. Fluphenazine: a preliminary study. Disease of the Nervous System 1959;20(4):167-70. [MEDLINE: 13652801]

\section{Davies 2007}

Davies LM, Lewis S, Jones PB, Barnes TR, Gaughran F, Hayhurst K, Markwick A, Lloyd H. Cost-effectiveness of first$v$. second-generation antipsychotic drugs: results from a randomised controlled trial in schizophrenia responding poorly to previous therapy. British Journal of Psychiatry 2007;191:14-22.

\section{Davis 1986}

Davis JM, Andriukatis S. The natural course of schizophrenia and effective maintenance drug therapy. Journal of Clincal Psychopharmacology 1986;6(1Suppl):2S-10S.

\section{Deeks 2000}

Deeks J. Issues in the selection for meta-analyses of binary data. In: Proceedings of the 8th International Cochrane Colloquium; 2000 Oct 25-28; Cape Town. Cape Town: The Cochrane Collaboration, 2000.

\section{Deeks 2011}

Deeks JJ, Higgins JPT, Altman DG, editor(s). Chapter 9: Analysing data and undertaking meta-analyses. In: Higgins JPT, Green S, editor(s). Cochrane Handbook for Systematic Reviews of Interventions Version 5.1.0 (updated March 2011). The Cochrane Collaboration, 2011. Available from www.handbook.cochrane.org.

\section{Dencker 1980}

Dencker SJ, Lepp M, Malm U. Do schizophrenics well adapted in the community need neuroleptics? A depot neuroleptic withdrawal study. Acta Psychiatria Scandinavica 1980;61((supp 279)):64-76.

\section{Divine 1992}

Divine GW, Brown JT, Frazer LM. The unit of analysis error in studies about physicians' patient care behavior. Journal of General Internal Medicine 1992;7:623-9.

\section{Donner 2002}

Donner A, Klar N. Issues in the meta-analysis of cluster randomized trials. Statistics in Medicine 2002;21:2971-80.

\section{Drummond 1996}

Drummond MF, Jefferson TO. Guidelines for authors and peer reviewers of economic submissions to the BMJ. BMJ 1996;313(3 August):275-83.

\section{Egger 1997}

Egger M, Davey Smith G, Schneider M, Minder C. Bias in meta-analysis detected by a simple, graphical test. $B M J$ 1997;315:629-34.

\section{Elbourne 2002}

Elbourne D, Altman DG, Higgins JPT, Curtina F, Worthingtond HV, Vaile A. Meta-analyses involving crossover trials: methodological issues. International Journal of Epidemiology 2002;31(1):140-9.

\section{Evers 2005}

Evers S, Goossens M, de Vet H, van Tulder M, Ament A. Criteria list for assessment of methodological quality of economic evaluations: Consensus on Health Economic Criteria. Int J Technol Assess Health Care 2005;21 (2 Spring):240-5.

\section{Furukawa 2006}

Furukawa TA, Barbui C, Cipriani A, Brambilla P, Watanabe N. Imputing missing standard deviations in meta-analyses can provide accurate results. Journal of Clinical Epidemiology 2006;59(7):7-10.

\section{Gjedde 2001}

Gjedde A, Wong DF. Quantification of neuroreceptors in living human brain v. endogenous neurotransmiter inhibition of haloperidol binding in psychosis. Journal of Cerebral Blood Flow Metabolism 2001;21(8):982-94. [MEDLINE: 11487734]

\section{Gulliford 1999}

Gulliford MC, Ukoumunne OC, Chinn S. Components of variance and intraclass correlations for the design of communitybased surveys and intervention studies: data from the Health Survey for England 1994. American Journal of Epidemiology 1999;149:876-83.

\section{Guy 1976}

Guy U. ECDEU assessment manual for psychopharmacology. Revised edition. Rockville: National Institute of Mental Health, 1976.

\section{HEED}

Health Economic Evaluation Database (HEED). Online ISBN: 9780470510933 . [DOI: 10.1002/9780470510933]

\section{HES 2012}

Hospital Episode Statistics, Admitted Patient Care - England 2011-12: Main Specialties (.xls). http://www.hscic.gov.uk/ searchcatalogue? productid $=9161 \& q=$ title $\% 3 a \% 22$ hospital +episode+statistics\%22\&sort=Relevance\&size=10\&page=1\#top (accessed May 2013) 2011-12. 


\section{Hietala 1995}

Hietala J, Syvalahti E, Vuorio K, Rakkolainen V, Bergman J, Haaparanta M, et al. Presynaptic dopamine function in striatum of neuroleptic-naive schizophrenic patients. Lancet 1995;346(8983):1130-1.

\section{Higgins 2003}

Higgins JPT, Thompson SG, Deeks JJ, Altman DG. Measuring inconsistency in meta-analyses. BMJ 2003;327:557-60.

\section{Higgins 2005}

Higgins JPT, Green S (editors). Cochrane Handbook for Systematic Reviews of Interventions 4.2.5 [updated May 2005] The Cochrane Library 2005;(3).

\section{Higgins 2011}

Higgins JPT, Green S, editor(s). Chapter 7: Selecting studies and collecting data. In: Higgins JPT, Green S, editor(s), Cochrane Handbook for Systematic Reviews of Interventions Version 5.1.0 (updated March 2011). Available from www.handbook.cochrane.org.

\section{Higgins 2011a}

Higgins JPT, Altman DG, Sterne JAC, editor(s). Chapter 8: Assessing risk of bias in included studies. In: Higgins JPT, Green S, editor(s). Cochrane Handbook for Systematic Reviews of Interventions Version 5.1.0 (updated March 2011). The Cochrane Collaboration, 2011. Available from www.handbook.cochrane.org.

\section{Holt 1960}

Holt JP, Wright ER. Preliminary results with fluphenazine (prolixin) in chronic psychotic patients. American Journal of Psychiatry 1960;117:157-9. [MEDLINE: 14402852]

\section{Hutton 2009}

Hutton JL. Number needed to treat and number needed to harm are not the best way to report and assess the results of randomised clinical trials. British Journal of Haematology 2009;146(1):27-30.

\section{Jablensky 1992}

Jablensky A, Sartorius N, Ernberg G, Anker M, Korten A, Cooper JE, et al. Schizophrenia: manifestations, incidence and course in different cultures. A World Health Organization ten-country study. Psychological Medicine Monograph Suppl. 1992;22(4):1092. [MEDLINE: 1565705]

\section{Kane 1986}

Kane JM, Woerner M, Sarantakos S. Depot neuroleptics: A comparison review of standard, intermediate and low-dose regimens. Journal of Clinical Psychiatry 1986;47(suppl 5):30-3.

\section{Kay 1986}

Kay SR, Opler LA, Fiszbein A. Positive and Negative Syndrome Scale (PANSS) Manual. North Tonawanda, NY: Multi-Health Systems, 1986.

\section{Leon 2006}

Leon AC, Mallinckrodt CH, Chuang-Stein C, Archibald DG, Archer GE, Chartier K. Attrition in randomized controlled clinical trials: methodological issues in psychopharmacology. Biological Psychiatry 2006;59(11):1001-5.

\section{Leucht 2005}

Leucht S, Kane JM, Kissling W, Hamann J, Etschel E, Engel RR. What does the PANSS mean? Schizophrenia Research 2005;79(2-3):231-8. [PMID: 15982856]

\section{Leucht 2005a}

Leucht S, Kane JM, Kissling W, Hamann J, Etschel E, Engel R. Clinical implications of brief psychiatric rating scale scores. British Journal of Psychiatry 2005;187:366-71. [PMID: 16199797]

\section{Leucht 2007}

Leucht S, Engel RR, Bauml J, Davis JM. Is the superior efficacy of new generation antipsychotics an artifact of LOCF? Schizophrenia Bulletin 2007;33(1):183-91. [PMID: 16905632]

\section{Lindstrom 1999}

Lindstrom LH, Gefvert O, Hagberg G, Lundberg T, Bergstrom M, Hartvig P, et al. Increased dopamine synthesis rate in medial prefrontal cortex and striatum in schizophrenia indicated by L-(beta-11C) DOPA and PET. Biological Psychiatry 1999;46(5):681-8. [MEDLINE: 10472420]

\section{Lorr 1953}

Lorr M. The Multidimensional Scale for Rating Psychiatric Patients. Washington D.C.: U.S.V.I, , T.B, 1953.

\section{Mangalore 2007}

Mangalore R, Knapp M. Cost of schizophrenia in England. J Ment Health Policy Econ 2007;10(1):23-41.

\section{Mardar 1984}

Mardar SR, Theodore VP, Mintz J, McKenzie J, Lebell M, Faltico G, May PRA. Costs and benefits of two doses of fluphenazine. Arch Gen Psychiatry 1984;41(Nov):1924-9.

\section{Marshall 2000}

Marshall M, Lockwood A, Bradley C, Adams C, Joy C, Fenton M. Unpublished rating scales: a major source of bias in randomised controlled trials of treatments for schizophrenia. British Journal of Psychiatry 2000;176:249-52.

\section{Matar 2007}

Matar HE, Almerie MQ. Oral fluphenazine versus placebo for schizophrenia. Cochrane Database of Systematic Reviews 2007, Issue 1. [DOI: 10.1002/14651858.CD006352]

\section{Meyer 2002}

Meyer-Lindenberg A, Miletich RS, Kohn PD, Esposito G, Carson M, Quarantelli M, et al. Reduced prefronatal activity predicts exaggerated striatal dopaminergic function in schizophrenia. Nature Neuroscience 2002;5(3):267-71. [MEDLINE: 11865311]

\section{Moher 2001}

Moher D, Schulz KF, Altman D. The CONSORT statement: revised recommendations for improving the quality of reports of parallel-group randomized trials. JAMA 2001;285(12):1987-91. 


\section{Overall 1962}

Overall JE, Gorham DR. The Brief Psychiatric Rating Scale. Psychological Reports 1962;10:799-812.

\section{PSSRU 2012}

Compiled by Lesley Curtis. Unit costs of health and social care 2012. http://www.pssru.ac.uk/project-pages/unit-costs/2012/ (accessed May 2013) 2012:47.

\section{Rust 1989}

Rust J, Golombok S. Modern Psychmetrics. London: Routledge, 1989.

\section{Schulz 1995}

Schulz KF, Chalmers I, Hayes RJ, Altman DG. Empirical evidence of bias: dimensions of methodological quality associated with estimates of treatment effects in controlled trials. JAMA 1995;273:408-12.

\section{Schulz 2010}

Schulz KF, Altman DG, Moher D. For the CONSORT Group. CONSORT 2010 Statement: updated guidelines for reporting parallel group randomised trials. Annals of Internal Medicine 2010 June 1;152(11):726-32.

\section{Schünemann 2008}

Schünemann HJ, Oxman AD, Vist GE, Higgins JPT, Deeks JJ, Glasziou P, et al. Chapter 12: Interpreting results and drawing conclusions. In: Higgins JPT, Green S, editors(s). Cochrane Handbook for Systematic Reviews of Interventions. The Cochrane Collaboration, 2008:359-83.

\section{Sterne 2011}

Sterne JAC, Egger M, Moher D, editor(s). Chapter 10: Addressing reporting biases. In: Higgins JPT, Green S, editor(s). Cochrane Handbook for Systematic Reviews of Intervention. Version 5.1.0 (updated March 2011). The Cochrane Collaboration, 2011. Available from www.handbook.cochrane.org.

\section{CHARACTERISTICS OF STUDIES}

Characteristics of included studies [ordered by study ID]

\section{Thornley 1998}

Thornley B, Adams C. Content and quality of 2000 controlled trials in schizophrenia over 50 years. BMJ 1998;317:1181-4.

\section{Ukoumunne 1999}

Ukoumunne OC, Gulliford MC, Chinn S, Sterne JAC, Burney PGJ. Methods for evaluating area-wide and organisation-based interventions in health and health care: a systematic review. Health Technology Assessment 1999;3(5):iii-92. [MEDLINE: 10982317]

\section{WHO 2005}

Essential Medicines. WHO Model List. 14th Edition. http:// whqlibdoc.who.int/hq/2005/a87017_eng.pdf.

\section{Wikipedia 2006}

Wikipedia (The Free Encyclopedia). http://en.wikipedia.org/ wiki/Fluphenazine\#Pharmacokinetics Accessed in Nov 2006.

\section{www.psychotropics.dk}

Psychotropics. http://www.psychotropics.dk/.

\section{Xia 2009}

Xia J, Adams CE, Bhagat N, Bhagat V, Bhoopathi P, El-Sayeh H, et al. Loss to outcomes stakeholder survey: the LOSS study. Psychiatric Bulletin 2009;33(7):254-7.

\section{References to other published versions of this review \\ Matar 2007a}

Matar HE, Almerie MQ. Oral fluphenazine versus placebo for schizophrenia. Cochrane Database of Systematic Reviews 2007, Issue 1. [DOI: 10.1002/14651858.CD006352]

\section{Matar 2007b}

Matar HE-D, Almerie MQ, Giraldo AM, Adams CE. Oral fluphenazine versus placebo for schizophrenia: A Cochrane systematic review of 40 years of randomised controlled trials.. Revista Colombiana de Psiquiatria 2007;36(1):8-17.

* Indicates the major publication for the study

Carpenter 1999

Study characteristics

\begin{tabular}{ll}
\hline Methods & Allocation: random. \\
& Blinding: double. \\
& Duration: 6 weeks (4 weeks presented usable data). ${ }^{\star}$ \\
& Design: parallel. \\
\hline Participants & Diagnosis: schizophrenia (DSM-III-R or RDC). \\
$\mathrm{N}=53$ (38 to relevant interventions). ${ }^{\star \star}$ & Age: mean 37 yrs. \\
\hline
\end{tabular}


Sex: M 38 (26 relevant), F 15 (12 relevant).

History: illness for $\sim 13$ yrs, clinically stable patients.

Excluded: patients with concurrent drug abuse, alcoholism, organic brain disorders and mental retar-

dation.

Setting: community, Maryland Psychiatric Research Center Outpatient Program (US).

Consent: written informed consent required.

\begin{tabular}{ll}
\hline Interventions & 1. Oral fluphenazine: dose $15 \mathrm{mg} /$ day, $\mathrm{N}=18$. \\
& 2. Placebo, $\mathrm{N}=20$. \\
& [3. Diazepam: dose $30 \mathrm{mg} /$ day, $\mathrm{N}=15]$.
\end{tabular}

\begin{tabular}{ll}
\hline Outcomes & Global state (CGI) - not improved or worsened. \\
& Unable to use - \\
& Mental state: BPRS (no usable data). \\
& Relapse (not given by each group). \\
& Sleep change ratings (no data).
\end{tabular}

\begin{tabular}{ll}
\hline Notes & $\begin{array}{l}{ }^{*} \text { Data were given only for the first } 4 \text { weeks of the study. } \\
{ }^{\star *} \text { Demographic data relate to the total of } 38 \text { people. }\end{array}$ \\
\hline
\end{tabular}

\section{Risk of bias}

\begin{tabular}{lll}
\hline Bias & Authors' judgement & Support for judgement \\
\hline $\begin{array}{l}\text { Random sequence genera- } \\
\text { tion (selection bias) }\end{array}$ & Low risk & $\begin{array}{l}\text { Random - "a stratified randomization procedure...was used to assign drug } \\
\text { treatment to balance study groups on gender, prior social function, and past } \\
\text { duration of hospital care" (p300). No details as to randomisation methods. }\end{array}$ \\
\hline $\begin{array}{l}\text { Allocation concealment } \\
\text { (selection bias) }\end{array}$ & Unclear risk & Not described. \\
\hline $\begin{array}{l}\text { Blinding (performance } \\
\text { bias and detection bias) } \\
\begin{array}{l}\text { All outcomes } \\
\text { Low risk }\end{array}\end{array}$ & $\begin{array}{l}\text { Double blind - no further details. If participants experienced worsening or ex- } \\
\text { acerbation of symptoms, they were removed from the study and treated on an } \\
\text { open basis with fluphenazine. }\end{array}$ \\
& Rating scales: raters not stated to be independent of treatment.
\end{tabular}

Incomplete outcome data Unclear risk No mention of participants lost to follow-up or leaving the study early.

(attrition bias)

All outcomes

Selective reporting (re- High risk $\quad$ No scale data reported for BPRS or CGI.
porting bias)

Other bias Unclear risk $\quad$ Funding: supported in part by NIMH grants (MH-35996 and MH-40279).

Clark 1971

\section{Study characteristics}

Methods
Allocation: random.
Blinding: double "identically appearing medication administrated from a bottle labelled only with the patient's name".
Duration: 6 weeks.


Clark 1971 (Continued)

Design: parallel.

$\begin{array}{ll}\text { Participants } & \text { Diagnosis: chronic schizophrenia. } \\ \mathrm{N}=76 \text { (37 to relevant interventions). } \\ \text { Age: mean } 33 \text { yrs (range } 18 \text { to 45). } \\ \text { Sex: M 23, F 53. } \\ \text { History: } 6 \text { months preadmission period free of hospitai } \\ \text { Excluded: childhood schizophrenia or autism, brain } \\ \text { chronic physical illness, epilepsy, drug addiction. } \\ \text { Setting: inpatient, Central State Griffin Memorial Hosp } \\ \text { Consent: not stated. } \\ \text { 1. Oral fluphenazine: dose 2-10 mg/day. } \mathrm{N}=18 . \\ \text { 2. Placebo. } \mathrm{N}=19 . \\ \text { [3. Chlorpromazine: dose } 100-1000 \mathrm{mg} / \mathrm{day} . \mathrm{N}=20 \text { ]. } \\ \text { [4. Thioridazine: dose } 100-1000 \mathrm{mg} / \text { day. } \mathrm{N}=19] .\end{array}$

Outcomes

Global state (using CGI): not improved or worsened; average score (CGI severity of illness ${ }^{\star}$ ).

Mental state: average score (BPRS*).

Leaving the study early: any reason; administrative/hospital transfer; AWOL; marked improvement allowing discharge.

Adverse effects: anticholinergic (dry mouth; blurred vision; nasal congestion; tachycardia; gastrointestinal distress); EPS (tremor; rigidity; associated movements; akinesia; akithisia; drooling; restlessness/ insomnia); CNS (anxiety/agitation/excitement/ confusion; sedation and lethargy; depression); cardiovascular (hypotension; syncope); others (rash).

Unable to use -

Global state: NOSIE (no SD).

Toxicity (no usable data).

Notes Unscheduled dose adjustments were permitted for toxicity or intolerance.

*SDs imputed 'between groups' using RevMan calculator.

\section{Risk of bias}

\begin{tabular}{|c|c|c|}
\hline Bias & Authors' judgement & Support for judgement \\
\hline $\begin{array}{l}\text { Random sequence genera- } \\
\text { tion (selection bias) }\end{array}$ & Low risk & $\begin{array}{l}\text { Random: "patients were assigned to treatment randomly in blocks of } \\
\text { four" (p404) - no further details. }\end{array}$ \\
\hline $\begin{array}{l}\text { Allocation concealment } \\
\text { (selection bias) }\end{array}$ & Unclear risk & $\begin{array}{l}\text { Participants were "assigned to treatment randomly in blocks of four" (p404) - } \\
\text { no further details. }\end{array}$ \\
\hline $\begin{array}{l}\text { Blinding (performance } \\
\text { bias and detection bias) } \\
\text { All outcomes }\end{array}$ & Low risk & $\begin{array}{l}\text { Double blind: "double blind design was maintained throughout the } \\
\text { study" (p404) - no further details. Identically-appearing capsules were dis- } \\
\text { pensed from a bottle labelled only with the participant name. } \\
\text { Rating scales: raters not stated to be independent of treatment. }\end{array}$ \\
\hline $\begin{array}{l}\text { Incomplete outcome data } \\
\text { (attrition bias) } \\
\text { All outcomes }\end{array}$ & Low risk & $\begin{array}{l}\text { Follow-up: } 85 \% \text { - } n=2 \text { participants left the study early, but their final measures } \\
\text { were obtained and used in the analysis ( } n=1 \text { receiving placebo due to behav- } \\
\text { ioural deterioration and } n=1 \text { receiving fluphenazine was discharged from the } \\
\text { hospital as markedly improved after two weeks). A further } n=11 \text { participants, } \\
\text { however, were dropped without final measures being obtained (placebo: } n=1 \\
\text { went AWOL; } n=1 \text { on convalescent leave; } n=1 \text { transferred to another hospital. } \\
\text { Thioridazine group: } n=2 \text { AWOL; } n=1 \text { medication intolerance. Chlorpromazine: } \\
n=1 \text { AWOL; } n=2 \text { refused oral medication. Fluphenazine: } n=1 \text { administrative }\end{array}$ \\
\hline
\end{tabular}


Clark 1971 (Continued)

transfer, $n=1$ AWOL). Dichotomised data presented as ITT (only $n=1$ missing from placebo). LOCF for CGI and BPRS.

\begin{tabular}{lll}
\hline $\begin{array}{l}\text { Selective reporting (re- } \\
\text { porting bias) }\end{array}$ & Unclear risk & No SDs reported for all scale data. \\
\hline Other bias & Unclear risk & $\begin{array}{l}\text { Funding: supported in part by Public Health Service Grant MH 11666 and Re- } \\
\text { search Scientist Development award No. K135278 from NIMH. Medication sup- } \\
\text { plied by Smith Kline and French Laboratories (chlorpromazine and placebo); } \\
\text { Sandoz Inc (thioridazine) and ER Squibb \& Sons (fluphenazine). }\end{array}$ \\
\hline
\end{tabular}

Goldberg 1964

\section{Study characteristics}

\begin{tabular}{|c|c|}
\hline Methods & $\begin{array}{l}\text { Allocation: random. } \\
\text { Blinding: double. } \\
\text { Duration: } 6 \text { weeks. } \\
\text { Design: multi-centre, parallel. }\end{array}$ \\
\hline Participants & $\begin{array}{l}\text { Diagnosis: schizophrenia. } \\
\mathrm{N}=463 \text { (190 to relevant interventions). } \\
\text { Age: } 16-45 \text { yrs. } \\
\text { Sex: male and female (equal distribution stated, however no number given). } \\
\text { History: newly admitted patients. } \\
\text { Excluded: childhood autism, brain syndrome, IQ < 70, epilepsy, drug addiction. } \\
\text { Setting: inpatient, Boston State Hospital (Massachusettes); District of Columbia General Hospital } \\
\text { (Washington DC); Kentucky State Hospital (Kentucky); Malcolm Bliss Mental Health Center (Missouri); } \\
\text { Mercy-Dougleaa Hosptial (Pennsylvania); Payne-Whitney CLinic (New York); Rochester State Hosptial } \\
\text { (Rochester, New York); Springfield State Hospital (Maryland); Institute of Living (Conneticut, US). } \\
\text { Consent: not stated. }\end{array}$ \\
\hline Interventions & $\begin{array}{l}\text { 1. Oral fluphenazine: dose } 1-16 \mathrm{mg} / \text { day. } \mathrm{N}=92 \text {. } \\
\text { 2. Oral placebo. } \mathrm{N}=98 . \\
\text { [3. Paraenteral fluphenazine. } \mathrm{N}=23 \text { ]. } \\
\text { 4. Chlorpromazine: dose } 200 \mathrm{mg} / \mathrm{day} . \mathrm{N}=112] \text {. } \\
\text { [5. Thioridazine: dose } 200 \mathrm{mg} / \text { day. } \mathrm{N}=111] \text {. } \\
\text { [6. Paraenteral placebo. } \mathrm{N}=27 \text { ]. } \\
\text { Additional medication: } \\
\text { Anti-parkinsonian medications. }{ }^{*}\end{array}$ \\
\hline Outcomes & $\begin{array}{l}\text { Leaving the study early (any reason; treatment failure; serious complication of treatment; marked early } \\
\text { remission; incorrect diagnosis; court cases, transfer, eloped). } \\
\text { Adverse effects: CNS (headache; drowsiness; convulsions or seizures) cardiovascular effects (dizziness, } \\
\text { faintness, weakness) anticholinergic effects (increased salivation; dry mouth/throat; gastrointestinal } \\
\text { distress and nausea; urinary disturbance; constipation; vomiting) endocrine (lactation; amenorrhoea; } \\
\text { swelling of breasts) extrapyramidal effects (loss of associated movements; facial rigidity; rigidity; rest- } \\
\text { lessness/insomnia; tremor; akithisia; dystonia) others (convulsion or seizures; diarrhoea; intercurrent } \\
\text { infection; rash). } \\
\text { Unable to use - } \\
\text { Global state (no SD).* } \\
\text { Mental state: IMPS, WBRS (no SD).** }\end{array}$ \\
\hline Notes & * $44 \%$ of fluphenazine group and $5 \%$ of placebo received anti-parkinsonian drugs. \\
\hline
\end{tabular}


Goldberg 1964 (Continued)

${ }^{* \star}$ Global rating of severity of metal illness, Global rating of improvement.

${ }^{\star \star \star}$ Results were not broken down by each drug group.

\section{Risk of bias}

\begin{tabular}{|c|c|c|}
\hline Bias & Authors' judgement & Support for judgement \\
\hline $\begin{array}{l}\text { Random sequence genera- } \\
\text { tion (selection bias) }\end{array}$ & Unclear risk & $\begin{array}{l}\text { Random: participants were "randomly assigned to one of four treatments on a } \\
\text { double-blind basis" (p247). }\end{array}$ \\
\hline $\begin{array}{l}\text { Allocation concealment } \\
\text { (selection bias) }\end{array}$ & Unclear risk & $\begin{array}{l}\text { Stratified by sex with "randomized assignment to drug treatment within each } \\
\text { sex group" (p247). In the three out of nine hospitals participating in the study } \\
\text { that admitted approximately equal number of White and Black participants, } \\
\text { this was taken into account and groups were further stratified by race. }\end{array}$ \\
\hline $\begin{array}{l}\text { Blinding (performance } \\
\text { bias and detection bias) } \\
\text { All outcomes }\end{array}$ & Unclear risk & $\begin{array}{l}\text { Double blind described, no further details. Participants received individually } \\
\text { numbered containers of medication. A flexile dosage schedule permitted the } \\
\text { treating physician to adjust dosage according to individuals' needs. } \\
\text { Rating scales: raters not stated to be independent of treatment. }\end{array}$ \\
\hline $\begin{array}{l}\text { Incomplete outcome data } \\
\text { (attrition bias) } \\
\text { All outcomes }\end{array}$ & High risk & $\begin{array}{l}\text { Follow-up: 74\%. Reasons for removal of study included administrative re- } \\
\text { movals (incorrect diagnoses; intercurrent medical illness; court cases, transfer, } \\
\text { elopement, etc), treatment-related removals (marked early remission; serious } \\
\text { complication of treatment; treatment failure). Those lost were not included in } \\
\text { the study report analysis. }\end{array}$ \\
\hline
\end{tabular}

Selective reporting (re- High risk No SDs reported for continuous data.

porting bias)

Other bias Unclear risk

Funding: supported by NIMH grants (MH 04661, 04663, 04667, 04673, 04674, $04675,04679,04803)$. Medications provided free of charge from Sandoz Pharmaceuticals (Hanover); Squibb Institute for Medical Research (New Brunswick); Smith Kline and French Laboratories (Philiadelphia).

Rating scales: raters not stated to be independent of treatment.

Hordern 1964

\section{Study characteristics}

\begin{tabular}{ll} 
Methods & Allocation: unclear. \\
& Blinding: double. \\
& Duration: 12 weeks. \\
& Design: parallel. \\
\hline Participants & Diagnosis: chronic schizophrenia. \\
$\mathrm{N}=75$ (50 to relevant interventions). \\
Age: mean 49 yrs. \\
Sex: all female. \\
History: hospitalisation > 2 yrs (mean $\sim 20$ yrs, $\sim$ SD 9), all have had previous unsuccessful phenoth- \\
iazines treatment, and none leucotomised. \\
Excluded: physical illness, epilepsy. \\
Setting: inpatient, Mont Park Hospital, Victoria (Australia). \\
Consent: not stated.
\end{tabular}


Hordern 1964 (Continued)

Interventions $\quad$ 1. Oral fluphenazine: dose $<14 \mathrm{mg} /$ day. $\mathrm{N}=25$.

2. Placebo. $\mathrm{N}=25$.

[3. Thioproperazine (max dose of $140 \mathrm{mg} /$ day). $\mathrm{N}=25$ ].

\begin{tabular}{ll}
\hline Outcomes & Global state: MADRS* - not improved or worsened. \\
& Adverse effects - extrapyramidal effects: dystonia; akinesia; parkinsonism; akathisia. \\
& Leaving study early. ${ }^{\star *}$ \\
& * Rated as either 'no change', 'clear worsening' and 'marked worsening' using the Multidimensional \\
& Rating Scale of the Veterans' Administration (Lorr 1953). \\
& ${ }^{\star *}$ Two participants from fluphenazine group left the study early and they were considered to have the \\
& worst outcomes. \\
& The ward sister's blind ratings of change of behaviour at the end of the trial: 9 placebo participants de- \\
& teriorated in contrast to 6 participants on fluphenazine. One placebo participant required additional \\
& nursing care because of severe negativism.
\end{tabular}

\section{Risk of bias}

\begin{tabular}{|c|c|c|}
\hline Bias & Authors' judgement & Support for judgement \\
\hline $\begin{array}{l}\text { Random sequence genera- } \\
\text { tion (selection bias) }\end{array}$ & High risk & $\begin{array}{l}\text { Randomisation unclear - participants were "divided into three groups of } 25 \\
\text { matched on age, chronicity and severity of illness" (p532). }\end{array}$ \\
\hline $\begin{array}{l}\text { Allocation concealment } \\
\text { (selection bias) }\end{array}$ & Unclear risk & Not described. \\
\hline $\begin{array}{l}\text { Blinding (performance } \\
\text { bias and detection bias) } \\
\text { All outcomes }\end{array}$ & Low risk & $\begin{array}{l}\text { Double blind (implied) - members of the ward staff were told that powerful } \\
\text { phenothiazine drugs were to be administered, but were unaware of which } \\
\text { participants were receiving the active medication. All medications were iden- } \\
\text { tical-looking tablets, dispensed by a medical officer who "took no part in } \\
\text { the rating procedure" (p533). Maximum blindness preserved in evaluations } \\
\text { claimed, as neither physicians entered the closed wards between ratings and } \\
\text { did not observe side effects during period of treatment. A blind assessment of } \\
\text { overall change was made at the end of the trial by the ward sister. } \\
\text { Rating scales: raters not stated to be independent of treatment. }\end{array}$ \\
\hline $\begin{array}{l}\text { Incomplete outcome data } \\
\text { (attrition bias) } \\
\text { All outcomes }\end{array}$ & Unclear risk & $\begin{array}{l}\text { Follow-up: } 95 \%-n=4 \text { participants were lost to follow-up by } 12 \text { weeks of } \\
\text { treatment, only } n=2 \text { were accounted for as having discontinued from active } \\
\text { drugs ( } n=1 \text { from fluphenazine; } n=1 \text { from thioproperazine). ITT used for medi- } \\
\text { um-term data. }\end{array}$ \\
\hline $\begin{array}{l}\text { Selective reporting (re- } \\
\text { porting bias) }\end{array}$ & Unclear risk & None detected. \\
\hline Other bias & Unclear risk & $\begin{array}{l}\text { Funding: all drugs and placebos were provided free of charge by May and Bak- } \\
\text { er (Australia) Limited ('Majeptil') and ER Squibb and Sons (Australia) Limited } \\
\text { ('Anatensol'). }\end{array}$ \\
\hline
\end{tabular}

Marder 1994

\section{Study characteristics}

Methods

Allocation: randomly assigned.

Blindness: double. 
Marder 1994 (Continued)

Duration: 2 years (preceded by 2 months stabilisation phase with low dose of fluphenazine decanoate 5-10 mg).

Design: parallel.

\begin{tabular}{ll}
\hline Participants & Diagnosis: schizophrenia (DSM-III-R). \\
$\mathrm{N}=36$. & Age: mean 40 yrs. \\
Sex: all male. \\
History: at least two documented episodes of acute schizophrenic illness \\
uing psychotic symptoms, randomly assigned when getting prodromal \\
Prodromal Scale. \\
Excluded: patients who could not be stabilised for 2 or more months with \\
decanoate every 2 weeks. \\
Setting: community, outpatients at Brentwood Division of West Los Ang \\
Center (US). \\
Consent: not stated. \\
1. Oral fluphenazine hydrochloride: dose $10 \mathrm{mg} /$ day. $\mathrm{N}=17$. \\
2. Placebo. $\mathrm{N}=19$. \\
Additional medication - \\
Fluphenazine decanoate: dose 5-10 mg/2weeks for all patients. $\mathrm{N}=36$. \\
Factored to: \\
A. Behavioural skills training. \\
B. Supportive group therapy. ${ }^{\star *}$
\end{tabular}

$\begin{array}{ll}\text { Outcomes } & \text { Relapse: defined as number of psychotic exacerbations. } \\ & \text { Percentage of time in exacerbated state (skew). } \\ & \text { Percentage of time in prodrome (skew). } \\ & \text { Leaving the study early: non-specific reasons. } \\ & \text { Unable to use - } \\ & \text { Adverse effects (no data). } \\ & { }^{*} \text { Defined as worsening of four points or more on the sum of the BPRS clusters for thought disturbance } \\ & \text { and paranoia or increase of three or more points on either cluster. }\end{array}$

\section{Risk of bias}

\begin{tabular}{lll}
\hline Bias & Authors' judgement & Support for judgement \\
\hline $\begin{array}{ll}\text { Random sequence genera- } \\
\text { tion (selection bias) }\end{array}$ & Unclear risk & $\begin{array}{l}\text { Random - possible participants were stabilised on low dose fluphenazine de- } \\
\text { canoate }(5 \text { to } 10 \mathrm{mg} \text { every } 14 \text { days) for two months and monitored every week } \\
\text { using an idiosyncratic prodromal rating scale. Participants were randomised } \\
\text { to either oral fluphenazine or placebo when they met criteria for a prodromal } \\
\text { episode. }\end{array}$
\end{tabular}

\begin{tabular}{|c|c|c|}
\hline $\begin{array}{l}\text { Allocation concealment } \\
\text { (selection bias) }\end{array}$ & Unclear risk & Not described. \\
\hline $\begin{array}{l}\text { Blinding (performance } \\
\text { bias and detection bias) } \\
\text { All outcomes }\end{array}$ & Unclear risk & $\begin{array}{l}\text { Double blind (implied), as participants who never experienced prodromal } \\
\text { episodes nor were assigned to either treatment were treated with } 5 \mathrm{mg} \text { oral } \\
\text { fluphenazine on an open label basis during exacerbations. } \\
\text { Rating scales: raters not stated to be independent of treatment. }\end{array}$ \\
\hline $\begin{array}{l}\text { Incomplete outcome data } \\
\text { (attrition bias) }\end{array}$ & High risk & $\begin{array}{l}\text { Follow-up: } 81 \%-n=6 \text { participants lost to follow-up by two years of treatment. } \\
\text { Only two participants accounted for as being omitted from analysis ( } n=1 \text { who }\end{array}$ \\
\hline
\end{tabular}


Marder 1994 (Continued)

All outcomes dropped-out during a prodromal episode, and $n=1$ who reached the two-year end point during a prodrome).

\begin{tabular}{lll}
\hline $\begin{array}{l}\text { Selective reporting (re- } \\
\text { porting bias) }\end{array}$ & Unclear risk & None detected. \\
\hline Other bias & Unclear risk & $\begin{array}{l}\text { Funding: study supported by the Medical Research Service of the Department } \\
\text { of Veterans Affairs, Washington DC (grant MH-41573) from National Institute of } \\
\text { Mental Health, Bethesda, Md; UCLA Mental Health Clinical Research Center for } \\
\text { Schizophrenia (grant MH-30911) from the National Institute of Mental Health. }\end{array}$ \\
\hline
\end{tabular}

Millar 1963

\section{Study characteristics}

\begin{tabular}{ll}
\hline Methods & Allocation: random. \\
Blindness: double. & Duration: 6 weeks. \\
& Design: cross-over (after 3 weeks). \\
\hline
\end{tabular}

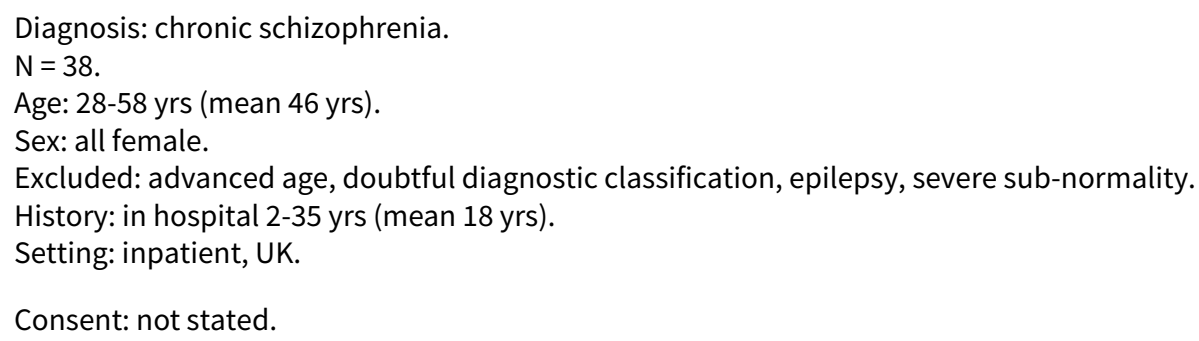

Interventions $\quad$ 1. Oral fluphenazine: dose $2.5 \mathrm{mg} /$ day. $\mathrm{N}=19$.

2. Placebo. $\mathrm{N}=19$.

Relapse.
Unable to use -
Improvement: no better or worse (data not reported by group).
Adverse effects (no data).
Lorr psychiatric rating scale (no SD, mean only).
Baker and Thorpe behaviour rating scale (no SD, mean only).
$\begin{aligned} & \text { Participants had been receiving chlorpromazine three times a day and were "mostly stabilised" on a } \\ & \text { certain dose. They were then given doses of fluphenazine, with this drug substituted for the chlorpro- } \\ & \text { mazine at approx. one fortieth of the dose. A single daily dose was given of } 2.5 \text { mg (with the exception } \\ & \text { of two cases who received } 20 \text { mg) with dose increase of } 2.5 \text { mg/day (one tablet). After participants re- } \\ & \text { ceived fluphenazine for } 2 \text { months, they were rated and randomised into intervention groups, receiving } \\ & \text { dosages established in the stabilisation phase. }\end{aligned}$

\section{Risk of bias}

Bias Authors' judgement Support for judgement

$\begin{array}{ll}\begin{array}{l}\text { Random sequence genera- } \\ \text { tion (selection bias) }\end{array} & \text { Unclear risk }\end{array} \begin{aligned} & \text { Random - participants were divided into two random groups; no further de- } \\ & \text { tails. }\end{aligned}$


Millar 1963 (Continued)

Allocation concealment Unclear risk Only hospital pharmacist knew the composition of the groups.
(selection bias)

$\begin{array}{ll}\begin{array}{l}\text { Blinding (performance } \\ \text { bias and detection bias) }\end{array} \quad \text { Low risk } & \begin{array}{l}\text { Double blind - only hospital pharmacist knew the composition of the groups; } \\ \text { medication was administered with matching placebo. }\end{array}\end{array}$

All outcomes

Rating scales: raters not stated to be independent of treatment.

Incomplete outcome data Unclear risk

(attrition bias)

No mention of participants lost to follow-up or leaving the study early.

All outcomes

$\begin{aligned} & \text { Selective reporting (re- } \\ & \begin{array}{l}\text { porting bias) } \\ \text { High risk }\end{array}\end{aligned} \quad \begin{aligned} & \text { Data not clearly described as to the stage of trial and relevant groups (i.e. pre- } \\ & \text { cross-over or post-cross-over). Full data not reported for continuous outcomes } \\ & \text { (missing means and SDs). }\end{aligned}$

Other bias Unclear risk Funding: fluphenazine tablets were provided by ER Squibb \& Sons.

\section{Rifkin 1976}

\section{Study characteristics}

$\begin{array}{ll}\text { Methods } & \text { Allocation: random. } \\ \text { Blindness: double. } & \text { Duration: } 1 \text { year (preceded by several months transitional period during which all patients were treated } \\ \text { exclusively with fluphenazine decanoate and oral fluphenazine). } \\ \text { Design: parallel. }\end{array}$

Diagnosis: schizophrenia (remitted).
N=73 (50 to relevant interventions).
Sex: M 50, F 23.
Age: $17-40$ yrs.
History: reached a stable remission while receiving FD and FPZ and showed no adverse effects.
Excluded: history of severe drug abuse or chronic schizophrenics. ${ }^{*}$
Setting: psychiatric aftercare clinic, Long Island Jewish-Hillside Medican Center (US).
Consent: informed consent obtained.

Interventions $\quad$ Oral fluphenazine: dose $5-20 \mathrm{mg} /$ day. $\mathrm{N}=28$.

2. Placebo. $\mathrm{N}=22$.

[3. Fluphenazine decanoate: dose $0.5-2.0 \mathrm{~mL} / 2$ weeks. $\mathrm{N}=23$ ].

Additional medication:

Prophylactic procyclidine $(5-15 \mathrm{mg} /$ day).**

Placebo procyclidine.

Psychotherapy biweekly during the first 6 months and monthly thereafter.

\begin{tabular}{ll}
\hline Outcomes & Death. \\
& Relapse (clinical judgement). \\
& Leaving the study early. \\
& Unable to use - \\
& Social and vocational functioning (results not broken down by individual drugs). \\
& Mental state: BPRS (no data). \\
& Global state: CGI, PER-C (no data). \\
& KAS (no usable data).
\end{tabular}


Rifkin 1976 (Continued)
Notes
${ }^{*}$ Chronic patients $>3$ previous hospitalisations.
** Prophylactic procyclidine for patients receiving active treatment and in the first 2 months for patients receiving placebo to prevent the emergence of extrapyramidal side effects during the fluphenazine decanoate washout period.

\section{Risk of bias}

\begin{tabular}{|c|c|c|}
\hline Bias & Authors' judgement & Support for judgement \\
\hline $\begin{array}{l}\text { Random sequence genera- } \\
\text { tion (selection bias) }\end{array}$ & Unclear risk & $\begin{array}{l}\text { Random: "randomly assigned" (p44). } 15 \% \text { of patients referred schizophrenics } \\
\text { were re-diagnosed using Kraepelinian Criteria as non schizophrenic and ran- } \\
\text { domised separately but treated in the same manner. }\end{array}$ \\
\hline $\begin{array}{l}\text { Allocation concealment } \\
\text { (selection bias) }\end{array}$ & Unclear risk & "Randomly assigned" (p44) - no further details. \\
\hline $\begin{array}{l}\text { Blinding (performance } \\
\text { bias and detection bias) }\end{array}$ & Low risk & Double blind: drugs were given in a "double blind fashion" (p44). \\
\hline All outcomes & & Rating scales: raters not stated to be independent of treatment. \\
\hline $\begin{array}{l}\text { Incomplete outcome data } \\
\text { (attrition bias) } \\
\text { All outcomes }\end{array}$ & Unclear risk & $\begin{array}{l}\text { Follow-up: } 89 \% \text {. Drop-outs mainly due to moving from the geographical area } \\
\text { or refusing further care. None of these patient's conditions had deteriorated } \\
\text { clinically. }\end{array}$ \\
\hline $\begin{array}{l}\text { Selective reporting (re- } \\
\text { porting bias) }\end{array}$ & High risk & $\begin{array}{l}\text { Not all adverse effects reported by group. No data reported for individual } \\
\text { groups using the BPRS, CGI, PER-C, KAS scales. }\end{array}$ \\
\hline Other bias & Unclear risk & Funding: supported by NIMH grant MH 21337-03. \\
\hline
\end{tabular}

RDC - Research Diagnostic Criteria for schizophrenia or schizoaffective disorders

DSM - Diagnostic and Statistical Manual

FD - Fluphenazine Decanoate

FPZ - Oral fluphenazine

Rating Scales:

KAS- Katz Adjustment Scale

Global state:

CGI - Clinical Global Impression

NOSIE - Nurse's Observation Scale for Inpatient Evaluation

Mental state:

BPRS - Brief Psychiatric Rating Scale

IMPS - Inpatient Multidimensional Psychiatric Scale

MADRS - modified Montgomery-Asberg Depression Rating Scale

PER-C - Periodic Evaluation Record-Community

WBRS - Burdock Ward Behaviour Rating Scale

Other:

CNS - central nervous system

EPS - extrapyramidal symptoms

ITT - intention-to-treat

LOCF - last observation carried forward

SD - standard deviation

Characteristics of excluded studies [ordered by study ID]

\begin{tabular}{ll}
\hline Study & Reason for exclusion \\
\hline Adler 1994 & Allocation: randomised. \\
\end{tabular}




\begin{tabular}{ll}
\hline Study & Reason for exclusion \\
\hline & Participants: people with non-organic psychosis (schizophrenia, schizoaffective disorder, unipolar \\
disorder, bipolar disorder or a delusional disorder). \\
Interventions: vitamin E versus placebo.
\end{tabular}

Baladini $1970 \quad$ Allocation: randomised.
Participants: people with schizophrenia.
Interventions: amitriptyline and fluphenazine (combination tablets) versus placebo.

\begin{tabular}{ll}
\hline Boyer 1995 & $\begin{array}{l}\text { Allocation: randomised. } \\
\text { Participants: people with schizophrenia. } \\
\text { Interventions: amisulpride versus fluphenazine versus placebo. }\end{array}$ \\
\hline Breier 1987 & $\begin{array}{l}\text { Allocation: unclear. } \\
\text { Participants: people with schizophrenia. } \\
\text { Interventions: fluphenazine versus placebo (withdrawal study). }\end{array}$
\end{tabular}

\begin{tabular}{ll}
\hline Carpenter 1992 & Allocation: randomised. \\
& Participants: people with schizophrenia. \\
& Interventions: diazepam versus depot fluphenazine versus placebo.
\end{tabular}

\begin{tabular}{ll}
\hline Chacon 1972 & Allocation: randomised. \\
& Participants: people with schizophrenia. \\
& Interventions: depot fluphenazine versus chlorpromazine versus placebo.
\end{tabular}

\begin{tabular}{ll}
\hline Chacon 1973 & Allocation: randomised. \\
& Participants: people with schizophrenia. \\
& Interventions: depot fluphenazine versus chlorpromazine versus placebo.
\end{tabular}

\begin{tabular}{ll}
\hline Coffman 1987 & Allocation: unclear. \\
& Participants: people with schizophrenia. \\
& Interventions: depot fluphenazine versus placebo (oral fluphenazine as a background).
\end{tabular}

\begin{tabular}{|c|c|}
\hline Del Giudice 1975 & $\begin{array}{l}\text { Allocation: randomised. } \\
\text { Participants: people with schizophrenia. } \\
\text { Interventions: oral phenothiazine versus phenothiazine enanthate. }\end{array}$ \\
\hline Doran 1990 & Allocation: not randomised. \\
\hline Dowing 1963 & $\begin{array}{l}\text { Allocation: randomised. } \\
\text { Participants: people with schizophrenia. } \\
\text { Interventions: fluphenazine versus chlorpromazine versus thioridazine versus placebo. } \\
\text { Outcomes: mental state (no SD). }\end{array}$ \\
\hline Elman 1999 & Allocation: not randomised. \\
\hline Haider 1968 & $\begin{array}{l}\text { Allocation: randomised. } \\
\text { Participants: people with schizophrenia. } \\
\text { Interventions: oral fluphenazine versus fluphenazine enanthate. }\end{array}$ \\
\hline
\end{tabular}

Hanlon $1970 \quad$ Allocation: unclear.

Participants: newly admitted patients to psychiatric wards, alcoholics, drug addicts, psychosis.

Held $1970 \quad$ Allocation: randomised.
Participants: people with schizophrenia.
Interventions: phenothiazines versus placebo.

Hogarty $1979 \quad$ Allocation: randomised.

Fluphenazine (oral) versus placebo for schizophrenia (Review) 


\begin{tabular}{ll}
\hline Study & Reason for exclusion \\
\hline Participants: people with schizophrenia. \\
Interventions: oral fluphenazine versus fluphenazine decanoate.
\end{tabular}

\begin{tabular}{ll}
\hline Holden 1970 & $\begin{array}{l}\text { Allocation: unclear. } \\
\text { Participants: people with schizophrenia. } \\
\text { Interventions: oral fluphenazine versus haloperidol. }\end{array}$ \\
\hline Howell 1961 & Allocation: unclear. \\
& Participants: people with functional psychosis.
\end{tabular}

\begin{tabular}{ll}
\hline Itil 1971 & Allocation: unclear. \\
& Participants: people with schizophrenia. \\
Interventions: oral fluphenazine low dose versus high dose.
\end{tabular}

\begin{tabular}{ll}
\hline Itil 1975 & Allocation: randomised. \\
& Participants: people with schizophrenia. \\
Interventions: fluphenazine versus haloperidol versus thiothixene.
\end{tabular}

\begin{tabular}{ll}
\hline Kane 1982 & Allocation: randomised. \\
& Participants: people with schizophrenia. \\
Interventions: oral fluphenazine, fluphenazine decanoate versus placebo. \\
Outcomes: results are not broken down by individual drug.
\end{tabular}

\begin{tabular}{ll}
\hline Kinross-Wright 1963 & Allocation: not randomised. \\
\hline Kinross-Wright 1964 & Allocation: randomised. \\
& Participants: people with schizophrenia. \\
Interventions: first stage - oral fluphenazine versus fluphenazine enanthate, second stage - \\
fluphenazine enanthate versus placebo.
\end{tabular}

\begin{tabular}{ll}
\hline Leff 1971 & Allocation: randomised. \\
& Participants: people with schizophrenia. \\
& Interventions: trifluoperazine versus chlorpromazine versus placebo.
\end{tabular}

\begin{tabular}{ll}
\hline Litman 1994 & $\begin{array}{l}\text { Allocation: randomised. } \\
\text { Participants: people with schizophrenia. } \\
\text { Interventions: fluphenazine versus clozapine. }\end{array}$ \\
\hline Marder 1989 & $\begin{array}{l}\text { Allocation: randomised. } \\
\text { Participants: people with schizophrenia. } \\
\text { Interventions: oral fluphenazine versus fluphenazine decanoate. }\end{array}$ \\
\hline Marder 1993 & Allocation: randomised. \\
& $\begin{array}{l}\text { Participants: people with schizophrenia. } \\
\text { Interventions: intensive behavioural skills training versus supportive group psychotherapy. }\end{array}$ \\
\hline Martin 1975 & $\begin{array}{l}\text { Allocation: randomised. } \\
\text { Participants: people with schizophrenia. } \\
\text { Interventions: benzhexol versus placebo. }\end{array}$ \\
\hline Matheu 1961 & Allocation: not randomised. \\
\hline Mattes 1984 & $\begin{array}{l}\text { Allocation: randomised. } \\
\text { Participants: people with schizophrenia. } \\
\text { Interventions: oral fluphenazine versus fluphenazine decanoate versus lithium. }\end{array}$ \\
\hline \hline
\end{tabular}




\begin{tabular}{ll}
\hline Study & Reason for exclusion \\
\hline
\end{tabular}

Pichot 1988

Allocation: randomised.

Participants: people with schizophrenia.

Interventions: fluphenazine versus amisulpride and haloperidol versus amisulpride.

$\begin{array}{ll}\text { Pickar } 1986 & \text { Allocation: randomised. } \\ & \text { Participants: people with schizophrenia. } \\ & \text { Interventions: oral fluphenazine versus placebo (withdrawal study). }\end{array}$

Pickar $1992 \quad$ Allocation: not randomised.

Quitkin $1978 \quad$ Allocation: randomised.

Participants: people with schizophrenia.

Interventions: fluphenazine decanoate versus penfluridol.

\begin{tabular}{ll}
\hline Sampath 1992 & Allocation: randomised. \\
& Participants: people with schizophrenia. \\
& Interventions: fluphenazine decanoate versus placebo (withdrawal study).
\end{tabular}

Schlosberg $1978 \quad$ Allocation: randomised.

Participants: people with schizophrenia.

Interventions: pipotiazine palmitate versus fluphenazine decanoate versus placebo.

\begin{tabular}{ll}
\hline Schooler 1976 & Allocation: randomised. \\
& Participants: people with schizophrenia. \\
& Interventions: fluphenazine decanoate versus oral fluphenazine, oral fluphenazine versus placebo \\
& (withdrawal study), fluphenazine decanoate versus placebo (withdrawal study).
\end{tabular}

\begin{tabular}{ll}
\hline Shafti 2009 & Allocation: randomised. \\
& Participants: people with schizophrenia. \\
& Interventions: fluphenazine decanoate (IM) versus placebo.
\end{tabular}

Shenoy $1981 \quad$ Allocation: randomised.

Participants: people with schizophrenia.

Interventions: fluphenazine decanoate versus placebo (withdrawal study).

\begin{tabular}{|c|c|}
\hline Steingard 1994 & $\begin{array}{l}\text { Allocation: randomised. } \\
\text { Participants: people with schizophrenia. } \\
\text { Interventions: fluphenazine versus placebo. } \\
\text { Outcomes: no usable data. }\end{array}$ \\
\hline Stevens 1976 & $\begin{array}{l}\text { Allocation: randomised. } \\
\text { Participants: people with schizophrenia. } \\
\text { Interventions: fluphenazine decanoate versus placebo. }\end{array}$ \\
\hline Turner 1966 & $\begin{array}{l}\text { Allocation: randomised. } \\
\text { Participants: people with schizophrenia. } \\
\text { Interventions: chlorpromazine versus fluphenazine versus placebo. } \\
\text { Outcomes: critical flicker fusion frequency (no usable data). }\end{array}$ \\
\hline Van Praag 1970 & $\begin{array}{l}\text { Allocation: randomised. } \\
\text { Participants: people with schizophrenia. } \\
\text { Interventions: oral fluphenazine versus fluphenazine decanoate. }\end{array}$ \\
\hline Vestre 1962 & $\begin{array}{l}\text { Allocation: randomised. } \\
\text { Participants: people with schizophrenia. } \\
\text { Interventions: fluphenazine versus triflupromazine versus phenobarbital. }\end{array}$ \\
\hline
\end{tabular}




\begin{tabular}{ll}
\hline Study & Reason for exclusion \\
\hline Watt 1978 & $\begin{array}{l}\text { Allocation: randomised. } \\
\text { Participants: people with schizophrenia. } \\
\text { Interventions: fluphenazine versus oral pimozide. }\end{array}$ \\
\hline Wistedt 1981 & $\begin{array}{l}\text { Allocation: randomised. } \\
\text { Participants: people with schizophrenia. } \\
\text { Interventions: fluphenazine decanoate or flupentixol decanoate versus placebo (withdrawal } \\
\text { study). }\end{array}$ \\
\hline Wistedt 1983 & $\begin{array}{l}\text { Allocation: randomised. } \\
\text { Participants: people with schizophrenia. } \\
\text { Interventions: fluphenazine decanoate, flupenthixol decanoate versus placebo. }\end{array}$ \\
\hline Zahn 1993 & $\begin{array}{l}\text { Allocation: randomised. } \\
\text { Participants: people with schizophrenia. } \\
\text { Interventions: clozapine versus conventional neuroleptics including oral fluphenazine and place- } \\
\text { bo. }\end{array}$ \\
\hline
\end{tabular}

IM - intramuscular

SD - standard deviation

\section{DATA AND ANALYSES}

Comparison 1. ORAL FLUPHENAZINE versus PLACEBO

\begin{tabular}{|c|c|c|c|c|}
\hline Outcome or subgroup title & No. of studies & $\begin{array}{l}\text { No. of partici- } \\
\text { pants }\end{array}$ & Statistical method & Effect size \\
\hline $\begin{array}{l}1.1 \text { Global state: } 1 . \text { Not improved } \\
\text { or worsened }\end{array}$ & 3 & & Risk Ratio (M-H, Fixed, 95\% Cl) & Subtotals only \\
\hline 1.1.1 short term (CGI/MDRS) & 3 & 125 & Risk Ratio (M-H, Fixed, 95\% Cl) & $0.80[0.57,1.12]$ \\
\hline 1.1.2 medium term (MDRS) & 1 & 50 & Risk Ratio (M-H, Fixed, 95\% Cl) & $1.12[0.79,1.58]$ \\
\hline 1.2 Global state: 2. Relapse & 3 & 124 & $\begin{array}{l}\text { Risk Ratio (M-H, Random, 95\% } \\
\mathrm{Cl} \text { ) }\end{array}$ & $0.35[0.07,1.68]$ \\
\hline 1.2.1 short term & 1 & 38 & $\begin{array}{l}\text { Risk Ratio (M-H, Random, 95\% } \\
\text { Cl) }\end{array}$ & $0.25[0.06,1.03]$ \\
\hline 1.2.2 long term & 2 & 86 & $\begin{array}{l}\text { Risk Ratio (M-H, Random, 95\% } \\
\text { Cl) }\end{array}$ & $0.39[0.05,3.31]$ \\
\hline $\begin{array}{l}1.3 \text { Global state: } 3 . \text { Percentage of } \\
\text { time in prodrome state (skewed } \\
\text { data) }\end{array}$ & 1 & & Other data & No numeric data \\
\hline 1.3.1 one-year data & 1 & & Other data & No numeric data \\
\hline 1.3.2 two-year data & 1 & & Other data & No numeric data \\
\hline
\end{tabular}




\begin{tabular}{|c|c|c|c|c|}
\hline Outcome or subgroup title & No. of studies & $\begin{array}{l}\text { No. of partici- } \\
\text { pants }\end{array}$ & Statistical method & Effect size \\
\hline $\begin{array}{l}\text { 1.4 Global state: } 4 \text {. Percentage of } \\
\text { time in exacerbated state (skewed } \\
\text { data) }\end{array}$ & 1 & & Other data & No numeric data \\
\hline 1.4.1 one-year data & 1 & & Other data & No numeric data \\
\hline 1.4.2 two-year data & 1 & & Other data & No numeric data \\
\hline $\begin{array}{l}1.5 \text { Global state: } 5 \text {. average score: } \\
\text { CGI - severity of illness score (high } \\
=\text { poor) }\end{array}$ & 1 & & $\begin{array}{l}\text { Mean Difference (IV, Fixed, 95\% } \\
\mathrm{CI})\end{array}$ & Subtotals only \\
\hline 1.5.1 short term & 1 & 36 & $\begin{array}{l}\text { Mean Difference (IV, Fixed, 95\% } \\
\mathrm{CI} \text { ) }\end{array}$ & $-0.77[-1.39,-0.15]$ \\
\hline $\begin{array}{l}1.6 \text { Leaving the study early: } 1 \text {. Non- } \\
\text { specific reasons }\end{array}$ & 5 & 363 & Risk Ratio (M-H, Fixed, 95\% Cl) & $0.73[0.49,1.10]$ \\
\hline 1.6.1 short term & 2 & 227 & Risk Ratio (M-H, Fixed, 95\% Cl) & $0.68[0.43,1.07]$ \\
\hline 1.6.2 medium term & 1 & 50 & Risk Ratio (M-H, Fixed, 95\% Cl) & $5.00[0.25,99.16]$ \\
\hline 1.6.3 long term & 2 & 86 & Risk Ratio (M-H, Fixed, 95\% Cl) & $0.69[0.24,1.97]$ \\
\hline $\begin{array}{l}1.7 \text { Leaving the study early: } 2 \text {. Spe- } \\
\text { cific reason - short term }\end{array}$ & 3 & & Risk Ratio (M-H, Fixed, 95\% Cl) & Subtotals only \\
\hline $\begin{array}{l}\text { 1.7.1 administrative/hospital } \\
\text { transfer }\end{array}$ & 1 & 37 & Risk Ratio (M-H, Fixed, 95\% Cl) & $1.06[0.07,15.64]$ \\
\hline 1.7.2 AWOL & 1 & 37 & Risk Ratio (M-H, Fixed, 95\% Cl) & $1.06[0.07,15.64]$ \\
\hline 1.7.3 court cases, transfer, eloped & 1 & 190 & Risk Ratio (M-H, Fixed, 95\% Cl) & $10.65[1.39,81.58]$ \\
\hline 1.7.4 incorrect diagnosis & 1 & 190 & Risk Ratio (M-H, Fixed, 95\% Cl) & $1.07[0.07,16.78]$ \\
\hline 1.7.5 marked early remission & 1 & 190 & Risk Ratio (M-H, Fixed, 95\% Cl) & $2.13[0.20,23.10]$ \\
\hline $\begin{array}{l}1.7 .6 \text { serious complication of treat- } \\
\text { ment }\end{array}$ & 1 & 190 & Risk Ratio (M-H, Fixed, 95\% Cl) & $11.71[0.66,208.85]$ \\
\hline 1.7.7 severe extrapyramidal effects & 1 & 50 & Risk Ratio (M-H, Fixed, 95\% Cl) & $3.00[0.13,70.30]$ \\
\hline 1.7.8 treatment failure & 1 & 190 & Risk Ratio (M-H, Fixed, 95\% Cl) & $0.11[0.03,0.35]$ \\
\hline $\begin{array}{l}1.8 \text { Leaving the study early: } 3 . \\
\text { Marked improvement/ hospital } \\
\text { discharge }\end{array}$ & 1 & & Risk Ratio (M-H, Fixed, 95\% Cl) & Subtotals only \\
\hline $\begin{array}{l}\text { 1.8.1 discharged due to marked } \\
\text { improvement }\end{array}$ & 1 & 36 & Risk Ratio (M-H, Fixed, 95\% Cl) & $3.00[0.13,69.09]$ \\
\hline $\begin{array}{l}1.9 \text { Adverse effects: } 1 \text {. Anticholiner- } \\
\text { gic effects - short term }\end{array}$ & 2 & & Risk Ratio (M-H, Fixed, 95\% Cl) & Subtotals only \\
\hline
\end{tabular}




\begin{tabular}{|c|c|c|c|c|}
\hline Outcome or subgroup title & No. of studies & $\begin{array}{l}\text { No. of partici- } \\
\text { pants }\end{array}$ & Statistical method & Effect size \\
\hline 1.9.1 blurred vision & 1 & 37 & Risk Ratio (M-H, Fixed, 95\% Cl) & $5.26[0.27,102.66]$ \\
\hline 1.9.2 constipation & 1 & 190 & Risk Ratio (M-H, Fixed, 95\% Cl) & $2.22[1.19,4.15]$ \\
\hline 1.9.3 drooling & 1 & 37 & Risk Ratio (M-H, Fixed, 95\% Cl) & $3.16[0.14,72.84]$ \\
\hline 1.9.4 dryness mouth or throat & 2 & 227 & Risk Ratio (M-H, Fixed, 95\% Cl) & $3.62[1.39,9.42]$ \\
\hline $\begin{array}{l}\text { 1.9.5 gastrointestinal distress and } \\
\text { nausea }\end{array}$ & 2 & 227 & Risk Ratio (M-H, Fixed, 95\% Cl) & $0.90[0.30,2.72]$ \\
\hline 1.9.6 increased salivation & 1 & 190 & Risk Ratio (M-H, Fixed, 95\% Cl) & $18.10[1.06,309.15]$ \\
\hline 1.9.7 nasal congestion & 1 & 37 & Risk Ratio (M-H, Fixed, 95\% Cl) & $3.16[0.14,72.84]$ \\
\hline 1.9.8 urinary disturbance & 1 & 190 & Risk Ratio (M-H, Fixed, 95\% Cl) & $3.20[0.34,30.17]$ \\
\hline 1.9 .9 vomiting & 1 & 190 & Risk Ratio (M-H, Fixed, 95\% Cl) & $5.32[0.26,109.41]$ \\
\hline $\begin{array}{l}1.10 \text { Adverse effects: } 2 \text {. Cardivascu- } \\
\text { lar effects - short term }\end{array}$ & 2 & & Risk Ratio (M-H, Fixed, 95\% Cl) & Subtotals only \\
\hline $\begin{array}{l}1.10 .1 \text { dizziness, faintness, weak- } \\
\text { ness }\end{array}$ & 1 & 190 & Risk Ratio (M-H, Fixed, 95\% Cl) & $2.34[0.85,6.49]$ \\
\hline 1.10.2 hypotension & 1 & 37 & Risk Ratio (M-H, Fixed, 95\% Cl) & $3.16[0.14,72.84]$ \\
\hline 1.10.3 syncope & 1 & 37 & Risk Ratio (M-H, Fixed, 95\% Cl) & $3.16[0.14,72.84]$ \\
\hline 1.10.4 tachycardia & 1 & 37 & Risk Ratio (M-H, Fixed, 95\% Cl) & $3.16[0.14,72.84]$ \\
\hline $\begin{array}{l}1.11 \text { Adverse effects: } 3 \text {. CNS - short } \\
\text { term }\end{array}$ & 2 & & Risk Ratio (M-H, Fixed, 95\% Cl) & Subtotals only \\
\hline $\begin{array}{l}\text { 1.11.1 anxiety, agitation, excite- } \\
\text { ment and confusion }\end{array}$ & 1 & 37 & Risk Ratio (M-H, Fixed, 95\% Cl) & $1.06[0.17,6.72]$ \\
\hline 1.11.2 convulsion or seizures & 1 & 190 & Risk Ratio (M-H, Fixed, 95\% Cl) & $0.35[0.01,8.60]$ \\
\hline 1.11.3 depression & 1 & 37 & Risk Ratio (M-H, Fixed, 95\% Cl) & $0.35[0.02,8.09]$ \\
\hline 1.11.4 drowsiness & 1 & 190 & Risk Ratio (M-H, Fixed, 95\% Cl) & $3.91[1.98,7.71]$ \\
\hline 1.11.5 headache & 1 & 190 & Risk Ratio (M-H, Fixed, 95\% Cl) & $1.17[0.52,2.63]$ \\
\hline 1.11.6 sedation and lethargy & 1 & 37 & Risk Ratio (M-H, Fixed, 95\% Cl) & $1.06[0.31,3.60]$ \\
\hline $\begin{array}{l}1.12 \text { Adverse effects: 4. Death - } \\
\text { long term }\end{array}$ & 1 & 50 & Risk Ratio (M-H, Fixed, 95\% Cl) & $2.38[0.10,55.72]$ \\
\hline $\begin{array}{l}1.13 \text { Adverse effects: } 5 \text {. Endocrine - } \\
\text { short term }\end{array}$ & 1 & & Risk Ratio (M-H, Fixed, 95\% Cl) & Subtotals only \\
\hline 1.13.1 amenorrhea & 1 & 190 & Risk Ratio (M-H, Fixed, 95\% Cl) & $1.07[0.27,4.14]$ \\
\hline
\end{tabular}




\begin{tabular}{|c|c|c|c|c|}
\hline Outcome or subgroup title & No. of studies & $\begin{array}{l}\text { No. of partici- } \\
\text { pants }\end{array}$ & Statistical method & Effect size \\
\hline 1.13.2 lactation & 1 & 190 & Risk Ratio (M-H, Fixed, 95\% Cl) & $7.45[0.39,142.32]$ \\
\hline 1.13.3 swelling of breasts & 1 & 190 & Risk Ratio (M-H, Fixed, 95\% Cl) & $5.32[0.26,109.41]$ \\
\hline $\begin{array}{l}\text { 1.14 Adverse effects: } 6 \text { a. Extrapyra- } \\
\text { midal effects - short term }\end{array}$ & 2 & & Risk Ratio (M-H, Fixed, 95\% Cl) & Subtotals only \\
\hline 1.14.1 akinesia & 1 & 37 & Risk Ratio (M-H, Fixed, 95\% Cl) & $3.16[0.14,72.84]$ \\
\hline 1.14.2 akathisia & 2 & 227 & Risk Ratio (M-H, Fixed, 95\% Cl) & $3.43[1.23,9.56]$ \\
\hline 1.14.3 associated movements & 1 & 37 & Risk Ratio (M-H, Fixed, 95\% Cl) & $7.37[0.41,133.37]$ \\
\hline 1.14.4 dystonia & 1 & 190 & Risk Ratio (M-H, Fixed, 95\% Cl) & $13.84[0.79,242.25]$ \\
\hline 1.14.5 facial rigidity & 1 & 190 & Risk Ratio (M-H, Fixed, 95\% Cl) & $2.77[1.03,7.46]$ \\
\hline $\begin{array}{l}1.14 .6 \text { loss of associated move- } \\
\text { ments }\end{array}$ & 1 & 190 & Risk Ratio (M-H, Fixed, 95\% Cl) & $6.39[1.95,20.98]$ \\
\hline 1.14.7 restlessness, insomnia & 2 & 227 & Risk Ratio (M-H, Fixed, 95\% Cl) & $0.99[0.69,1.40]$ \\
\hline 1.14.8 rigidity & 2 & 227 & Risk Ratio (M-H, Fixed, 95\% Cl) & $3.54[1.76,7.14]$ \\
\hline 1.14.9 tremor & 2 & 227 & Risk Ratio (M-H, Fixed, 95\% Cl) & $3.19[1.25,8.11]$ \\
\hline $\begin{array}{l}1.15 \text { Adverse effects: } 6 \mathrm{~b} \text {. Extrapyra- } \\
\text { midal effects - medium term }\end{array}$ & 1 & & Risk Ratio (M-H, Fixed, 95\% Cl) & Subtotals only \\
\hline 1.15.1 akathisia & 1 & 50 & Risk Ratio (M-H, Fixed, 95\% Cl) & $1.20[0.42,3.43]$ \\
\hline 1.15.2 akinesia & 1 & 50 & Risk Ratio (M-H, Fixed, 95\% Cl) & $11.00[0.64,188.95]$ \\
\hline 1.15.3 dystonia & 1 & 50 & Risk Ratio (M-H, Fixed, 95\% Cl) & $1.09[0.92,1.29]$ \\
\hline 1.15.4 parkinsonism & 1 & 50 & Risk Ratio (M-H, Fixed, 95\% Cl) & $5.50[1.36,22.32]$ \\
\hline $\begin{array}{l}1.16 \text { Adverse effects: } 7 \text {. Others - } \\
\text { short term }\end{array}$ & 2 & & Risk Ratio (M-H, Fixed, 95\% Cl) & Subtotals only \\
\hline 1.16.1 convulsion or seizures & 1 & 190 & Risk Ratio (M-H, Fixed, 95\% Cl) & $0.35[0.01,8.60]$ \\
\hline 1.16.2 diarrhoea & 1 & 190 & Risk Ratio (M-H, Fixed, 95\% Cl) & $5.32[0.26,109.41]$ \\
\hline 1.16.3 intercurrent infection & 1 & 190 & Risk Ratio (M-H, Fixed, 95\% Cl) & $1.07[0.22,5.14]$ \\
\hline 1.16.4 rash & 2 & 227 & Risk Ratio (M-H, Fixed, 95\% Cl) & $0.76[0.15,3.78]$ \\
\hline $\begin{array}{l}\text { 1.17 Sensitivity analysis: } 1 . \\
\text { CHRONIC versus ACUTE }\end{array}$ & 2 & & Risk Ratio (M-H, Fixed, 95\% Cl) & Subtotals only \\
\hline $\begin{array}{l}\text { 1.17.1 Acute: Global state - not im- } \\
\text { proved - short term }\end{array}$ & 1 & 37 & Risk Ratio (M-H, Fixed, 95\% Cl) & $0.59[0.24,1.42]$ \\
\hline
\end{tabular}




\begin{tabular}{|c|c|c|c|c|}
\hline Outcome or subgroup title & No. of studies & $\begin{array}{l}\text { No. of partici- } \\
\text { pants }\end{array}$ & Statistical method & Effect size \\
\hline $\begin{array}{l}\text { 1.17.2 Chronic: global state - not } \\
\text { improved - short term }\end{array}$ & 1 & 50 & Risk Ratio (M-H, Fixed, 95\% Cl) & $0.93[0.56,1.55]$ \\
\hline $\begin{array}{l}\text { 1.18 Sensitivity analysis: } 2 \text {. LOW } \\
\text { DOSES ( } 1-5 \mathrm{mg} / \text { day) versus HIGH } \\
\text { DOSES ( } 5 \mathrm{mg} / \text { day>) }\end{array}$ & 3 & & Risk Ratio (M-H, Fixed, 95\% Cl) & Subtotals only \\
\hline $\begin{array}{l}\text { 1.18.1 High dose: Global state - not } \\
\text { improved - short term }\end{array}$ & 1 & 38 & Risk Ratio (M-H, Fixed, 95\% Cl) & $0.79[0.48,1.31]$ \\
\hline $\begin{array}{l}\text { 1.18.2 Flexible dose: Global state - } \\
\text { not improved - short term }\end{array}$ & 2 & 87 & Risk Ratio (M-H, Fixed, 95\% Cl) & $0.80[0.51,1.25]$ \\
\hline $\begin{array}{l}\text { 1.19 Sensitivity analysis: } 3 \text {. OPER- } \\
\text { ATIONAL CRITERIA versus LOOSE } \\
\text { DEFINITIONS }\end{array}$ & 3 & & Risk Ratio (M-H, Fixed, 95\% Cl) & Subtotals only \\
\hline $\begin{array}{l}\text { 1.19.1 DSM-III-R: Global state - not } \\
\text { improved - short term }\end{array}$ & 1 & 38 & Risk Ratio (M-H, Fixed, 95\% Cl) & $0.79[0.48,1.31]$ \\
\hline $\begin{array}{l}1.19 .2 \text { Loose definition: global } \\
\text { state - not improved - short term }\end{array}$ & 2 & 87 & Risk Ratio (M-H, Fixed, 95\% Cl) & $0.80[0.51,1.25]$ \\
\hline $\begin{array}{l}1.20 \text { Sensitivity analysis: 4. BEFORE } \\
1990 \text { versus AFTER } 1990\end{array}$ & 3 & & Risk Ratio (M-H, Fixed, 95\% Cl) & Subtotals only \\
\hline $\begin{array}{l}\text { 1.20.1 Before 1990: Global state - } \\
\text { not improved - short term }\end{array}$ & 2 & 87 & Risk Ratio (M-H, Fixed, 95\% Cl) & $0.80[0.51,1.25]$ \\
\hline $\begin{array}{l}\text { 1.20.2 After 1990: Global state - not } \\
\text { improved - short term }\end{array}$ & 1 & 38 & Risk Ratio (M-H, Fixed, 95\% Cl) & $0.79[0.48,1.31]$ \\
\hline
\end{tabular}


Analysis 1.1. Comparison 1: ORAL FLUPHENAZINE versus PLACEBO, Outcome 1: Global state: 1 . Not improved or worsened

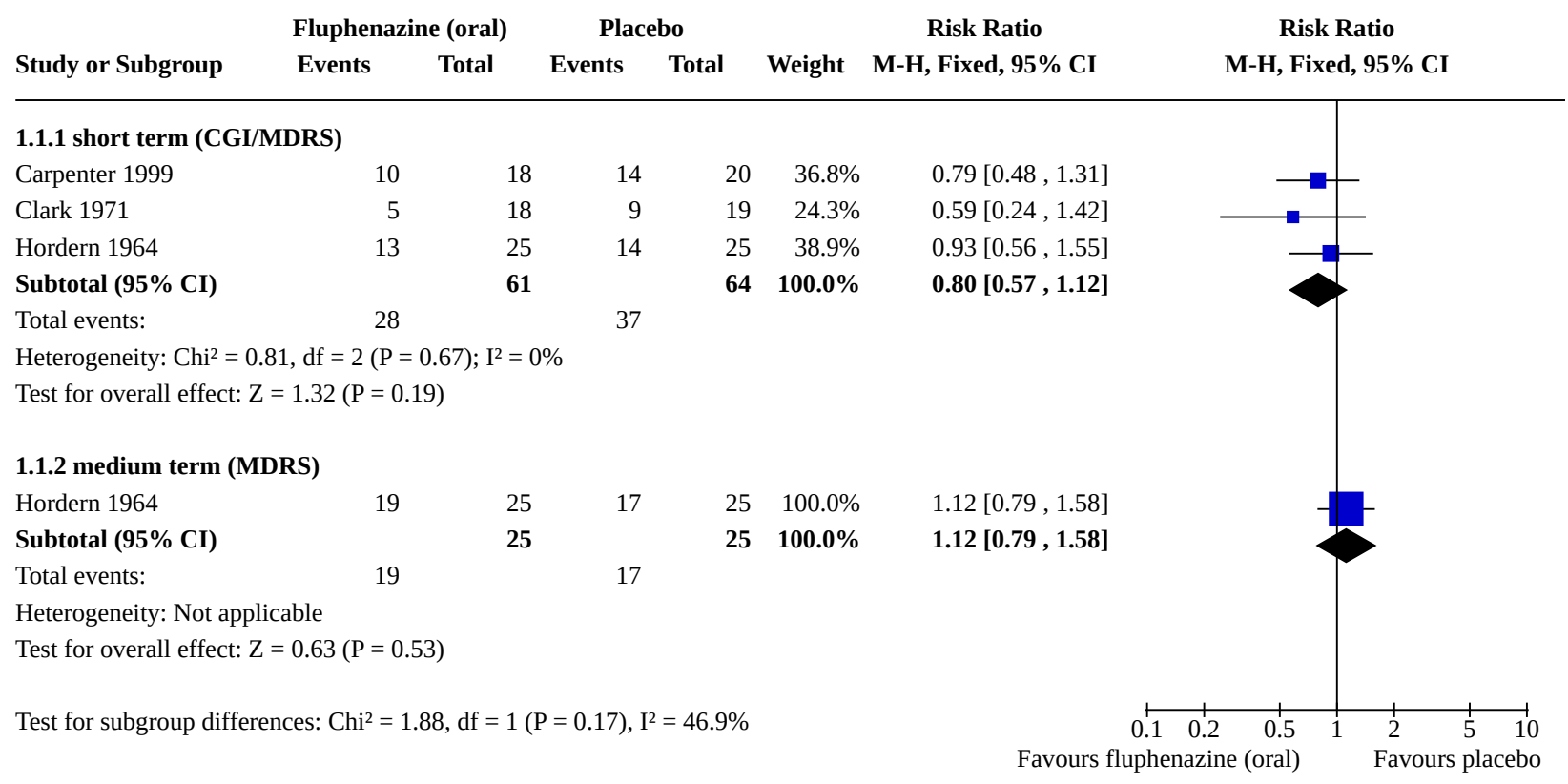

\section{Analysis 1.2. Comparison 1: ORAL FLUPHENAZINE versus PLACEBO, Outcome 2: Global state: 2. Relapse}

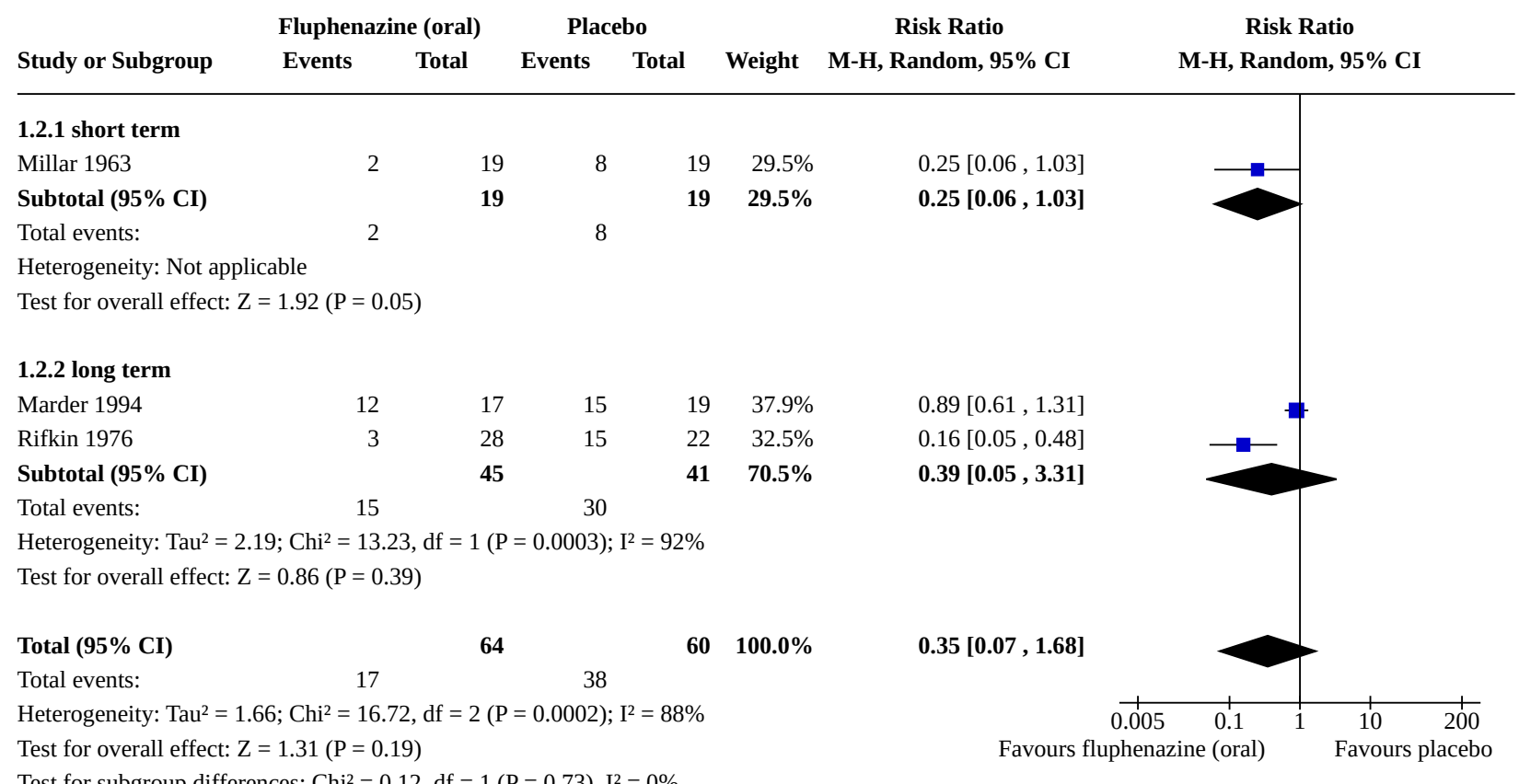

\section{Analysis 1.3. Comparison 1: ORAL FLUPHENAZINE versus PLACEBO, Outcome 3: Global state: 3. Percentage of time in prodrome state (skewed data)}

Global state: 3. Percentage of time in prodrome state (skewed data)

\begin{tabular}{llll}
\hline Study & Mean & SD \\
\hline one-year data & & \\
\hline
\end{tabular}

Fluphenazine (oral) versus placebo for schizophrenia (Review) 


\begin{tabular}{lllll}
\multirow{2}{*}{ Marder 1994 } & Oral fluphenazine & 10.5 & 15.90 & 22.30 \\
\cline { 2 - 4 } & Placebo & 19.4 & & 19 \\
\hline two-year data & & & 3.80 & 14 \\
\hline Marder 1994 & Oral fluphenazine & 2.80 & 5.70 & 15 \\
\cline { 2 - 4 } & Placebo & 4.90 & \\
\hline
\end{tabular}

Analysis 1.4. Comparison 1: ORAL FLUPHENAZINE versus PLACEBO, Outcome 4: Global state: 4. Percentage of time in exacerbated state (skewed data)

Global state: 4. Percentage of time in exacerbated state (skewed data)

\begin{tabular}{lllll}
\hline Study & Intervention & Mean & SD & N \\
\hline one-year data & & & & 15.00 \\
\hline Marder 1994 & Oral fluphenazine & 11.8 & 10.70 & \\
\cline { 2 - 5 } & Placebo & 7.20 & & \\
\hline two-year data & & & 19 & \\
\hline Marder 1994 & Oral fluphenazine & 5.50 & 10.40 & 14 \\
\cline { 2 - 5 } & Placebo & 12.9 & 13.6 & 15 \\
\hline
\end{tabular}

Analysis 1.5. Comparison 1: ORAL FLUPHENAZINE versus PLACEBO, Outcome 5: Global state: 5. average score: $\mathrm{CGI}$ - severity of illness score (high = poor)

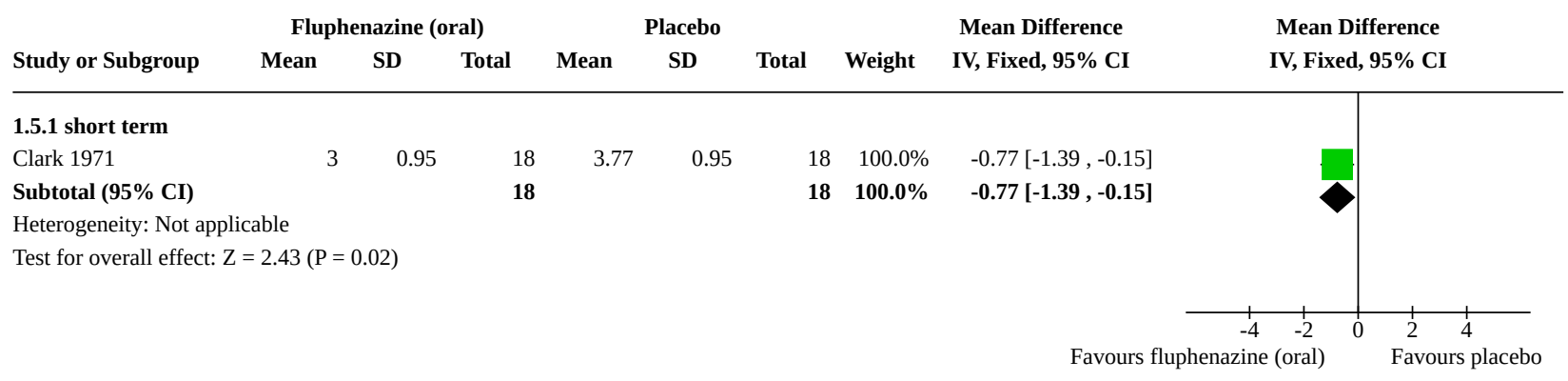




\section{Analysis 1.6. Comparison 1: ORAL FLUPHENAZINE versus PLACEBO,} Outcome 6: Leaving the study early: 1 . Non-specific reasons

\begin{tabular}{|c|c|c|c|c|c|c|}
\hline \multirow[b]{2}{*}{ Study or Subgroup } & \multicolumn{2}{|c|}{ Fluphenazine (oral) } & \multicolumn{2}{|c|}{ Placebo } & \multirow[b]{2}{*}{ Weight } & Risk Ratio \\
\hline & Events & Total & Events & Total & & M-H, Fixed, 95\% CI \\
\hline \multicolumn{7}{|l|}{ 1.6.1 short term } \\
\hline Clark 1971 & 2 & 18 & 4 & 19 & $9.2 \%$ & $0.53[0.11,2.54]$ \\
\hline Goldberg 1964 & 21 & 92 & 32 & 98 & $72.9 \%$ & $0.70[0.44,1.12]$ \\
\hline Subtotal (95\% CI) & & 110 & & 117 & $82.0 \%$ & $0.68[0.43,1.07]$ \\
\hline Total events: & 23 & & 36 & & & \\
\hline
\end{tabular}

Heterogeneity: $\mathrm{Chi}^{2}=0.11, \mathrm{df}=1(\mathrm{P}=0.74) ; \mathrm{I}^{2}=0 \%$

Test for overall effect: $\mathrm{Z}=1.67(\mathrm{P}=0.09)$

1.6.2 medium term

\section{Hordern 1964}

Subtotal (95\% CI)

Total events:

\section{2}

25

0

25

$1.2 \%$

$5.00[0.25,99.16]$

Heterogeneity: Not applicable

Test for overall effect: $\mathrm{Z}=1.06(\mathrm{P}=0.29)$

\subsection{3 long term}

Marder 1994

Rifkin 1976

Subtotal (95\% CI)

0

$5.00[0.25,99.16]$

Total events:

3

17

17
28

4

$19 \quad 8.9 \%$

$0.84[0.22,3.22]$

45

$22 \quad 7.9 \%$

$0.52[0.10,2.87]$

Heterogeneity: $\mathrm{Chi}^{2}=0.18, \mathrm{df}=1(\mathrm{P}=0.67) ; \mathrm{I}^{2}=0 \%$

Test for overall effect: $\mathrm{Z}=0.69(\mathrm{P}=0.49)$

\section{Total (95\% CI)}

180

183

Total events:

30

43

Heterogeneity: $\mathrm{Chi}^{2}=1.98, \mathrm{df}=4(\mathrm{P}=0.74) ; \mathrm{I}^{2}=0 \%$

Test for overall effect: $\mathrm{Z}=1.50(\mathrm{P}=0.13)$

Test for subgroup differences: $\mathrm{Chi}^{2}=1.68, \mathrm{df}=2(\mathrm{P}=0.43), \mathrm{I}^{2}=0 \%$

Risk Ratio

M-H, Fixed, 95\% CI 
Analysis 1.7. Comparison 1: ORAL FLUPHENAZINE versus PLACEBO, Outcome 7: Leaving the study early: 2 . Specific reason - short term

\begin{tabular}{|c|c|c|c|c|c|c|c|}
\hline & Fluphen & e (oral) & Pla & & & Risk Ratio & Risk Ratio \\
\hline Study or Subgroup & Events & Total & Events & Total & Weight & M-H, Fixed, 95\% CI & M-H, Fixed, 95\% CI \\
\hline
\end{tabular}

1.7.1 administrative/hospital transfer

Clark 1971

Subtotal (95\% CI)

18

Total events:

Heterogeneity: Not applicable

Test for overall effect: $\mathrm{Z}=0.04(\mathrm{P}=0.97)$

\subsubsection{AWOL}

Clark 1971

Subtotal (95\% CI)

Total events:

Heterogeneity: Not applicable

Test for overall effect: $\mathrm{Z}=0.04(\mathrm{P}=0.97)$

\subsection{3 court cases, transfer, eloped}

Goldberg 1964

Subtotal (95\% CI)

10

Total events:

Heterogeneity: Not applicable

Test for overall effect: $\mathrm{Z}=2.28(\mathrm{P}=0.02)$

1.7.4 incorrect diagnosis

Goldberg 1964

Subtotal (95\% CI)

Total events:

Heterogeneity: Not applicable

Test for overall effect: $\mathrm{Z}=0.04(\mathrm{P}=0.96)$

\subsection{5 marked early remission}

\section{Goldberg 1964}

Subtotal (95\% CI)

$2 \quad 92$

Total events:

2

Heterogeneity: Not applicable

Test for overall effect: $\mathrm{Z}=0.62(\mathrm{P}=0.53)$

1.7.6 serious complication of treatment

\section{Goldberg 1964}

Subtotal (95\% CI)

Total events: 5

Heterogeneity: Not applicable

Test for overall effect: $\mathrm{Z}=1.67(\mathrm{P}=0.09)$

\subsection{7 severe extrapyramidal effects}

\section{Hordern 1964}

Subtotal (95\% CI)

Total events:

Heterogeneity: Not applicable

Test for overall effect: $\mathrm{Z}=0.68(\mathrm{P}=0.49)$

\subsection{8 treatment failure}

Goldberg 1964

Subtotal (95\% CI)

Total events:

3

$2.13[0.20,23.10]$

$2.13[0.20,23.10]$
M-H, Fixed, 95\% CI

Heternoeneitv: Not annlicahle 


\section{Analysis 1.7. (Continued)}

\section{Total events:}

Heterogeneity: Not applicable

Test for overall effect: $\mathrm{Z}=3.75(\mathrm{P}=0.0002)$
29

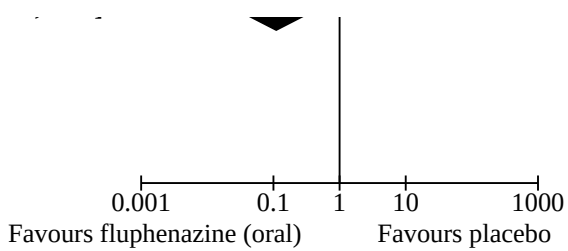

Analysis 1.8. Comparison 1: ORAL FLUPHENAZINE versus PLACEBO, Outcome 8: Leaving the study early: 3. Marked improvement/ hospital discharge

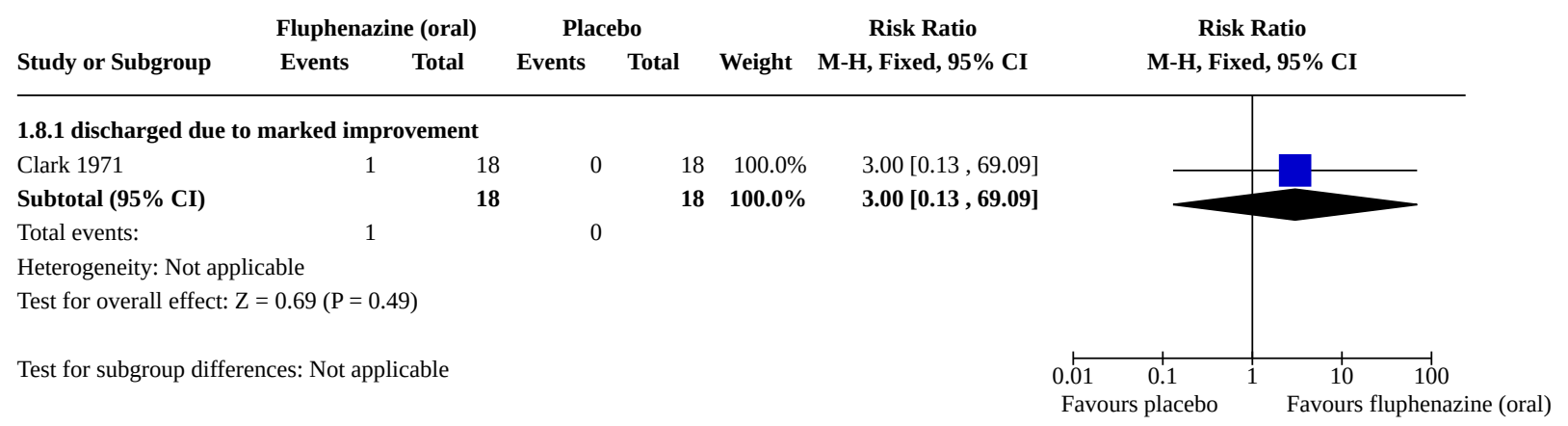


Analysis 1.9. Comparison 1: ORAL FLUPHENAZINE versus PLACEBO, Outcome 9: Adverse effects: 1. Anticholinergic effects - short term

\begin{tabular}{|c|c|c|c|c|c|c|}
\hline \multirow[b]{2}{*}{ Study or Subgroup } & \multicolumn{2}{|c|}{ Fluphenazine (oral) } & \multicolumn{2}{|c|}{ Placebo } & \multirow[b]{2}{*}{ Weight } & \multirow{2}{*}{$\begin{array}{c}\text { Risk Ratio } \\
\text { M-H, Fixed, 95\% CI }\end{array}$} \\
\hline & Events & Total & Events & Total & & \\
\hline \multicolumn{7}{|l|}{ 1.9.1 blurred vision } \\
\hline Clark 1971 & 2 & 18 & 0 & 19 & $100.0 \%$ & $5.26[0.27,102.6$ \\
\hline Subtotal (95\% CI) & & 18 & & 19 & $100.0 \%$ & $5.26[0.27,102.6$ \\
\hline Total events: & 2 & & 0 & & & \\
\hline
\end{tabular}

Heterogeneity: Not applicable

Test for overall effect: $\mathrm{Z}=1.10(\mathrm{P}=0.27)$

\subsection{2 constipation}

Goldberg 1964

Subtotal (95\% CI)

Total events:

\section{5}

Heterogeneity: Not applicable

Test for overall effect: $\mathrm{Z}=2.49(\mathrm{P}=0.01)$

\subsection{3 drooling}

Clark 1971

Subtotal (95\% CI)

Total events:

Heterogeneity: Not applicable

Test for overall effect: $\mathrm{Z}=0.72(\mathrm{P}=0.47)$

1.9.4 dryness mouth or throat

Clark 1971

Goldberg 1964

0

Subtotal (95\% CI)

Total events:

Heterogeneity: Not applicable

Test for overall effect: $\mathrm{Z}=2.64(\mathrm{P}=0.008)$

1.9.5 gastrointestinal distress and nausea

$\begin{array}{llr}\text { Clark } 1971 & 0 & 18 \\ \text { Goldberg } 1964 & 5 & 92 \\ \text { Subtotal (95\% CI) } & & \mathbf{1 1 0}\end{array}$

$\begin{array}{rrrr}18 & 2 & 19 & 38.6 \% \\ 92 & 4 & 98 & 61.4 \% \\ \mathbf{1 1 0} & & \mathbf{1 1 7} & \mathbf{1 0 0 . 0 \%}\end{array}$

$0.21[0.01,4.11]$

$1.33[0.37,4.81]$

$0.90[0.30,2.72]$

Not estimable

$3.62[1.39,9.42]$

$3.62[1.39,9.42]$

Total events:

Heterogeneity: $\mathrm{Chi}^{2}=1.28, \mathrm{df}=1(\mathrm{P}=0.26) ; \mathrm{I}^{2}=22 \%$

Test for overall effect: $\mathrm{Z}=0.19(\mathrm{P}=0.85)$

\subsection{6 increased salivation}

Goldberg 1964

Subtotal (95\% CI)

Total events:

Heterogeneity: Not applicable

Test for overall effect: $\mathrm{Z}=2.00(\mathrm{P}=0.05)$

1.9.7 nasal congestion

Clark 1971

Subtotal (95\% CI)

18

Heterogeneity: Not applicable

Test for overall effect: $\mathrm{Z}=0.72(\mathrm{P}=0.47)$

1.9.8 urinary disturbance

Goldberg 1964

3

0

Suhtotal (95\% CI)

$\begin{array}{llll}92 & 1 & 98 & 100.0 \% \\ \mathbf{9 2} & & \mathbf{9 8} & \mathbf{1 0 n . 0} \%\end{array}$

$3.20[0.34,30.17]$

3.20 [0.34 . 30.17]
Risk Ratio

M-H, Fixed, 95\% CI 


\section{Analysis 1.9. (Continued)}

$\begin{array}{lllllll}\text { Goldberg } 1964 & 3 & 92 & 1 & 98 & 100.0 \% & 3.20[0.34,30.17] \\ \text { Subtotal (95\% CI) } & & \mathbf{9 2} & & \mathbf{9 8} & \mathbf{1 0 0 . 0 \%} & \mathbf{3 . 2 0}[\mathbf{0 . 3 4}, \mathbf{3 0 . 1 7}] \\ \text { Total events: } & 3 & & 1 & & & \end{array}$

Heterogeneity: Not applicable

Test for overall effect: $\mathrm{Z}=1.01(\mathrm{P}=0.31)$

\subsection{9 vomiting}

Goldberg 1964

Subtotal (95\% CI)

Total events:

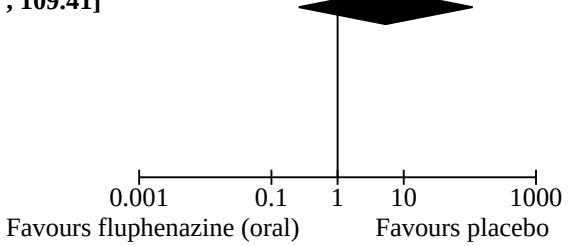

\section{Analysis 1.10. Comparison 1: ORAL FLUPHENAZINE versus PLACEBO, Outcome 10: Adverse effects: 2. Cardivascular effects - short term}

\begin{tabular}{llcccccc} 
& \multicolumn{2}{c}{ Fluphenazine (oral) } & \multicolumn{2}{c}{ Placebo } & \multicolumn{2}{c}{ Risk Ratio } & \multicolumn{2}{c}{ Risk Ratio } \\
Study or Subgroup & Events & Total & Events & Total & Weight & M-H, Fixed, 95\% CI & M-H, Fixed, 95\% CI
\end{tabular}

1.10.1 dizziness, faintness, weakness

Goldberg 1964

Subtotal (95\% CI)

92

$92 \quad 5$

$2.34[0.85,6.49]$

Total events:

11

92

5

$98 \quad 100.0 \%$

$2.34[0.85,6.49]$

Heterogeneity: Not applicable

Test for overall effect: $\mathrm{Z}=1.64(\mathrm{P}=0.10)$

\subsection{2 hypotension}

Clark 1971

Subtotal (95\% CI)

Total events:

18

0

$19 \quad 100.0 \%$

$3.16[0.14,72.84]$

Heterogeneity: Not applicable

Test for overall effect: $\mathrm{Z}=0.72(\mathrm{P}=0.47)$

\subsection{3 syncope}

Clark 1971

Subtotal (95\% CI)

1

$\begin{array}{ll}18 & 0 \\ 18 & 0\end{array}$

$19 \quad 100.0 \%$

$3.16[0.14,72.84]$

Total events:

1

$19 \quad \mathbf{1 0 0 . 0} \%$

$3.16[0.14,72.84]$

Heterogeneity: Not applicable

Test for overall effect: $\mathrm{Z}=0.72(\mathrm{P}=0.47)$

\subsection{4 tachycardia}

Clark 1971

Subtotal (95\% CI)

Total events:

Heterogeneity: Not applicable

Test for overall effect: $\mathrm{Z}=0.72(\mathrm{P}=0.47)$

$$
0
$$

$19 \quad \mathbf{1 0 0 . 0} \%$ 


\section{Analysis 1.11. Comparison 1: ORAL FLUPHENAZINE versus} PLACEBO, Outcome 11: Adverse effects: 3. CNS - short term

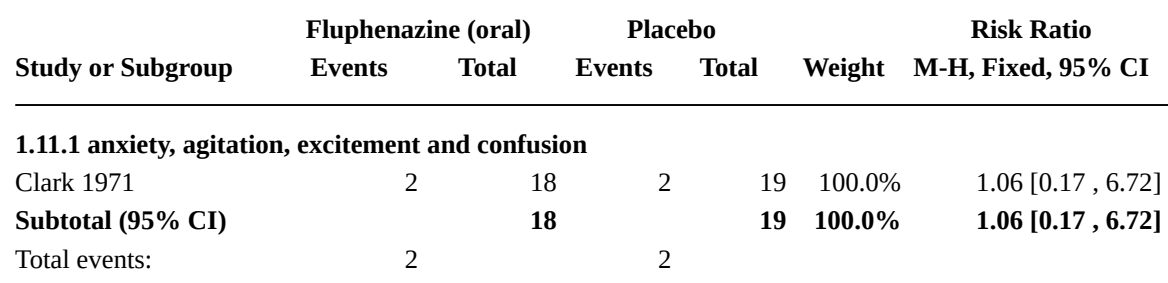

Heterogeneity: Not applicable

Test for overall effect: $\mathrm{Z}=0.06(\mathrm{P}=0.95)$

1.11.2 convulsion or seizures

Goldberg 1964

Subtotal (95\% CI)

Total events: 0

92

1

$98 \quad 100.0 \%$

Heterogeneity: Not applicable

Test for overall effect: $\mathrm{Z}=0.64(\mathrm{P}=0.52)$

\subsection{3 depression}

Clark 1971

Subtotal (95\% CI)

Total events:

18

Heterogeneity: Not applicable

Test for overall effect: $\mathrm{Z}=0.65(\mathrm{P}=0.51)$

\subsection{4 drowsiness}

Goldberg 1964

Subtotal (95\% CI)

Total events:

33

Heterogeneity: Not applicable

Test for overall effect: $\mathrm{Z}=3.93(\mathrm{P}<0.0001)$

\subsection{5 headache}

Goldberg 1964

Subtotal (95\% CI)

Total events:

11

Heterogeneity: Not applicable

Test for overall effect: $\mathrm{Z}=0.38(\mathrm{P}=0.70)$

1.11.6 sedation and lethargy

Clark 1971

Subtotal (95\% CI)

Total events:

Heterogeneity: Not applicable

Test for overall effect: $\mathrm{Z}=0.09(\mathrm{P}=0.93)$
Risk Ratio M-H, Fixed, 95\% CI 
Analysis 1.12. Comparison 1: ORAL FLUPHENAZINE versus PLACEBO, Outcome 12: Adverse effects: 4. Death - long term

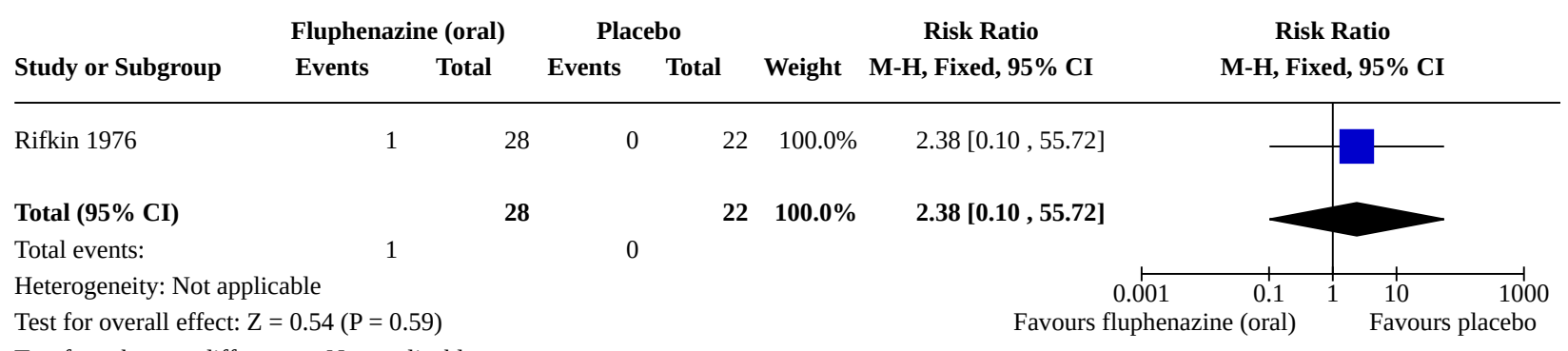

Test for subgroup differences: Not applicable

Analysis 1.13. Comparison 1: ORAL FLUPHENAZINE versus PLACEBO, Outcome 13: Adverse effects: 5. Endocrine - short term

\begin{tabular}{|c|c|c|c|c|c|c|c|}
\hline & Fluphen & e (oral) & Pla & & & Risk Ratio & Risk Ratio \\
\hline Study or Subgroup & Events & Total & Events & Total & Weight & $95 \%$ & M-H. Fixed, 95\% CI \\
\hline
\end{tabular}

\subsection{1 amenorrhea}

Goldberg 1964

Subtotal (95\% CI)

Totals

Weight M-H, Fixed, 95\% C

M-H, Fixed, 95\% CI

Heterogeneity: Not applicable

Test for overall effect: $\mathrm{Z}=0.09(\mathrm{P}=0.93)$

1.13.2 lactation

Goldberg 1964

Subtotal (95\% CI)

Total events:

$\begin{array}{llll}92 & 4 & 98 & 100.0 \% \\ \mathbf{9 2} & & \mathbf{9 8} & \mathbf{1 0 0 . 0} \%\end{array}$

$1.07[0.27,4.14]$

Heterogeneity: Not applicable

Test for overall effect: $\mathrm{Z}=1.33(\mathrm{P}=0.18)$

1.13.3 swelling of breasts

Goldberg 1964

Subtotal (95\% CI)

$\begin{array}{lll}4 & 92 & 4 \\ 4 & 92 & \\ 4 & & 4\end{array}$

$100.0 \%$

$1.07[0.27,4.14]$

Total events:

292

$98 \quad 100.0 \%$

$5.32[0.26,109.41]$

Heterogeneity: Not applicable

2

92

$98 \quad 100.0 \%$

$5.32[0.26,109.41]$

Test for overall effect: $\mathrm{Z}=1.08(\mathrm{P}=0.28)$

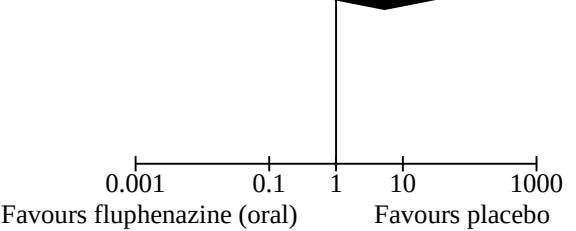


Analysis 1.14. Comparison 1: ORAL FLUPHENAZINE versus PLACEBO, Outcome 14: Adverse effects: $6 a$. Extrapyramidal effects - short term

\begin{tabular}{llllllll} 
& \multicolumn{2}{c}{ Fluphenazine (oral) } & \multicolumn{2}{c}{ Placebo } & \multicolumn{2}{c}{ Risk Ratio } & \multicolumn{2}{c}{ Risk Ratio } \\
Study or Subgroup & Events & Total & Events & Total & Weight & M-H, Fixed, 95\% CI & M-H, Fixed, 95\% CI
\end{tabular}

\begin{tabular}{lcccccc}
\hline $\mathbf{1 . 1 4 . 1}$ akinesia & & & & & & \\
Clark 1971 & 1 & 18 & 0 & 19 & $100.0 \%$ & $3.16[0.14, \mathbf{7 2 . 8 4}]$ \\
Subtotal (95\% CI) & & $\mathbf{1 8}$ & & $\mathbf{1 9}$ & $\mathbf{1 0 0 . 0 \%}$ & $\mathbf{3 . 1 6}[\mathbf{0 . 1 4}, \mathbf{7 2 . 8 4}]$ \\
Total events: & 1 & & 0 & & &
\end{tabular}

Heterogeneity: Not applicable

Test for overall effect: $\mathrm{Z}=0.72(\mathrm{P}=0.47)$

\subsection{2 akathisia}

\section{Clark 1971}

Goldberg 1964

Subtotal (95\% CI)

Total events:

$\begin{array}{rrr}3 & \\ 11 & 110\end{array}$

18
92
110

$\begin{array}{rr}19 & 11.2 \% \\ 98 & 88.8 \% \\ \mathbf{1 1 7} & \mathbf{1 0 0 . 0 \%}\end{array}$

$7.37[0.41,133.37]$

$2.93[0.97,8.87]$

$3.43[1.23,9.56]$

Heterogeneity: $\mathrm{Chi}^{2}=0.35, \mathrm{df}=1(\mathrm{P}=0.56) ; \mathrm{I}^{2}=0 \%$

Test for overall effect: $\mathrm{Z}=2.35(\mathrm{P}=0.02)$

1.14.3 associated movements

$\begin{array}{lll}\text { Clark } 1971 & 3 & 18 \\ \text { Subtotal (95\% CI) } & & \mathbf{1 8} \\ \text { Total events: } & 3 & \end{array}$

$19 \quad 100.0 \%$

$7.37[0.41,133.37]$

$19 \quad 100.0 \% \quad 7.37[0.41,133.37]$

Heterogeneity: Not applicable

Test for overall effect: $\mathrm{Z}=1.35(\mathrm{P}=0.18)$

\subsection{4 dystonia}

Goldberg 1964

Subtotal (95\% CI)

Total events:

Heterogeneity: Not applicable

Test for overall effect: $\mathrm{Z}=1.80(\mathrm{P}=0.07)$

\subsection{5 facial rigidity}

Goldberg 1964

Subtotal (95\% CI)

6

Total events:

92

$98 \quad 100.0 \%$

$98 \quad 100.0 \%$

$2.77[1.03,7.46]$

Heterogeneity: Not applicable

Test for overall effect: $\mathrm{Z}=2.01(\mathrm{P}=0.04)$

\subsection{6 loss of associated movements}

Goldberg $1964 \quad 18$

Subtotal (95\% CI)

Total events:

Heterogeneity: Not applicable

Test for overall effect: $\mathrm{Z}=3.06(\mathrm{P}=0.002)$

1.14.7 restlessness, insomnia

$\begin{array}{lrrrrrr}\text { Clark 1971 } & 1 & 18 & 1 & 19 & 2.5 \% & 1.06[0.07,15.64] \\ \text { Goldberg 1964 } & 36 & 92 & 39 & 98 & 97.5 \% & 0.98[0.69,1.40] \\ \text { Subtotal (95\% CI) } & & \mathbf{1 1 0} & & \mathbf{1 1 7} & \mathbf{1 0 0 . 0 \%} & \mathbf{0 . 9 9}[\mathbf{0 . 6 9}, \mathbf{1 . 4 0}]\end{array}$

Total events: $\quad 37 \quad 40$

Heterogeneity: $\mathrm{Chi}^{2}=0.00, \mathrm{df}=1(\mathrm{P}=0.96) ; \mathrm{I}^{2}=0 \%$

Test for overall effect: $\mathrm{Z}=0.08(\mathrm{P}=0.93)$

\subsection{8 rigidity}

Clark 1971

Foldherg 1964

$\begin{array}{rllll}8 & 18 & 1 & 19 & 11.2 \% \\ 77 & 97 & 8 & 98 & 88.8 \%\end{array}$

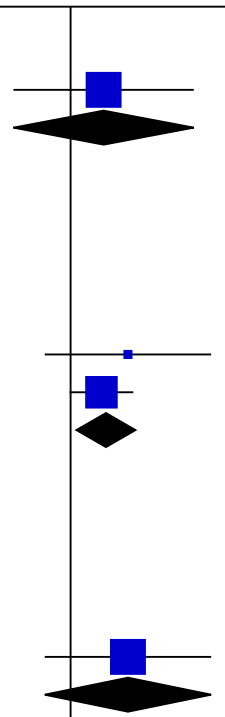




\section{Analysis 1.14. (Continued)}

$\begin{array}{lrrrrrr}\text { Clark 1971 } & 8 & 18 & 1 & 19 & 11.2 \% & 8.44[1.17,60.94] \\ \text { Goldberg 1964 } & 22 & 92 & 8 & 98 & 88.8 \% & 2.93[1.37,6.25] \\ \text { Subtotal (95\% CI) } & & \mathbf{1 1 0} & & \mathbf{1 1 7} & \mathbf{1 0 0 . 0 \%} & \mathbf{3 . 5 4}[\mathbf{1 . 7 6 , \mathbf { 7 . 1 4 } ]}\end{array}$
30

Heterogeneity: $\mathrm{Chi}^{2}=0.98, \mathrm{df}=1(\mathrm{P}=0.32) ; \mathrm{I}^{2}=0 \%$

Test for overall effect: $\mathrm{Z}=3.54(\mathrm{P}=0.0004)$

\subsection{9 tremor}

Clark 1971

Goldberg 1964

$5 \quad 18$

Subtotal (95\%

$11 \quad 92$

Total events:

16

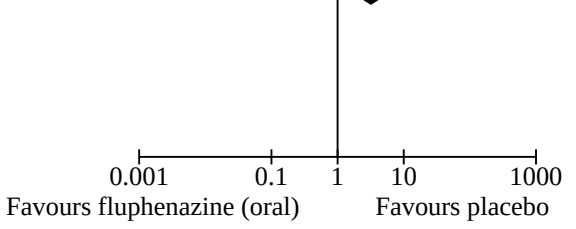

Analysis 1.15. Comparison 1: ORAL FLUPHENAZINE versus PLACEBO, Outcome 15: Adverse effects: 6 b. Extrapyramidal effects - medium term

\begin{tabular}{|c|c|c|c|c|c|c|c|}
\hline \multicolumn{3}{|c|}{ Fluphenazine (oral) } & \multicolumn{2}{|c|}{ Placebo } & \multicolumn{2}{|r|}{ Risk Ratio } & \multirow{2}{*}{$\begin{array}{c}\text { Risk Ratio } \\
\text { M-H, Fixed, 95\% CI }\end{array}$} \\
\hline Study or Subgroup & Events & Total & Events & Total & Weight & M-H, Fixed, 95\% CI & \\
\hline
\end{tabular}

\subsection{1 akathisia}

Hordern 1964

Subtotal (95\% CI)

25
25

$25 \quad 100.0 \%$

Total events:

6

25

5

$25 \quad 100.0 \%$

$1.20[0.42,3.43]$

Heterogeneity: Not applicable

Test for overall effect: $\mathrm{Z}=0.34(\mathrm{P}=0.73)$

\subsection{2 akinesia}

Hordern 1964

Subtotal (95\% CI)

Total events:

$5 \quad 25$

25

0

$25 \quad 100.0 \%$

$11.00[0.64,188.95]$

Heterogeneity: Not applicable

Test for overall effect: $\mathrm{Z}=1.65(\mathrm{P}=0.10)$

1.15.3 dystonia

Hordern 1964

Subtotal (95\% CI)

Total events:

25
25

25
25

$25 \quad 100.0 \%$

$25 \quad 100.0 \%$

$1.09[0.92,1.29]$

$1.09[0.92,1.29]$

Heterogeneity: Not applicable

Test for overall effect: $\mathrm{Z}=1.03(\mathrm{P}=0.30)$

\subsection{4 parkinsonism}

\section{Hordern 1964}

Subtotal (95\% CI)

Total events:

$11 \quad 25$

25
25

Heterogeneity: Not applicable

Test for overall effect: $\mathrm{Z}=2.39(\mathrm{P}=0.02)$

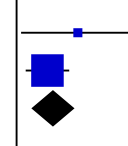


Analysis 1.16. Comparison 1: ORAL FLUPHENAZINE versus PLACEBO, Outcome 16: Adverse effects: 7. Others - short term

\begin{tabular}{|c|c|c|c|c|c|c|c|}
\hline & Flupher & e (oral) & Pla & & & Risk Ratio & Risk Ratio \\
\hline Study or Subgroup & Events & Total & Events & Total & Weight & M-H, Fixed, 95\% CI & M-H, Fixed, 95\% CI \\
\hline
\end{tabular}

1.16.1 convulsion or seizures

Goldberg 1964

Subtotal (95\% CI)

Total events:

(1)

92

92

92

(20)

Heterogeneity: Not applicable

Test for overall effect: $\mathrm{Z}=0.64(\mathrm{P}=0.52)$

\subsection{2 diarrhoea}

Goldberg 1964

Subtotal (95\% CI)

Total events:

2

92

92

Heterogeneity: Not applicable

Test for overall effect: $\mathrm{Z}=1.08(\mathrm{P}=0.28)$

1.16.3 intercurrent infection

Goldberg 1964

Subtotal (95\% CI)

Total events:

3

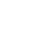

92

3

$98 \quad 100.0 \%$

3

Heterogeneity: Not applicable

Test for overall effect: $\mathrm{Z}=0.08(\mathrm{P}=0.94)$

1.16.4 rash

Clark 1971

Goldberg 1964

Subtotal (95\% CI)

Total events:

92

110

Heterogeneity: $\mathrm{Chi}^{2}=1.23, \mathrm{df}=1(\mathrm{P}=0.27) ; \mathrm{I}^{2}=19 \%$

Test for overall effect: $\mathrm{Z}=0.34(\mathrm{P}=0.73)$
$1.07[0.22,5.14]$

$1.07[0.22,5.14]$

$0.35[0.01,8.60]$

$0.35[0.01,8.60]$

$5.32[0.26,109.41]$

$5.32[0.26,109.41]$

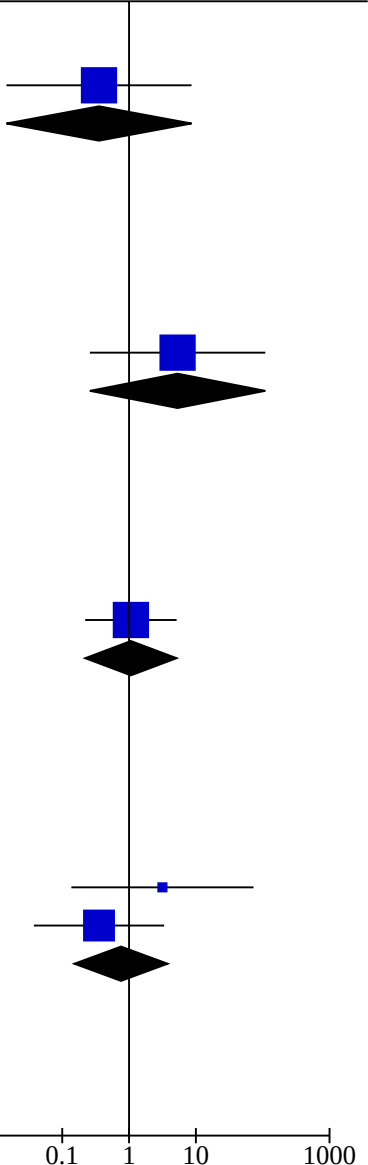

Favours fluphenazine (oral) Favours placebo 


\section{Analysis 1.17. Comparison 1: ORAL FLUPHENAZINE versus PLACEBO,} Outcome 17: Sensitivity analysis: 1 . CHRONIC versus ACUTE

\begin{tabular}{llcccccc} 
& \multicolumn{2}{c}{ Fluphenazine (oral) } & \multicolumn{2}{c}{ Placebo } & \multicolumn{2}{c}{ Risk Ratio } & \multicolumn{2}{c}{ Risk Ratio } \\
Study or Subgroup & Events & Total & Events & Total & Weight & M-H, Fixed, 95\% CI & M-H, Fixed, 95\% CI
\end{tabular}

1.17.1 Acute: Global state - not improved - short term

Clark 1971

Subtotal (95\% CI)

Total events:

$5 \quad 18$

189

$19 \quad 100.0 \%$

$0.59[0.24,1.42]$

Heterogeneity: Not applicable

Test for overall effect: $\mathrm{Z}=1.18(\mathrm{P}=0.24)$

1.17.2 Chronic: global state - not improved - short term

Hordern 1964

1325

Heterogeneity: Not applicable

Test for overall effect: $\mathrm{Z}=0.28(\mathrm{P}=0.78)$

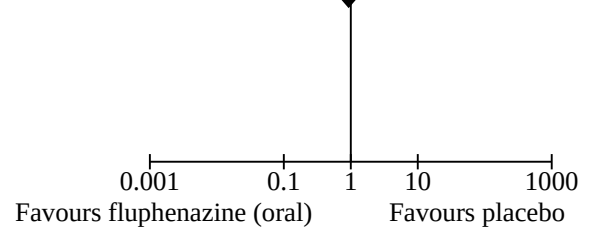

Analysis 1.18. Comparison 1: ORAL FLUPHENAZINE versus PLACEBO, Outcome 18: Sensitivity analysis: 2 . LOW DOSES (1-5 $\mathrm{mg} /$ day) versus HIGH DOSES ( $5 \mathrm{mg} /$ day $>$ )

\begin{tabular}{llllllll} 
& \multicolumn{2}{l}{ Fluphenazine (oral) } & \multicolumn{2}{c}{ Placebo } & \multicolumn{2}{c}{ Risk Ratio } & \multicolumn{2}{c}{ Risk Ratio } \\
Study or Subgroup & Events & Total & Events & Total & Weight & M-H, Fixed, 95\% CI & M-H, Fixed, 95\% CI
\end{tabular}

1.18.1 High dose: Global state - not improved - short term

$\begin{array}{lcccccc}\text { Carpenter } 1999 & 10 & 18 & 14 & 20 & 100.0 \% & 0.79[0.48,1.31] \\ \text { Subtotal (95\% CI) } & & \mathbf{1 8} & & \mathbf{2 0} & \mathbf{1 0 0 . 0 \%} & \mathbf{0 . 7 9}[\mathbf{0 . 4 8 , \mathbf { 1 . 3 1 } ]} \\ \text { Total events: } & 10 & & 14 & & & \end{array}$

Heterogeneity: Not applicable

Test for overall effect: $\mathrm{Z}=0.90(\mathrm{P}=0.37)$

1.18.2 Flexible dose: Global state - not improved - short term

$\begin{array}{lrrrrrr}\text { Clark } 1971 & 5 & 18 & 9 & 19 & 38.5 \% & 0.59[0.24,1.42] \\ \text { Hordern } 1964 & 13 & 25 & 14 & 25 & 61.5 \% & 0.93[0.56,1.55] \\ \text { Subtotal (95\% CI) } & & \mathbf{4 3} & & \mathbf{4 4} & \mathbf{1 0 0 . 0 \%} & \mathbf{0 . 8 0}[\mathbf{0 . 5 1}, \mathbf{1 . 2 5}] \\ \text { Total events: } & 18 & & 23 & & & \end{array}$

Heterogeneity: $\mathrm{Chi}^{2}=0.81, \mathrm{df}=1(\mathrm{P}=0.37) ; \mathrm{I}^{2}=0 \%$

Test for overall effect: $\mathrm{Z}=0.99(\mathrm{P}=0.32)$

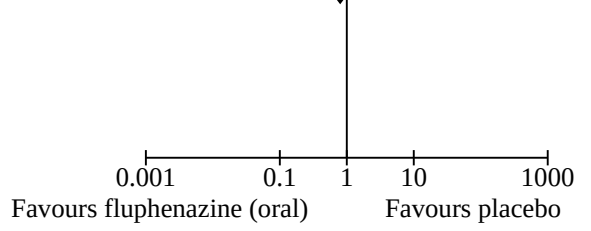


Analysis 1.19. Comparison 1: ORAL FLUPHENAZINE versus PLACEBO, Outcome 19: Sensitivity analysis: 3. OPERATIONAL CRITERIA versus LOOSE DEFINITIONS

\begin{tabular}{llcccccc} 
& \multicolumn{2}{c}{ Fluphenazine (oral) } & \multicolumn{2}{c}{ Placebo } & \multicolumn{2}{c}{ Risk Ratio } & \multicolumn{2}{c}{ Risk Ratio } \\
Study or Subgroup & Events & Total & Events & Total & Weight & M-H, Fixed, 95\% CI & M-H, Fixed, 95\% CI
\end{tabular}

1.19.1 DSM-III-R: Global state - not improved - short term

$\begin{array}{lcccccc}\text { Carpenter } 1999 & 10 & 18 & 14 & 20 & 100.0 \% & 0.79[0.48,1.31] \\ \text { Subtotal (95\% CI) } & & \mathbf{1 8} & & \mathbf{2 0} & \mathbf{1 0 0 . 0 \%} & \mathbf{0 . 7 9}[\mathbf{0 . 4 8 , \mathbf { 1 . 3 1 } ]} \\ \text { Total events: } & 10 & & 14 & & & \end{array}$

Total events:
Heterogeneity: Not applicable

Test for overall effect: $\mathrm{Z}=0.90(\mathrm{P}=0.37)$

1.19.2 Loose definition: global state - not improved - short term

$\begin{array}{lrrrrrr}\text { Clark 1971 } & 5 & 18 & 9 & 19 & 38.5 \% & 0.59[0.24,1.42] \\ \text { Hordern 1964 } & 13 & 25 & 14 & 25 & 61.5 \% & 0.93[0.56,1.55] \\ \text { Subtotal (95\% CI) } & & \mathbf{4 3} & & \mathbf{4 4} & \mathbf{1 0 0 . 0 \%} & \mathbf{0 . 8 0}[\mathbf{0 . 5 1}, \mathbf{1 . 2 5}]\end{array}$

Tubtal events:

1823

Heterogeneity: $\mathrm{Chi}^{2}=0.81, \mathrm{df}=1(\mathrm{P}=0.37) ; \mathrm{I}^{2}=0 \%$

Test for overall effect: $\mathrm{Z}=0.99(\mathrm{P}=0.32)$

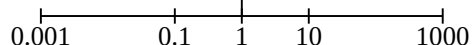

Favours fluphenazine (oral) $\quad$ Favours placebo

Analysis 1.20. Comparison 1: ORAL FLUPHENAZINE versus PLACEBO,

Outcome 20: Sensitivity analysis: 4. BEFORE 1990 versus AFTER 1990

\begin{tabular}{|c|c|c|c|c|c|c|c|}
\hline & Fluphe & e (oral) & Pla & & & Risk Ratio & Risk Ratio \\
\hline Study or Subgroup & Events & Total & Events & Total & Weight & M-H, Fixed, 95\% CI & M-H, Fixed, 95\% CI \\
\hline
\end{tabular}

1.20.1 Before 1990: Global state - not improved - short term

$\begin{array}{llll}\text { Clark } 1971 & 5 & 18 & 9\end{array}$

Hordern 1964

Subtotal (95\% CI)

$13 \quad 25$

25
43

14

$19 \quad 38.5 \%$

$0.59[0.24,1.42]$

Total events:

18

$44 \quad 100.0 \%$

$0.93[0.56,1.55]$

$0.80[0.51,1.25]$

Heterogeneity: $\mathrm{Chi}^{2}=0.81, \mathrm{df}=1(\mathrm{P}=0.37) ; \mathrm{I}^{2}=0 \%$

Test for overall effect: $\mathrm{Z}=0.99(\mathrm{P}=0.32)$

1.20.2 After 1990: Global state - not improved - short term

Carpenter 1999

10

$18 \quad 14$

23

Subtotal (95\% CI)

18

14

$20 \quad 100.0 \%$

$0.79[0.48,1.31]$

Total events:

10

$20 \quad 100.0 \%$

$0.79[0.48,1.31]$

Heterogeneity: Not applicable

Test for overall effect: $\mathrm{Z}=0.90(\mathrm{P}=0.37)$

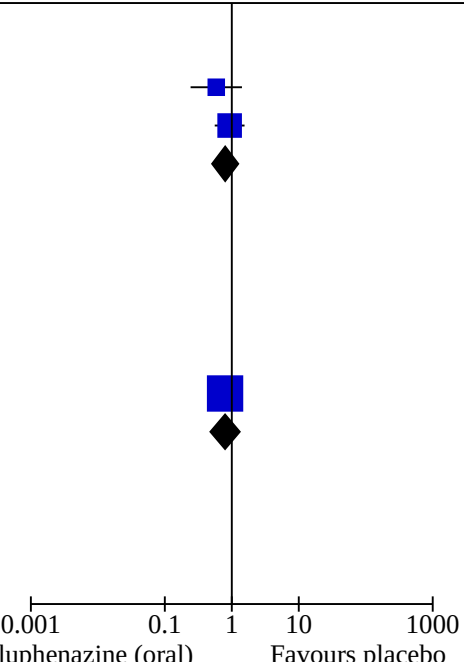

Favours fluphenazine (oral) 


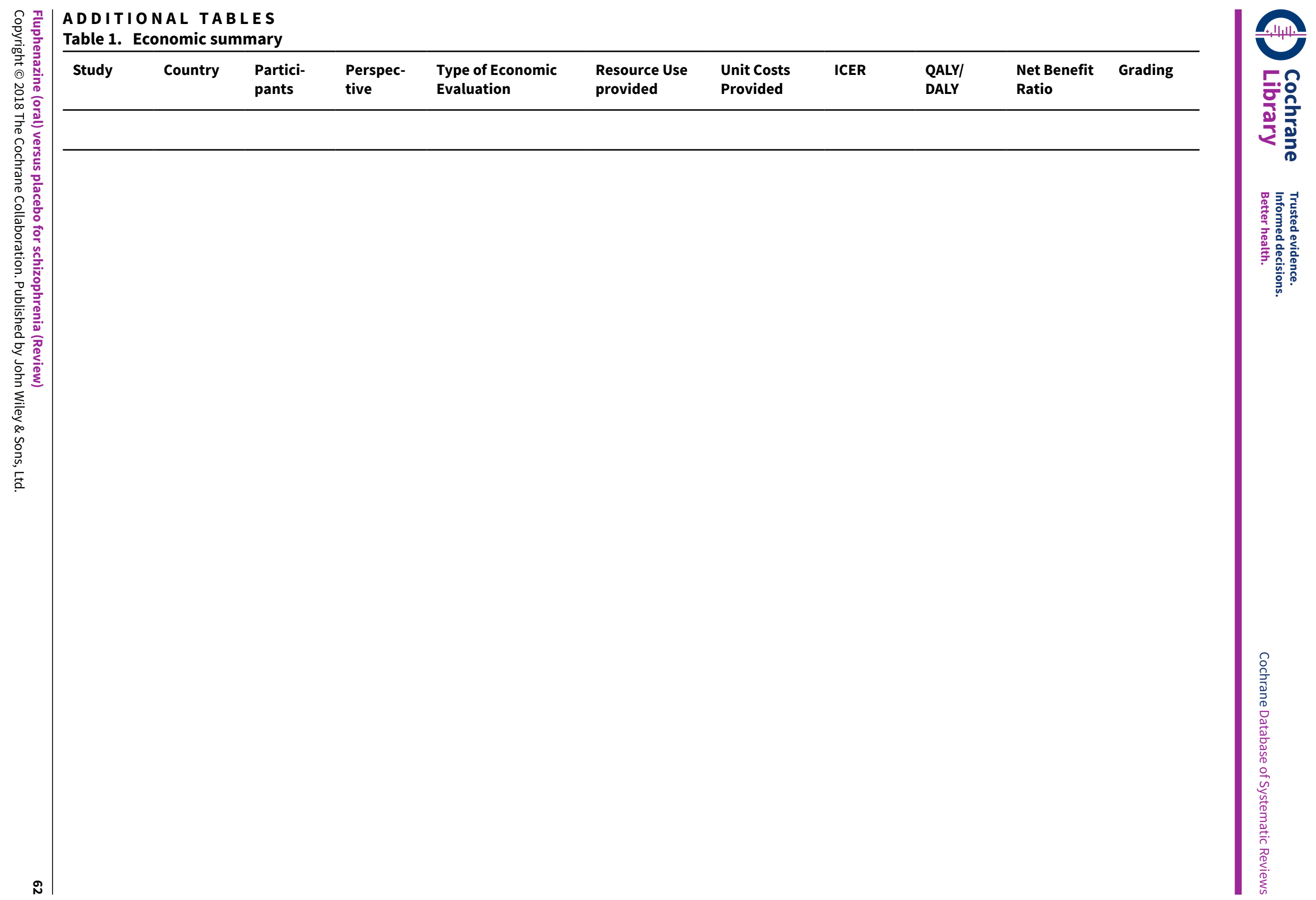


Table 2. Economic studies: excluded

\begin{tabular}{lll}
\hline Study ID & Status & Reasons for exclusion \\
\hline Matar 2007 & Excluded & Allocation: randomised (current systematic review). \\
\hline Mardar 1984 & Excluded & Allocation: randomised. \\
& Particiapants: schizophrenia. \\
& Interventions: fluphenazine IM. \\
\hline
\end{tabular}

Table 3. Economic outcomes: 1. Base case*

\begin{tabular}{|c|c|c|c|c|c|}
\hline \multirow[t]{2}{*}{ Base Case } & \multirow[t]{2}{*}{$\begin{array}{l}\text { Cost per day } \\
\text { (£) }\end{array}$} & \multicolumn{2}{|c|}{ Cost of actual relapse $(£)$} & \multicolumn{2}{|c|}{$\begin{array}{l}\text { Cost of relapse for study population } \\
(\varepsilon)^{\star \star}\end{array}$} \\
\hline & & Fluphenazine & Placebo & Fluphenazine & Placebo \\
\hline $\begin{array}{l}\text { Median length }{ }^{1} \text { of stay and } \\
\text { mean cost }{ }^{2}\end{array}$ & 5,408 & 91,936 & 205,504 & 1,437 & 3,425 \\
\hline
\end{tabular}

116 days.

$2 £ 338$.

*Unlike the effectiveness data of this review, the included economic studies have not been weighted according to sample size; hence risk ratios (RR) of cost of relapse for the study population (if calculated) may not be equal to the RR as calculated by RevMan.

${ }^{\star \star}$ Cost attributed to each individual participant within each arm of the trial, irrespective of whether they relapsed or not.

${ }^{\star \star \star}$ For ease of interpretation, lower number is preferred over higher.

Table 4. Economic outcomes: 2. Sensitivity analysis*

\begin{tabular}{|c|c|c|c|c|c|}
\hline \multirow[t]{2}{*}{ Sensitivity analyses } & \multirow[t]{2}{*}{$\begin{array}{l}\text { Cost per day } \\
(£)\end{array}$} & \multicolumn{2}{|c|}{ Cost of actual relapse $(£)$} & \multicolumn{2}{|c|}{$\begin{array}{l}\text { Cost of relapse for study popu- } \\
\text { lation }(£)^{\star \star}\end{array}$} \\
\hline & & Fluphenazine & Placebo & Fluphenazine & Placebo \\
\hline Mean length of stay ${ }^{1}$ and mean cost ${ }^{3}$ & 18,049 & 306,833 & 685,862 & 4,794 & 11,431 \\
\hline $\begin{array}{l}\text { Mean length of stay }{ }^{1} \text { and mean lower } \\
\text { quartile cost }{ }^{4}\end{array}$ & 15,966 & 271,422 & 606,708 & 4,241 & 10,112 \\
\hline $\begin{array}{l}\text { Mean length of stay }{ }^{1} \text { and mean upper } \\
\text { quartile } \operatorname{cost}^{5}\end{array}$ & 20,078 & 341,326 & 762,964 & 5,333 & 12,716 \\
\hline $\begin{array}{l}\text { Median length of stay }{ }^{2} \text { and mean lower } \\
\text { quartile cost } 4\end{array}$ & 4,784 & 81,328 & 181,792 & 1,271 & 3,030 \\
\hline $\begin{array}{l}\text { Median length of stay }{ }^{2} \text { and mean upper } \\
\text { quartile cost } 5\end{array}$ & 6,016 & 102,272 & 228,608 & 1,598 & 3,810 \\
\hline
\end{tabular}

\footnotetext{
153.4 days

216 days

$3 £ 338$
} 
*Unlike the effectiveness data of this review, the included economic studies have not been weighted according to sample size; hence risk ratios (RR) of cost of relapse for the study population (if calculated) may not be equal to the RR as calculated by RevMan.

${ }^{\star *}$ Cost attributed to each individual participant within each arm of the trial, irrespective of whether they relapsed or not.

${ }^{\star \star \star}$ For ease of interpretation, lower number is preferred over higher.

\section{AP P E N DICES}

\section{Appendix 1. Previous search strategy}

\section{2006 search}

\section{Cochrane Schizophrenia Group's trials register (September 2006)}

We searched the Cochrane Schizophrenia Group's trials register (September 2006) using the phrase:

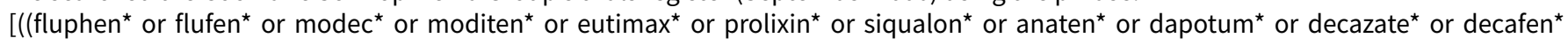
or decentan* or fludecate* or lyogen* or lyoridin* or mirenil*) in title, abstract and index fields in REFERENCE) OR (fluphenazin* in interventions field in STUDY)]

The Cochrane Schizophrenia Group's Trials Register is compiled by systematic searches of major databases, handsearches and conference proceedings (see group module).

\section{2012-2013 Searches}

\section{Cochrane Schizophrenia Group's trials register (May 2012)}

The Trial Search Co-ordinator searched the Cochrane Schizophrenia Group's Trials Register 15th May 2012 using the same search criteria as our initial 2006 review.

For details of previous search please see Appendix 1.

[((fluphen ${ }^{\star}$ or flufen ${ }^{\star}$ or modec $^{\star}$ or moditen ${ }^{\star}$ or eutimax ${ }^{\star}$ or prolixin ${ }^{\star}$ or siqualon ${ }^{\star}$ or anaten ${ }^{\star}$ or dapotum ${ }^{\star}$ or decazate $^{\star}$ or decafen $^{\star}$ or decentan* or fludecate* or lyogen* or lyoridin* or mirenil ${ }^{\star}$ ) in title, abstract and index fields in REFERENCE) OR (fluphenazin* in interventions field in STUDY)]

The Cochrane Schizophrenia Group's Trials Register is compiled by systematic searches of major databases, handsearches and conference proceedings (see group module).

\section{Economic study search of Cochrane Schizophrenia Group Health Economic Database (2013)}

For the economic search, we replicated the above strategy in the Cochrane Schizophrenia Group Health Economic Database (CSzGHED) on 23 July 2013. The database of studies relates to cost-effectiveness of schizophrenia treatments. This database was constructed from systematic searches of four databases: Health Economic Evaluation Database (HEED), National Health Services Health Economic Database (NHS EED), Cost-Effectiveness Analysis Registry (CEA) and EconLit as well as Cochrane Registry.

\section{Appendix 2. Previous data collection and analysis section}

\section{Selection of trials}

We (HEM, MQA) independently inspected the citations identified from the search. We identified potentially relevant abstracts and ordered full papers to reassess these for inclusion and methodological quality. We discussed and reported any disagreements.

\section{Assessment of methodological quality}

We assessed the methodological quality of included trials in this review using the criteria described in the Cochrane Handbook (Higgins 2005). These criteria are based on the evidence of a strong relationship between allocation concealment and direction of effect (Schulz 1995), and define the following categories:

A. Low risk of bias (adequate allocation concealment)

B. Moderate risk of bias (some doubt about the results)

C. High risk of bias (inadequate allocation concealment). For the purpose of the analysis in this review, trials were included if they met the Cochrane Handbook criteria A or B.

Only trials falling in category A or category B were included in this review.

\section{Data collection}

3.1 Data extraction 
We (HEM and MQA) independently extracted data and, where further clarification was needed, the authors' of trials were contacted to provide missing data. Any disagreements were discussed and the decisions documented.

\subsection{Intention to treat analysis}

Where people were lost to follow-up at the end of the study, it was assumed that they had a poor outcome and once they were randomised they were included in the analysis (intention-to-treat (ITT) analysis).

\section{Data synthesis}

4.1 Data types: We assessed outcomes using continuous (e.g. average changes on a behaviour scale), categorical (e.g. one of three categories on a behaviour scale, such as 'little change', 'moderate change' or 'much change') or dichotomous measures, e.g. either 'no important changes' or 'important changes' in a person's behaviour. RevMan software does not currently support categorical data, so we only presented these in the text of the review.

\subsection{Dichotomous - yes/no - data}

Where the original authors of the studies gave outcomes such as 'clinically improved' or 'not clinically improved' we recorded this. If possible, we attempted to convert relevant outcome measures to dichotomous data by identifying cut off points on rating scales and dividing people accordingly into 'clinically improved' or 'not clinically improved'. For example, the Brief Psychiatric Rating Scale (BPRS) (Overall 1962) is used frequently as a measure of change of symptoms in studies. We defined a $50 \%$ change on this particular scale as clinically important although it was recognised that for many people, especially those with chronic or severe illness, a less rigorous definition of important improvement (e.g. $25 \%$ on the BPRS) would be equally valid. If individual patient data were available, we used the $50 \%$ cut-off for the definition in the case of non-chronically ill people and $25 \%$ for those with chronic illness. For dichotomous data we estimated fixed-effect (FE) relative risk (RR) with a 95\% confidence interval (Cl), and calculated the number needed to treat/harm (NNT/H) statistic. If heterogeneity was found (see section 5) we used a random-effects model.

4.3 Continuous data: We excluded continuous data if more than $50 \%$ of people were lost to follow-up. Continuous data were reported as presented in the original studies, without making any assumptions about those lost to follow-up.

4.3.1. Skewed data: Continuous data on mental health outcomes are often not 'normally' distributed. To avoid the pitfall of applying parametric tests to non-parametric data, we applied the following standards to all data before inclusion: (a) standard deviations (SD) and means were reported in the paper or were obtainable from the authors, (b) when a scale started from a finite number (such as zero), the $\mathrm{SD}$, when multiplied by two, was less than the mean (as otherwise the mean was unlikely to be an appropriate measure of the centre of the distribution - (Altman 1996). Endpoint scores on scales often have a finite start and end point and this rule can be applied to them. However, we reported data not meeting these standards in the text of the results section if they had been analysed with appropriate nonparametric tests. Scale-derived change data were reported if no endpoint data were available. Their normality cannot be tested as above, despite the distinct possibility of skew.

4.3.2. Rating scales: a wide range of instruments are available to measure outcomes in mental health studies. These instruments vary in quality and many are not validated, or are even ad hoc. It is accepted generally that measuring instruments should have the properties of reliability (the extent to which a test effectively measures anything at all) and validity (the extent to which a test measures that which it is supposed to measure) (Rust 1989). Unpublished scales are known to be subject to bias in trials of treatments for schizophrenia (Marshall 2000). Therefore, we only included continuous data from rating scales if the measuring instrument had been described in a peer-reviewed journal. In addition, we set the following minimum standards for instruments: The instrument should either be (a) a self-report or (b) completed by an independent rater or relative (not the therapist) and (c) the instrument should be a global assessment of an area of functioning.

4.3.3 Summary statistic: For continuous outcomes we estimated the weighted mean difference (WMD) between groups. Again, if heterogeneity was found (see section 5 ) we used a random-effects model.

4.3.4 Cluster trials: studies increasingly employ 'cluster randomisation' (such as randomisation by clinician or practice) but analysis and pooling of clustered data poses problems. Firstly, authors often fail to account for intra class correlation in clustered studies, leading to a 'unit of analysis' error (Divine 1992) whereby P values are spuriously low, confidence intervals unduly narrow and statistical significance overestimated. This causes type I errors (Bland 1997; Gulliford 1999).

Where clustering was not accounted for in primary studies, we presented the data in a table, with a $\left({ }^{\star}\right)$ symbol to indicate the presence of a probable unit of analysis error. In subsequent versions of this review we will seek to contact first authors of studies to obtain intra class correlation co-efficients of their clustered data and to adjust for this by using accepted methods (Gulliford 1999). Where clustering has been incorporated into the analysis of primary studies, we will also present these data as if from a non-cluster randomised study, but adjusted for the clustering effect.

We have sought statistical advice and have been advised that the binary data as presented in a report should be divided by a 'design effect'. This is calculated using the mean number of participants per cluster $(\mathrm{m})$ and the intra-class correlation co-efficient (ICC) Design effect = $1+(m-1)^{\star}$ ICC (Donner 2002). If the ICC was not reported it was assumed to be 0.1 (Ukoumunne 1999).

\section{Investigation for heterogeneity}

Fluphenazine (oral) versus placebo for schizophrenia (Review) 
We judged clinical heterogeneity within all comparisons between included studies, and visually inspected graphs in order to investigate the possibility of statistical heterogeneity. This was supplemented by the $\mathrm{I}^{2}$ statistic which provides an estimate of the percentage of variability due to heterogeneity rather than to chance alone. An $1^{2}$ estimate equal to or greater than or equal to $75 \%$ indicates the presence of high levels of heterogeneity (Higgins 2003). In such cases, we sought to remove outlying trial(s) and perform a sensitivity analyses both with and without these outlying trials. Where no obvious outlying trial(s) could be identified, we analysed and reported the result using a randomeffects model, which takes into account that the effects being estimated are not identical.

\section{Sensitivity analyses}

We undertook several sensitivity analyses (see: Objectives).

\section{General}

If possible, we presented data in the graphs so that a result to the left of the line of no effect favoured oral fluphenazine.

\section{Appendix 3. Previously published methods}

\section{Criteria for considering studies for this review}

\section{Types of studies}

We included all relevant randomised controlled trials. We included trials described as 'double-blind' if it was implied that the study was randomised and we included these in a sensitivity analysis. If their inclusion did not result in a substantive difference, they remained in the analyses. If their inclusion did result in statistically significant differences, we did not add the data from these lower quality studies to the results of the better trials, but presented these within a subcategory. We excluded quasi-randomised studies, such as those allocating by alternate days of the week.

With regards to selecting studies for economic evaluations, two review authors graded studies as per the following:

Grade A - Full economic evaluation: studies that focus on cost-effectiveness analysis, cost-utility analysis and cost benefit analysis.

Grade B - Partial economic evaluation: studies that focus on cost-analysis, cost-minimisation studies and cost-description of oral fluphenazine.

Grade C - Randomised trials that reported limited information, such as estimates of resources use or costs associated with oral fluphenazine.

\section{Types of participants}

We included people diagnosed with schizophrenia or schizophrenia-like illnesses using any criteria, irrespective of age, sex or severity of illness.

\section{Types of interventions}

\section{Fluphenazine: any dose of only oral administration}

\section{Placebo: (active or inactive) or no treatment}

\section{Types of outcome measures}

Where possible, outcomes were made binary by dividing them into two categories - 'clinically significant change' and 'no clinically significant change'.

We categorised outcomes as short term (0-8 weeks), medium term (9 to 26 weeks) and long term (27 weeks to 104 weeks).

\section{Primary outcomes}

1. Global state

\subsection{Not improved or worsened}

\section{Adverse effects}

\subsection{General}

\subsection{Specific}

2.2.1 Extrapyramidal symptoms (parkinsonian symptoms, dystonia, akathisia, and tardive dyskinesia)

\subsubsection{Anticholinergic symptoms}

\subsubsection{Others}




\section{Secondary outcomes}

1. Global state

1.1 Relapse

1.2 Time in exacerbated state

1.3 Leaving the study early

1.4 Length of stay in hospital

1.5 Satisfaction with treatment - participant/carer

1.6 Death

2. Mental state

2.1 General symptoms

2.2 Specific symptoms

2.2.1 Positive symptoms (delusions, hallucinations, disordered thinking)

2.2.2 Negative symptoms (avolition, poor self-care, blunted affect)

2.2.3 Mood - depression

\section{Behaviour}

\subsection{General behaviour}

3.2 Specific behaviours (e.g. aggressive or violent behaviour)

3.2.1 Social functioning

3.2.2 Employment status during trial (employed/unemployed)

\subsubsection{Occurrence of violent incidents (to self, others or property)}

\section{Economic}

\subsection{Cost of care}

\section{5. 'Summary of findings' table}

We used the GRADE approach to interpret findings (Schünemann 2008) and used the GRADE profiler to import data from Review Manager (RevMan) to create 'Summary of findings' table/s. These tables provide outcome-specific information concerning the overall quality of evidence from each included study in the comparison, the magnitude of effect of the interventions examined, and the sum of available data on all outcomes we rated as important to patient-care and decision making. We selected the following main outcomes for inclusion in the 'Summary of findings' table.

1. Global state - not improved or worsened - medium term.

2. Relapse - long term.

3. Adverse effects: death - long term.

4. Adverse effects: extrapyramidal effects (akathisia) - short term.

5. Adverse effects: extrapyramidal effects (rigidity) - short term.

\section{Search methods for identification of studies}

\section{Electronic searches}

\section{Cochrane Schizophrenia Group's Study-Based Register of Trials}

On 23 December 2014 and 9 November 2016, the information specialist searched the register using the following search strategy:

( ${ }^{\star}$ Fluphenazine* AND *Placebo*) in Intervention Field of STUDY

In such study-based register, searching the major concept retrieves all the synonyms and relevant studies because all the studies have already been organised based on their interventions and linked to the relevant topics.

This register is compiled by systematic searches of major resources (including AMED, BIOSIS, CINAHL, EMBASE, MEDLINE, PsycINFO, PubMed, and registries of clinical trials) and their monthly updates, hand-searches, grey literature, and conference proceedings (see Group's Module). There is no language, date, document type, or publication status limitations for inclusion of records into the register. 
For previous searches, please see Appendix 1.

\section{Searching other resources}

\section{Reference searching}

We inspected references of all identified studies for further relevant studies.

\section{Personal contact}

We contacted the first author of each included study for information regarding unpublished trials.

\section{Data collection and analysis}

Methods used in data collection and analysis for this update are below; for previous methods please see Appendix 2.

\section{Selection of studies}

For this 2012 update, review authors HEM and MQA inspected citations from the new electronic search and identified relevant abstracts. $\mathrm{HEM}$ and MQA also inspected full articles of the abstracts meeting inclusion criteria and carried out the reliability check of all citations from the new electronic search.

For the selection of economic studies, VF and SS inspected all retrieved citations identified by the economic database search, and where disputes arose, the full report was acquired for further inspection.

\section{Data extraction and management}

\section{Extraction}

For this update, HEM and MQA extracted data from included studies. We extracted data presented only in graphs and figures whenever possible. When further information was necessary, we contacted authors of studies in order to obtain missing data or for clarification. We encountered multi-centre trials, however, we were unable to extract data relevant to each component centre separately; this was because the study was published many years ago, and such data were unavailable (Goldberg 1964).

For the economic analysis had VF and SS found Grade A and B studies (see Types of studies), they would have investigated whether appraisal had already been undertaken by NHS EED using their search tool derived for this purpose. If appraisal had not been undertaken, VF and SS would have applied the NHS EED tool to the data. In this current review, there were only Grade C studies available; therefore, we extracted outcome data directly from the already-included effectiveness studies. We recognised that much information would be lacking to get results that are both valid and reliable.

\section{Management}

\subsection{Forms}

We extracted data onto standard, simple forms.

\subsection{Scale-derived data}

We included continuous data from rating scales only if:

a. the psychometric properties of the measuring instrument have been described in a peer-reviewed journal (Marshall 2000); and

b. the measuring instrument has not been written or modified by one of the trialists for that particular trial.

Ideally, the measuring instrument should either be i. a self-report or ii. completed by an independent rater or relative (not the therapist). We realise that this is not often reported clearly; we have noted whether or not this is the case in Description of studies.

\subsection{Endpoint versus change data}

There are advantages of both endpoint and change data. Change data can remove a component of between-person variability from the analysis. On the other hand, calculation of change needs two assessments (baseline and endpoint), which can be difficult in unstable and difficult to measure conditions such as schizophrenia. We decided primarily to use endpoint data, and only use change data if the former were not available. Had enough studies reported continuous data, we would have combined endpoint and change data in the analysis and used mean differences (MD) rather than standardised mean differences (SMD) throughout (Higgins 2011, Chapter 9.4.5.2).

\subsection{Skewed data}

Continuous data on clinical and social outcomes are often not normally distributed. To avoid the pitfall of applying parametric tests to non-parametric data, we aimed to apply the following standards to all data before inclusion:

a) standard deviations (SDs) and means are reported in the paper or obtainable from the authors; 
b) when a scale starts from the finite number zero, the SD, when multiplied by two, is less than the mean (as otherwise the mean is unlikely to be an appropriate measure of the centre of the distribution (Altman 1996));

c) if a scale started from a positive value (such as the Positive and Negative Syndrome Scale (PANSS), (Kay 1986)), which can have values from 30 to 210), we modified the calculation described above to take the scale starting point into account. In these cases skew is present if $2 \mathrm{SD}>(\mathrm{S}-\mathrm{S} \mathrm{min})$, where $\mathrm{S}$ is the mean score and $\mathrm{S}$ min is the minimum score.

Endpoint scores on scales often have a finite start and end point and these rules can be applied. We entered skewed endpoint data from studies of fewer than 200 participants as 'other data' within the Data and analyses rather than into a statistical analysis. Skewed data pose less of a problem when looking at mean if the sample size is large; we would have entered such endpoint data into syntheses had we encountered such data.

When continuous data are presented on a scale that includes a possibility of negative values (such as change data), it is difficult to tell whether data are skewed or not; therefore, we entered skewed change data into analyses regardless of size of study.

\subsection{Common measure}

Had we encountered such measures, in order to facilitate comparison between trials, we would have converted variables that can be reported in different metrics, such as days in hospital (mean days per year, per week or per month) to a common metric (e.g. mean days per month).

\subsection{Conversion of continuous to binary}

Had such data been available, we would have made efforts to convert outcome measures to dichotomous data. This can be done by identifying cut-off points on rating scales and dividing participants accordingly into 'clinically improved' or 'not clinically improved'. It is generally assumed that if there is a 50\% reduction in a scale-derived score such as the Brief Psychiatric Rating Scale (BPRS, Overall 1962) or the PANSS (Kay 1986); this could be considered as a clinically significant response (Leucht 2005; Leucht 2005a). If data based on these thresholds were not available, we would have used the primary cut-off presented by the original authors.

\subsection{Direction of graphs}

We entered data in such a way that the area to the left of the line of no effect indicated a favourable outcome for oral fluphenazine. Where keeping to this made it impossible to avoid outcome titles with clumsy double-negatives (e.g. 'Not improved'), we reported data where the left of the line indicates an unfavourable outcome. This was the case with outcome 1.10 Leaving the study early: 3. marked improvement/ hospital discharge (Analysis 1.8), which reflected a positive outcome.

\section{Assessment of risk of bias in included studies}

For this update, HEM and MQA worked independently by using criteria described in the Cochrane Handbook for Systematic Reviews of Interventions (Higgins 2011) to assess trial quality. This new set of criteria is based on evidence of associations between overestimate of effect and high risk of bias of the article such as sequence generation, allocation concealment, blinding, incomplete outcome data and selective reporting. Where inadequate details of randomisation and other characteristics of trials were provided, we contacted authors of the studies in order to obtain additional information. We have noted the level of risk of bias in both the text of the review and in the Summary of findings 1.

This review also aimed to assess the overall methodological quality of each study included in the economic evaluation. Assessment of risk bias will use the checklist developed by Drummond 1996 and the CHEC criteria list (Evers 2005) for Grade A and B studies. Had we found any economic studies of Grade A or B level, this would have been noted in the summary as well as in a separate table (Table 1). In this current review, only Grade C level studies were used, and therefore the same judgement for risk of bias was employed as for the effectiveness studies.

\section{Measures of treatment effect}

\section{Binary data}

For binary outcomes, we calculated a standard estimation of the risk ratio (RR) and its $95 \%$ confidence interval (CI). It has been shown that RR is more intuitive (Boissel 1999) than odds ratios and that odds ratios tend to be interpreted as RR by clinicians (Deeks 2000). For statistically significant results, we used 'Summary of findings' tables to calculate the number needed to treat to provide benefit (NNTB)/ to induce harm (NNTH) statistic and its $95 \% \mathrm{Cl}$.

\section{Continuous data}

For continuous outcomes, we estimated mean difference (MD) between groups. 


\section{Unit of analysis issues}

\section{Cluster trials}

Studies increasingly employ 'cluster randomisation' (such as randomisation by clinician or practice), but analysis and pooling of clustered data poses problems. Authors often fail to account for intra-class correlation in clustered studies, leading to a 'unit of analysis' error (Divine 1992) whereby $P$ values are spuriously low, Cls unduly narrow and statistical significance overestimated. This causes type I errors (Bland 1997; Gulliford 1999).

Had we encountered such studies, we would have presented data in a table, with a $\left(^{*}\right)$ symbol to indicate the presence of a probable unit of analysis error. In subsequent versions of this review, we will seek to contact first authors of studies to obtain intra-class correlation coefficients (ICCS) or their clustered data and to adjust for this by using accepted methods (Gulliford 1999). We have sought statistical advice and have been advised that the binary data as presented in a report should be divided by a 'design effect'. This is calculated using the mean number of participants per cluster $(\mathrm{m})$ and the ICC [Design effect $\left.=1+(\mathrm{m}-1)^{\star} \mathrm{ICC}\right]$ (Donner 2002). No cluster trials were identified in this review; however, if in future updates of this review cluster-randomised studies are identified, where the ICC is not reported it will be assumed to be 0.1 (Ukoumunne 1999).

\section{Cross-over trials}

A major concern of cross-over trials is the carry-over effect. It occurs if an effect (e.g. pharmacological, physiological or psychological) of the treatment in the first phase is carried over to the second phase. As a consequence, on entry to the second phase the participants can differ systematically from their initial state despite a wash-out phase. For the same reason cross-over trials are not appropriate if the condition of interest is unstable (Elbourne 2002). As both effects are very likely in severe mental illness, we only used data of the first phase of crossover studies. This was the case in Millar 1963.

\section{Studies with multiple treatment groups}

Had we found studies that involved more than two relevant treatment arms, we would have presented the additional treatment arms in comparisons. However, we found no such studies; if, in future updates of this review, if such studies are identified, binary data will be simply added and combined within the two-by-two table. If data are continuous, we will combine data following the formula in section 7.7.3.8 (Combining groups) of the Cochrane Handbook for Systemic reviews of Interventions (Higgins 2011). Where the additional treatment arms were not relevant, we did not reproduce these data.

\section{Dealing with missing data}

\section{Overall loss of credibility}

At some degree of loss of follow-up, data must lose credibility (Xia 2009). We chose that, for any particular outcome, should more than $60 \%$ of data be unaccounted for, we would not reproduce these data or use them within analyses. If, however, more than $60 \%$ of those in one arm of a study were lost, but the total loss was less than $40 \%$, we would have marked such data with $\left({ }^{\star}\right)$ to indicate that such a result may well be prone to bias.

\section{Binary}

In the case where attrition for a binary outcome is between $0 \%$ and $60 \%$ and where these data are not clearly described, had we found such studies, we would have presented data on a 'once-randomised-always-analyse' basis (an intention-to-treat analysis). Those leaving the study early would be assumed to have the same rates of negative outcome as those who completed, with the exception of the outcome of death and adverse effects. For these outcomes, the rate of those who stay in the study - in that particular arm of the trial - would be used for those who did not. We undertook a sensitivity analysis to test how prone the primary outcomes were to change when data only from people who completed the study to that point were compared to the intention-to-treat analysis using the above assumptions.

\section{Continuous}

\subsection{Attrition}

In the case where attrition for a continuous outcome is between 0 and $60 \%$, and data only from people who complete the study to that point are reported, we presented and used these data.

\subsection{Standard deviations}

Had standard deviations not been reported, we first would have tried to obtain the missing values from the authors. If not available, where there were missing measures of variance for continuous data, but an exact standard error and confidence intervals available for group means, and either $\mathrm{P}$ value or T value available for differences in mean, we would have calculated them according to the rules described in the Cochrane Handbook for Systemic reviews of Interventions (Higgins 2011). Had only the standard error (SE) been reported, standard deviations (SDs) can be calculated by the formula SD = SE * square root ( $\mathrm{n}$ ). Chapters 7.7.3 and 16.1.3 of the Cochrane Handbook for Systemic reviews of Interventions (Higgins 2011) present detailed formula for estimating SDs from P values, T or F values, confidence intervals, ranges or other statistics. If these formula do not apply, we would have calculated the SDs according to a validated imputation method which is based on the SDs of the other included studies (Furukawa 2006). Although some of these imputation strategies can introduce error, the 
alternative would be to exclude a given study's outcome and thus to lose information. Had we imputed data, and if future updates of this review employ use of imputed data, we will examine the validity of the imputations in a sensitivity analysis excluding the imputed values. Had we needed to, we would have imputed standard deviations using this model for Clark 1971.

\subsection{Last observation carried forward}

We anticipated that in some studies the method of last observation carried forward (LOCF) would be employed within the study report. As with all methods of imputation to deal with missing data, LOCF introduces uncertainty about the reliability of the results (Leucht 2007). Therefore, where LOCF data have been used in the trial, if less than $50 \%$ of the data have been assumed, we reproduced these data and indicated that they are the product of LOCF assumptions.

\section{Assessment of heterogeneity}

\section{Clinical heterogeneity}

We considered all included studies initially, without seeing comparison data, to judge clinical heterogeneity. We simply inspected all studies for clearly outlying people or situations which we had not predicted would arise. When such situations or participant groups arose, we fully discussed these.

\section{Methodological heterogeneity}

We considered all included studies initially, without seeing comparison data, to judge methodological heterogeneity. We simply inspected all studies for clearly outlying methods which we had not predicted would arise. When such methodological outliers arose, we fully discussed these.

\section{Statistical heterogeneity}

\subsection{Visual inspection}

We visually inspected graphs to investigate the possibility of statistical heterogeneity.

\subsection{Employing the $I^{2}$ statistic}

We investigated heterogeneity between studies by considering the $\mathrm{I}^{2}$ method alongside the Chi $2 \mathrm{P}$ value. The $\mathrm{I}^{2}$ provides an estimate of the percentage of inconsistency thought to be due to chance (Higgins 2003). The importance of the observed value of $I^{2}$ depends on $\mathrm{i}$. magnitude and direction of effects and ii. strength of evidence for heterogeneity (e.g. P value from Chi ${ }^{2}$ test, or a $\mathrm{Cl}_{\text {for I }}^{2}$ ). An $\mathrm{I}^{2}$ estimate greater than or equal to around 50\% accompanied by a statistically significant $\mathrm{Chi}^{2}$ statistic was interpreted as evidence of substantial levels of heterogeneity (Higgins 2011). When substantial levels of heterogeneity were found in the primary outcome, we explored reasons for heterogeneity (Subgroup analysis and investigation of heterogeneity).

\section{Assessment of reporting biases}

Reporting biases arise when the dissemination of research findings is influenced by the nature and direction of results (Egger 1997). These are described in Section 10 of the Cochrane Handbook (Higgins 2011). We are aware that funnel plots may be useful in investigating reporting biases but are of limited power to detect small-study effects. We did not use funnel plots for outcomes where there were 10 or fewer studies, or where all studies were of similar sizes.

\section{Data synthesis}

We understand that there is no closed argument for preference for use of fixed-effect or random-effects models. The random-effects method incorporates an assumption that the different studies are estimating different, yet related, intervention effects. This often seems to be true to us and the random-effects model takes into account differences between studies even if there is no statistically significant heterogeneity. There is, however, a disadvantage to the random-effects model: it puts added weight onto small studies which often are the most biased ones. Depending on the direction of effect, these studies can either inflate or deflate the effect size. We chose the fixed-effect model for all analyses, but used of the random-effects model where heterogeneity was present.

\section{Economic Summary}

Data was summarised according to the Cochrane Campbell Economic Methods Group (Higgins 2011) and a narrative abstract provided for each included study. A table summarising the data was also provided for any studies had they been identified.

We anticipated that most studies would be Grade $C$ level of economic evidence and that we would use data from such studies to calculate a GBP value associated with the outcomes. These approximate values were calculated by (a) using the PSSRU calculation of $£ 338$ (weighted average of all adult mental health inpatient bed days) per hospital bed day based in a UK NHS setting (PSSRU 2012), and (b) assuming that one relapse equals one hospital admission, a median length of stay as 16 days, as per Hospital Episode Statistics 2012 (HES 2012 ; main speciality 'adult mental illness') we utilised results of the effects of the intervention that presented service use data for an adult ward as well as for relapse rates (HES is a data warehouse containing details of all admissions, outpatient appointments and A\&E attendances at NHS hospitals in England). 
We have not factored any associated costs (including cost and resource use of treatment) prior to the relevant measured outcomes of relapse and hospital discharge. We are using UK NHS PSSRU reference costs of 2012, and therefore present the outcomes in terms of a GBP value found in the comparison data as a proxy measure for relative risk, which is achieved through the assumption of average (median) length of hospital stay (16 days) and average cost per day (£338). The average cost of relapse - based on our assumption that one relapse equals one hospital admission lasting 16 days $(338 \times 16)$ - has been calculated at $£ 5,408$ per person. From this number, the average cost of relapse has been calculated for both (a) the number of participants alone who experienced relapse in both the intervention or control group $(n=$ relapsed $\times 5,408)$ and (b) the entire population at risk of relapse between groups $(£$ of $n=$ relapsed per group $\div$ total $N$ receiving intervention across studies).

The authors wish to emphasise the numerous assumptions that have been made for the purposes of presenting this economic data, specifically at Grade $\mathrm{C}$ quality level:

1. The current included studies contributing to the Grade C-level of quality were undertaken between the years of 1963 to 1999 ; and, taking this into account -

2. The average length of stay and costs have been calculated from current available data, that is, according to $2012 \mathrm{HES}$ costs, from most primarily a UK NHS perspective; and

3. The GBP value data that are presented reflect a proxy measure only; that is, the GBP value of the intervention effect on the measured outcome, and not taking into account any costs or resource use that may likely have been incurred prior to the actual outcome (which includes, but is not limited to, costs and resource use prior to intervention, the intervention itself and post-intervention up to outcome).

\section{Subgroup analysis and investigation of heterogeneity}

\section{Subgroup analyses - only primary outcomes}

\subsection{Clinical state, stage or problem}

We proposed to undertake this review and provide an overview of the effects of oral fluphenazine for people with schizophrenia in general. In addition, however, we tried to report data on subgroups of people in the same clinical state, stage and with similar problems.

\section{Investigation of heterogeneity}

If inconsistency was high, we have reported this. First, we investigated whether data had been entered correctly. Second, if data were correct, we visually inspected the graph and successively removed outlying studies to see if homogeneity was restored. For this review we decided that should this occur with data contributing to the summary finding of no more than around $10 \%$ of the total weighting, we would present data. If not, then we did not pool data and discussed issues. We know of no supporting research for this $10 \%$ cut-off, but we used prediction intervals as an alternative to this unsatisfactory state.

When unanticipated clinical or methodological heterogeneity was obvious, we simply stated hypotheses regarding these for future reviews or versions of this review. We did not anticipate undertaking analyses relating to these.

\section{Sensitivity analysis}

It was expected that several sensitivity analyses could be undertaken within this review. The following hypotheses were be tested:

When compared with placebo, for the primary outcomes of interest (see: Criteria for considering studies for this review), fluphenazine is differentially effective for:

\section{Men and women.}

2. People who are under 18 years of age, between 18 and 64 , or over 65 years of age.

3. People who became ill recently (i.e. acute episode approximately less than one month's duration) as opposed to people who have been ill for a longer duration.

4. People who are given low doses (1- $5 \mathrm{mg} /$ day), and those given high doses (over $5 \mathrm{mg} /$ day).

5. People who have schizophrenia diagnosed according to any operational criterion i.e. a pre-stated checklist of symptoms/ problems/time periods/exclusions) as opposed to those who have entered the trial with loosely defined illness.

\section{People treated earlier (pre-1990) and people treated in recent years (1990 to 2006).}

We additionally applied all sensitivity analyses to the primary outcomes of this review.

\section{Implication of randomisation}

We aimed to include trials in a sensitivity analysis if they were described in some way so as to imply randomisation. For the primary outcomes, we included these studies and if there was no substantive difference when the implied randomised studies were added to those with better description of randomisation, then we entered all data from these studies. 


\section{Assumptions for lost binary data}

Where assumptions had to be made regarding people lost to follow-up (see Dealing with missing data), we compared the findings of the primary outcomes when we use our assumption/s and when we used data only from people who completed the study to that point. If there was a substantial difference, we reported results and discussed them but continued to employ our assumption.

Where assumptions had to be made regarding missing SDs data (see Dealing with missing data), we compared the findings of the primary outcomes when we used our assumption/s and when we used data only from people who completed the study to that point. A sensitivity analysis was undertaken to test how prone results are to change when completer-only data only are compared to the imputed data using the above assumption. If there was a substantial difference, we reported results and discussed them.

\section{Risk of bias}

We analysed the effects of excluding trials that were judged to be at high risk of bias across one or more of the domains of randomisation (implied as randomised with no further details available): allocation concealment, blinding and outcome reporting for the meta-analysis of the primary outcome. If the exclusion of trials at high risk of bias did not substantially alter the direction of effect or the precision of the effect estimates, then we included data from these trials in the analyses.

\section{Imputed values}

We also sought to undertake a sensitivity analysis to assess the effects of including data from trials where we used imputed values for ICC in calculating the design effect in cluster- randomised trials.

If we noted substantial differences in the direction or precision of effect estimates in any of the sensitivity analyses listed above, we did not pool data from the excluded trials with the other trials contributing to the outcome, but presented them separately.

\section{Fixed-effect and random-effects}

We synthesised data using a fixed-effect model; however, we also synthesised data for the primary outcome using a random-effects model to evaluate whether this altered the significance of the results.

\section{Economic summary}

We undertook a sensitivity analysis taking into account both the mean length of hospital stay; the median length of hospital stay (HES 2012); and the associated upper (£376) and lower quartile (£299) ranges of the weighted average cost of all adult mental health inpatient bed days (PSSRU 2012), to investigate how far this affects the direction of the estimated value.

\section{WHAT'S NEW}

\begin{tabular}{lll}
\hline Date & Event & Description \\
\hline 7 July 2020 & Amended & $\begin{array}{l}\text { A typo in the plain language summary ammended. Sluphenazine } \\
\text { (typo) has been corrected to Fluphenazine. }\end{array}$ \\
\hline
\end{tabular}

\section{H I S T O R Y}

Review first published: Issue 1, 2007

\begin{tabular}{lll}
\hline Date & Event & Description \\
\hline 10 May 2018 & $\begin{array}{l}\text { New citation required but conclusions } \\
\text { have not changed }\end{array}$ & $\begin{array}{l}\text { Review search date is updated, no new studies have been added } \\
\text { to the review and conclusions are unchanged. }\end{array}$ \\
\hline 28 December 2017 & New search has been performed & Serach updated and no new study or reference was found. \\
\hline 9 November 2016 & Amended & Search was updated and no new study or reference was found. \\
\hline 12 February 2015 & $\begin{array}{l}\text { New citation required but conclusions } \\
\text { have not changed }\end{array}$ & $\begin{array}{l}\text { No new studies have been added to the review, no change to } \\
\text { conclusions. }\end{array}$ \\
\hline
\end{tabular}




\begin{tabular}{|c|c|c|}
\hline Date & Event & Description \\
\hline 13 January 2015 & Amended & $\begin{array}{l}\text { Update search run } 23 / 12 / 14 \text { and one additional reference added } \\
\text { to Included studies (Clark 1971). }\end{array}$ \\
\hline 4 September 2013 & Amended & $\begin{array}{l}\text { This review now contains pilot methods to assist economic con- } \\
\text { sideration of the clinical results. These methods are included } \\
\text { and implemented in this amendment. }\end{array}$ \\
\hline 9 July 2013 & $\begin{array}{l}\text { New citation required but conclusions } \\
\text { have not changed }\end{array}$ & $\begin{array}{l}\text { No new conclusions made to the review after results of } 2012 \text { up- } \\
\text { date search added. }\end{array}$ \\
\hline 18 March 2013 & New search has been performed & $\begin{array}{l}\text { Review update completed: seven new studies identified in up- } \\
\text { date search, each of which was excluded with reasons. 'Summa- } \\
\text { ry of findings' table added to grade the quality of the evidence. } \\
\text { New format 'Risk of bias' tables have been constructed, with new } \\
\text { ratings applied. }\end{array}$ \\
\hline \multirow[t]{2}{*}{15 May 2012} & Amended & $\begin{array}{l}\text { Update search of Cochrane Schizophrenia Group's Trial Register } \\
\text { (see Search methods for identification of studies). }\end{array}$ \\
\hline & & 7 studies added to awaiting assessment \\
\hline 5 October 2011 & Amended & Contact details updated. \\
\hline 4 August 2010 & Amended & Contact details updated. \\
\hline 15 February 2010 & Amended & Contact details updated. \\
\hline 13 August 2008 & Amended & Contact Author details updated \\
\hline 25 April 2008 & Amended & Converted to new review format. \\
\hline 14 November 2006 & $\begin{array}{l}\text { New citation required and conclusions } \\
\text { have changed }\end{array}$ & Substantive amendment \\
\hline
\end{tabular}

\section{CONTRIBUTIONS OF AUTHORS}

Hosam E Matar screened the search results, organised the retrieval of papers, appraised the papers and extracted data, analysed and interpreted the data, managed the data and entered data in RevMan, and wrote the final report.

Muhammad Qutayba Almerie screened the search results, organised the retrieval of papers, appraised the papers and extracted data, managed the data and entered data in RevMan, analysed and interpreted the data and wrote the final report.

Stephanie Sampson updated the abstract, search and results section, constructed PRISMA diagram and Summary of findings table, carried out economic evaluation.

Vivek Futardo: carried out economic evaluation.

\section{DECLARATIONS OF INTEREST}

None known.

\section{SOURCES OF SUPPORT}

\section{Internal sources}

- No internal sources of support provided, Other 


\section{External sources}

- National Institute for Health Research (NIHR), UK

UK Cochrane Collaboration Programme Grant 2011; Reference number: 10/4001/15

\section{DIFFERENCES BETWEEN PROTOCOLANDREVIEW}

An economic review team added and carried out an economic studies search in order to identify any high-quality economic analyses relating to the intervention. Where this was not possible, the economic review authors would have used a lower-grade of 'economic summary', using the calculations described in the Methods section of this review.

\section{NDEX TERMS}

\section{Medical Subject Headings (MeSH)}

Administration, Oral; Akathisia, Drug-Induced [epidemiology]; Antipsychotic Agents [adverse effects] [*therapeutic use]; Fluphenazine [adverse effects] [*therapeutic use]; Placebos [therapeutic use]; Randomized Controlled Trials as Topic; Recurrence; Schizophrenia [ ${ }^{\star}$ drug therapy] [mortality]

\section{MeSH check words}

Humans 